\author{
UNIVERSIDADE DE SÃO PAULO \\ ESCOLA DE ENGENHARIA DE SÃO CARLOS \\ DEPARTAMENTO DE HIDRÁULICA E SANEAMENTO
}

NAYARA FALANCA

MODELAGEM E SIMULAÇÃO PARA TRANSFERÊNCIA DE OXIGÊNIO EM AERAÇÃO FORÇADA POR BOLHAS UTILIZANDO OS MÉTODOS MAC E CRANK-NICOLSON

VERSÃO CORRIGIDA

São Carlos

2013 



\section{MODELAGEM E SIMULAÇÃO PARA TRANSFERÊNCIA DE OXIGÊNIO EM AERAÇÃO FORÇADA POR BOLHAS UTILIZANDO OS MÉTODOS MAC E CRANK-NICOLSON}

Dissertação apresentada à Escola de Engenharia de São Carlos, da Universidade de São Paulo, como parte dos requisitos para a obtenção do título de Mestre em Ciências: Engenharia Hidráulica e Saneamento.

ORIENTADOR: Prof. Dr. Nivaldo Aparecido Corrêa

\section{VERSÃO CORRIGIDA}

São Carlos 


\section{AUTORIZO A REPRODUÇÃO TOTAL OU PARCIAL DESTE TRABALHO, POR QUALQUER MEIO CONVENCIONAL OU ELETRÔNICO, PARA FINS DE ESTUDO E PESQUISA, DESDE QUE CITADA A FONTE.}

Falanca, Nayara
M177m odelagem e simulação para transferênciade oxigênio em aeração forçada por bolhas utilizando os métodos MAC e Crank-Nicolson / Nayara Falanca; orientador Nivaldo Aparecido Corrêa. São Carlos, 2013.

Dissertação (Mestrado) - Programa de Pós-Graduação e Área de Concentração em Hidráulica e Saneamento -Escola de Engenharia de São Carlos da Universidade de São Paulo, 2013.

1. Modelagem. 2. Aeração. 3. Bolhas. 4. MAC. I. Título. 


\section{FOLHA DE JULGAMENTO}

Candidata: Engenheira NAYARA FALANCA.

Título da dissertação: "Modelagem e simulação para transferência de oxigênio em aeração forçada por bolhas utilizando os métodos MAC e Crank-Nicolson".

Data da defesa: $21 / 10 / 2013$

\section{Comissão Julgadora:}

Prof. Dr. Nivaldo Aparecido Corrêa (Orientador)

(Escola de Engenharia de São Carlos/EESC)

Prof. Dr. Demerval José Mazzini Sartori

(Universidade Federal de São Carlos/UFSCar)

Prof ${ }^{\mathrm{a}}$. Dr ${ }^{\mathrm{a}}$. Alessandra Pereira da Silva

(Universidade Federal de São Paulo/UNIFESP)
Resultado:
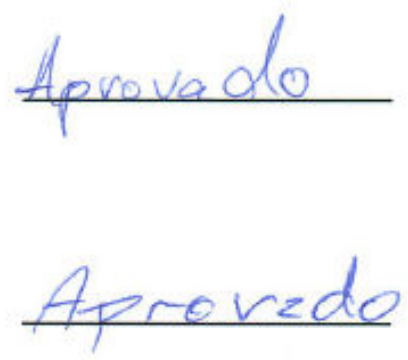

APROVADO

Coordenadora do Programa de Pós-Graduação em Engenharia Hidráulica e Saneamento:

Profa. Associada Maria Bernadete A. Varesche Silva

Presidente da Comissão de Pós-Graduação:

Prof. Titular Denis Vinicius Coury 

A Deus e a minha família, com toda minha fé, amor e gratidão, pelos princípios e carinho repassados. 



\section{AGRADECIMENTOS}

A Deus pela minha vida, pela minha fé, por me sustentar nos momentos difíceis e dar forças diariamente, pois sem Ele eu não estaria aqui.

À minha família, pelo amor, pelo esforço e dedicação despendidos. Mesmo distantes se fizeram presentes em todos os momentos através de telefonemas, e-mails e viagens, por meio deste apoio a caminhada tornou-se mais leve e agradável.

Ao meu pai Arnaldo Falanca e à minha mãe Maria Marta Pavan, à minha irmã Marianna Falanca, às minhas avós Mafalda e Ângela (i. m.), aos meus avôs Osvaldin e Agostinho, meus sinceros agradecimentos, você são minha vida. Amo vocês!

Ao professor Dr. Nivaldo Aparecido Corrêa, meu orientador. Obrigada pelo conhecimento repassado, pela paciência, ajuda, incentivo, compreensão, ensinamentos e valores pessoais que permanecerão por uma vida.

Ao meu companheiro e amigo Rodrigo Martins de Almeida, por estar comigo diariamente tornando meus dias mais felizes, pelas palavras de força, ajuda em minha caminhada pessoal e profissional, pelo amor e carinho.

Às minhas amigas (em especial Ana Manoella, Letícia, Maévi e Marcella) e amigos de Campo Grande/MS, pelos momentos agradáveis e apoio.

Às minhas amigas, amigos e colegas de São Carlos, que conheci durante o mestrado, enquanto todos estavam longe de suas famílias, nós criamos uma família e com certeza sempre lembraremos uns aos outros com um sorriso no rosto.

Aos meus amigos do Laboratório de Fenômenos de Transporte Andreza, Elaine, Guilherme, Natália e Felipe, pela amizade, colaboração e momentos de entretenimento.

Aos professores e funcionários do Departamento de Hidráulica e Saneamento pelo bom convívio e apoio.

À CAPES (Coordenação de Aperfeiçoamento de Pessoal de Nível Superior) pelo suporte financeiro concedido. 

“Tu, Senhor e Deus nosso, és digno de receber a glória, a honra e o poder, porque criaste todas as coisas, e por tua vontade elas existem e foram criadas." 



\section{RESUMO}

\section{FALANCA, N. Modelagem e simulação para transferência de oxigênio em aeração}

forçada por bolhas utilizando os métodos MAC e Crank-Nicolson. 2013. 100p. Dissertação (Mestrado) - Escola de Engenharia de São Carlos, Universidade de São Paulo, São Carlos 2013.

A aeração artificial em meio líquido visa suprir a baixa concentração de oxigênio dissolvido em ambientes deficientes deste, sendo um processo comumente aplicado na área de tratamento de efluentes por processos aeróbios. Uma forma de produzir aeração artificial é através de difusores submersos no fundo de um tanque com formação de bolhas, que ascendem e transferem seu oxigênio ao longo da coluna d'água. Para simular e melhor entender este processo e sua fluidodinâmica, um modelo inicial simplificado foi proposto, baseado em conceitos teóricos e equações que representem o fenômeno, como a de dispersão de bolhas, velocidades médias e concentração de oxigênio dissolvido. Foi considerado para realização dos cálculos um tanque retangular, com entrada de água a esquerda e saída de água a direita, com superfície sólida ao fundo e superfície livre acima, em contato com o ar. As equações de transporte de massa foram discretizadas no tempo, utilizando a técnica de CrankNicolson e no espaço segundo metodologia de diferenças centrais, solucionadas posteriormente por meio de técnicas iterativas do tipo Gauss-Seidel. As equações de transporte de quantidade de movimento foram resolvidas com o método MAC, explícito nas velocidades do fluido e implícito na pressão, para fornecer o campo de velocidade e pressão. A equação de que fornece o perfil de espalhamento das bolhas foi tomada como uma Equação Gaussiana de dispersão bidimensional. A implementação computacional necessária para aplicação das abordagens foi no ambiente de programação MATLAB. O método MAC e a técnica Crank-Nicolson apresentaram resultados satisfatórios para simulações rápidas e noção do comportamento do fluido e da concentração de oxigênio dissolvido.

Palavras chave: Modelagem, aeração, bolhas, MAC. 


\begin{abstract}
FALANCA, N. Modeling and simulation for oxygen transfer in forced aeration bubbles using the MAC and Crank-Nicolson methods. 2013. 100p. Dissertação (Mestrado) - Escola de Engenharia de São Carlos, Universidade de São Paulo, São Carlos 2013.

The artificial aeration in aqueous mean aims to supply low concentration of dissolved oxygen in deficient atmospheres of it. This process is commonly applied in the field of wastewater treatment by aerobic processes. One way to produce artificial aeration is through diffusers submerged at the bottom of a tank with the formation of bubbles, which ascend and transfer its oxygen throughout the water column. To simulate and better understand this process and its fluid dynamics, a simplified initial model was proposed based on theoretical concepts and equations that represent the phenomenon, as the dispersion of bubbles, average speeds and dissolved oxygen concentration. It was considered for the calculations one rectangular tank with the water inlet and water outlet from left to right, with solid surface to the bottom and free surface at the top in contact with air. The mass transport equations were discretized in time, using the Crank-Nicolson technique and in space according to the methodology of central differences, subsequently resolved by Gauss-Seidel technique iterative. The transport equations of momentum were solved with the MAC method, explicit on the velocities of the fluid and implicit on pressure, to afford the velocity field and pressure. The equation which provides the spreading profiles of bubbles was taken as a two-dimensional Gaussian dispersion equation. The computational implementation necessary for application of the approaches was the programming environment MATLAB. The MAC method and CrankNicolson technique showed satisfactory results for quick simulations and notion of the behavior of the fluid and the concentration of dissolved oxygen.
\end{abstract}

Keywords: Modeling, aeration, bubbles, MAC. 


\section{LISTA DE FIGURAS}

Figura 1 - Esquema geral do principio da conservação de massa.

Figura 2 - Esquema de malha temporal conforme a técnica de Crank-Nicolson. Considera-se um ponto na metade do intervalo como referência para os cálculos.......................................30

Figura 3 - Aparato experimental. Adaptado de Oliveira (2008).............................................34

Figura 4 - Espalhamento gaussiano das bolhas, assumido com diâmetro uniforme e velocidade constante. Fonte: Vuitik (2013).

Figura 5 - Observação do raio da pluma e da sobreposição da $C_{b}$. Fonte: Arquivo pessoal....37

Figura 6 - Malha computacional, $i$ varia de 1 até 10 e $j$ varia de 1 até 72.

Figura 7 - Malha discretizada para o cálculo da concentração de bolhas

Figura 8 - Observação do raio da pluma com relação ao ponto $i, j$ e superposição de efeitos dos bicos injetores. Fonte: Arquivo pessoal.

Figura 9 - Célula da malha deslocada. A pressão é armazenada no centro, enquanto que as velocidades são armazenadas nas faces.

Figura 10 - A discretização das derivadas presentes na equação de momento na direção $x$ é feita no ponto $(i, j+1 / 2)$.

Figura 11 - A discretização das derivadas presentes na equação de momento na direção $\boldsymbol{y}$ é

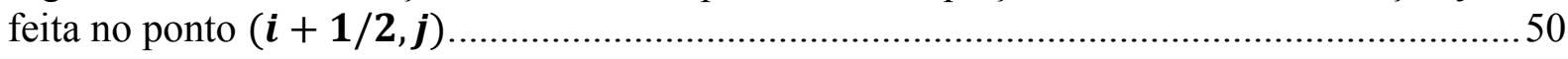

Figura 12 - Ordem de grandeza da concentração de bolhas $C_{b}$

Figura 13 - Perfil da $\mathrm{C}_{\mathrm{b}}$ (número de bolhas $/ \mathrm{m} 3$ ) da pluma para 1 injetor somente. Malha de $10 \times 72$.

Figura 14 - Perfil da $C_{b}$ (número de bolhas $/ \mathrm{m}^{3}$ ) da pluma para 5 injetores. Malha de 10x72..65

Figura 15 - Perfil da $\mathrm{C}_{\mathrm{b}}$ (número de bolhas $/ \mathrm{m}^{3}$ ) da pluma para 10 injetores. Malha de 10x72.

Figura 16 - Perfil da $\mathrm{C}_{\mathrm{b}}$ (número de bolhas $/ \mathrm{m}^{3}$ ) da pluma para 24 injetores. Malha de 10x72.

Figura 17 - Gráfico dos vetores das velocidades no tanque. Malha 10x 72 ...........................67

Figura 18 - Gráfico dos vetores de velocidades na região de entrada do canal.......................68

Figura 19 - Gráfico dos vetores de velocidade na região de saída do canal............................68

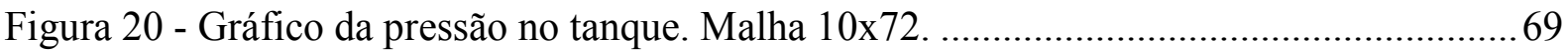

Figura 21 - Perfil de concentração de oxigênio dissolvido $\mathrm{C}_{\mathrm{OD}}\left(\mathrm{Kg} / \mathrm{m}^{3}\right)$ no tanque para 1 injetor localizado em $\mathrm{x}=1,26 \mathrm{~m}$. Malha de 10x72. Tempo simulado: $1 \mathrm{~s}$. 
Figura 22 - Perfil $\mathrm{C}_{\mathrm{OD}}\left(\mathrm{Kg} / \mathrm{m}^{3}\right)$ no tanque para 1 injetor localizado em $\mathrm{x}=1,26 \mathrm{~m}$. Malha de 10x72. Tempo simulado: $50 \mathrm{~s}$.

Figura 23 - Perfil da $\mathrm{C}_{\mathrm{OD}}\left(\mathrm{Kg} / \mathrm{m}^{3}\right)$ no tanque para 1 injetor localizado em $\mathrm{x}=1,26 \mathrm{~m}$. Malha de 10x72. Tempo simulado: $100 \mathrm{~s}$.

Figura 24 - Perfil da $\mathrm{C}_{\mathrm{OD}}\left(\mathrm{Kg} / \mathrm{m}^{3}\right)$ no tanque para 1 injetor localizado em $\mathrm{x}=1,26 \mathrm{~m}$. Malha de 10x72. Tempo simulado: $1000 \mathrm{~s}$.

Figura 25 - Perfil da $\mathrm{C}_{\mathrm{OD}}\left(\mathrm{Kg} / \mathrm{m}^{3}\right)$ no tanque para 5 injetores localizados em $\mathrm{x}=0,43 \mathrm{~m}, 0,84 \mathrm{~m}$, $1,26 \mathrm{~m}, 1,68 \mathrm{~m}$ e 2,09m respectivamente. Malha de 10x72. Tempo simulado: $1 \mathrm{~s}$. 72

Figura 26 - Perfil da $\mathrm{C}_{\mathrm{OD}}\left(\mathrm{Kg} / \mathrm{m}^{3}\right)$ no tanque para 5 injetores localizados em $\mathrm{x}=0,43 \mathrm{~m}, 0,84 \mathrm{~m}$, $1,26 \mathrm{~m}, 1,68 \mathrm{~m}$ e $2,09 \mathrm{~m}$ respectivamente. Malha de 10x72. Tempo simulado: $50 \mathrm{~s}$. 73

Figura 27 - Perfil da $\mathrm{C}_{\mathrm{OD}}\left(\mathrm{Kg} / \mathrm{m}^{3}\right)$ no tanque para 5 injetores localizados em $\mathrm{x}=0,43 \mathrm{~m}, 0,84 \mathrm{~m}$, $1,26 \mathrm{~m}, 1,68 \mathrm{~m}$ e $2,09 \mathrm{~m}$ respectivamente. Malha de $10 \times 72$. Tempo simulado: $100 \mathrm{~s}$. .73

Figura 28 - Perfil da $\mathrm{C}_{\mathrm{OD}}\left(\mathrm{Kg} / \mathrm{m}^{3}\right)$ no tanque para 5 injetores localizados em $\mathrm{x}=0,43 \mathrm{~m}, 0,84 \mathrm{~m}$, $1,26 \mathrm{~m}, 1,68 \mathrm{~m}$ e $2,09 \mathrm{~m}$ respectivamente. Malha de $10 \times 72$. Tempo simulado: $200 \mathrm{~s}$ 74

Figura 29 - Perfil da $\mathrm{C}_{\mathrm{OD}}\left(\mathrm{Kg} / \mathrm{m}^{3}\right)$ no tanque para 5 injetores localizados em $\mathrm{x}=0,43 \mathrm{~m}, 0,84 \mathrm{~m}$, $1,26 \mathrm{~m}, 1,68 \mathrm{~m}$ e $2,09 \mathrm{~m}$ respectivamente. Malha de 10x72. Tempo simulado: $300 \mathrm{~s}$ 75

Figura 30 - Perfil da $\mathrm{C}_{\mathrm{OD}}\left(\mathrm{Kg} / \mathrm{m}^{3}\right)$ no tanque para 10 injetores dispostos igualmente entre si por aproximadamente $0,23 \mathrm{~m}$. Malha de $10 \times 72$. Tempo simulado: $1 \mathrm{~s}$.

Figura 31 - Perfil da $\mathrm{C}_{\mathrm{OD}}\left(\mathrm{Kg} / \mathrm{m}^{3}\right)$ no tanque para 10 injetores dispostos igualmente entre si por aproximadamente $0,23 \mathrm{~m}$. Malha de 10x72. Tempo simulado: $25 \mathrm{~s}$.

Figura 32 - Perfil da $\mathrm{C}_{\mathrm{OD}}\left(\mathrm{Kg} / \mathrm{m}^{3}\right)$ no tanque para 10 injetores dispostos igualmente entre si por aproximadamente $0,23 \mathrm{~m}$. Malha de $10 \times 72$. Tempo simulado: $50 \mathrm{~s}$.

Figura 33 - Perfil da $\mathrm{C}_{\mathrm{OD}}\left(\mathrm{Kg} / \mathrm{m}^{3}\right)$ no tanque para 10 injetores dispostos igualmente entre si por aproximadamente $0,23 \mathrm{~m}$. Malha de 10x72. Tempo simulado: $200 \mathrm{~s}$.

Figura 34 - Perfil da $\mathrm{C}_{\mathrm{OD}}\left(\mathrm{Kg} / \mathrm{m}^{3}\right)$ no tanque para 24 injetores dispostos igualmente entre si por aproximadamente $0,10 \mathrm{~m}$. Malha de 10x72. Tempo simulado: $1 \mathrm{~s}$.

Figura 35 - Perfil da $\mathrm{C}_{\mathrm{OD}}\left(\mathrm{Kg} / \mathrm{m}^{3}\right)$ no tanque para 24 injetores dispostos igualmente entre si por aproximadamente $0,10 \mathrm{~m}$. Malha de 10x72. Tempo simulado: $5 \mathrm{~s}$.

Figura 36 - Perfil da $\mathrm{C}_{\mathrm{OD}}\left(\mathrm{Kg} / \mathrm{m}^{3}\right)$ no tanque para 24 injetores dispostos igualmente entre si por aproximadamente $0,10 \mathrm{~m}$. Malha de 10x72. Tempo simulado: $10 \mathrm{~s}$.

Figura 37 - Perfil da $\mathrm{C}_{\mathrm{OD}}\left(\mathrm{Kg} / \mathrm{m}^{3}\right)$ no tanque para 24 injetores dispostos igualmente entre si por aproximadamente $0,10 \mathrm{~m}$. Malha de 10x72. Tempo simulado: $50 \mathrm{~s}$. 


\section{LISTA DE SIGLAS}

DF Diferenças Finitas

DFC Dinâmica dos Fluidos Computacional

MAC $\quad$ Marker and Cell

MATLAB Matrix Laboratory

MDF Método das Diferenças Finitas

MEV Método dos Elementos Finitos

MVF Métodos dos Volumes Finitos

N-S Navier-Stokes

OD Oxigênio Dissolvido

OP Sondas Ópticas de Dupla Ponta

PIV Velocimetria por Imagem de Particulas

SIMPLE Semi Implicit Linked Equations

SOR Sucessive Over-relaxation ou Sobre-relaxação Sucessiva

TDMA Algoritmo Tridiagonal 


\section{LISTA DE SÍMBOLOS}

\section{Símbolos Latinos}

\begin{tabular}{|c|c|c|}
\hline$a$ & Área interfacial da bolha & $\mathrm{m}^{2}$ \\
\hline$B_{x}$ & Força de campo na direção $\mathrm{x}$ & \\
\hline$B_{y}$ & Força de campo na direção y & \\
\hline$B_{z}$ & Força de campo na direção z & \\
\hline$c$ & Fator de segurança & \\
\hline$C_{A}$ & Concentração de uma substância A & $\mathrm{Kg} / \mathrm{m}^{3}$ \\
\hline$C_{b}$ & Concentração de bolhas & $\mathrm{n}^{\mathrm{o}}$ de bolhas $/ \mathrm{m}^{3}$ \\
\hline$C_{O D}$ & Concentração de oxigênio dissolvido & $\mathrm{Kg} / \mathrm{m}^{3}$ \\
\hline$C_{O D S}$ & Concentração de saturação do oxigênio dissolvido & $\mathrm{Kg} / \mathrm{m}^{3}$ \\
\hline$C_{S}$ & Concentração na superfície & $\mathrm{Kg} / \mathrm{m}^{3}$ \\
\hline$C_{\infty}$ & Concentração no seio líquido & $\mathrm{Kg} / \mathrm{m}^{3}$ \\
\hline CONV & Termos convectivos discretizados da equação de Navier-Stokes & \\
\hline$d_{b}$ & Diâmetro da bolha & $\mathrm{m}$ \\
\hline$D$ & Difusividade & $\mathrm{m}^{2} / \mathrm{s}$ \\
\hline$D_{A B}$ & Difusividade molecular de uma substância A no meio B & $\mathrm{m}^{2} / \mathrm{s}$ \\
\hline$D_{\text {bolha }}$ & Difusividade de bolhas em água & $\mathrm{m}^{2} / \mathrm{s}$ \\
\hline$D_{t}$ & Difusividade turbulenta & $\mathrm{m}^{2} / \mathrm{s}$ \\
\hline$D_{t_{x}}$ & Difusividade turbulenta na direção x & $\mathrm{m}^{2} / \mathrm{s}$ \\
\hline$D_{t_{y}}$ & Difusividade turbulenta na direção y & $\mathrm{m}^{2} / \mathrm{s}$ \\
\hline$E$ & Erro & \\
\hline$F$ & Soma dos termos convectivos, viscosos e da velocidade, no eixo $x$ & \\
\hline$F P$ & Função para cálculo do método híbrido de discretização & \\
\hline$g$ & Aceleração devida à ação da gravidade & $\mathrm{m} / \mathrm{s}^{2}$ \\
\hline$\dot{g}$ & Taxa de produção de massa & $\mathrm{Kg} /\left(\mathrm{m}^{2} \cdot \mathrm{s}\right)$ \\
\hline$G$ & Soma dos termos convectivos, viscosos e da velocidade, no eixo $y$ & \\
\hline$h_{m}$ & Coeficiente de transferência de massa & $1 / \mathrm{s}$ \\
\hline$k_{g}$ & Coeficiente de transferência de massa no filme gasoso & $1 / \mathrm{s}$ \\
\hline$k_{g}$ & Coeficiente de transferência de massa no filme líquido & $1 / \mathrm{s}$ \\
\hline$K_{L}$ & Coeficiente de transferência global de massa & $1 / \mathrm{s}$ \\
\hline$K_{L} a$ & Coeficiente volumétrico de transferência de massa & $1 / \mathrm{s}$ \\
\hline
\end{tabular}




\begin{tabular}{|c|c|c|}
\hline$\dot{m}$ & Fluxo de massa & $\mathrm{Kg} /\left(\mathrm{m}^{2} \cdot \mathrm{s}\right)$ \\
\hline$N_{\text {inj }}$ & Número de injetores existentes no tanque & \\
\hline$N X$ & Número de linhas do eixo $\mathrm{x}$ & \\
\hline$N Y$ & Número de linhas do eixo y & \\
\hline$n_{b}$ & Número de bolhas & $\mathrm{n}^{\mathrm{o}}$ de bolhas/s \\
\hline $\mathrm{p}$ & Pressão & $\mathrm{Pa}$ \\
\hline$P e$ & Número de Péclet & \\
\hline $\operatorname{poinj}(n)$ & Posição do injetor $n$ & $\mathrm{~m}$ \\
\hline$Q_{a r}$ & Vazão de ar no bico injetor & $\mathrm{m}^{3} / \mathrm{s}$ \\
\hline$r$ & Raio de espalhamento da bolha ao redor da linha central da pluma & $\mathrm{m}$ \\
\hline$R e$ & Número de Reynolds & \\
\hline$S c$ & Número de Schimidt & \\
\hline$S h$ & Número de Sherwood & \\
\hline$S$ & Função sinal & \\
\hline$t$ & Tempo & $\mathrm{s}$ \\
\hline$u$ & Componente da velocidade na direção x & $\mathrm{m} / \mathrm{s}$ \\
\hline $\bar{u}$ & Média da velocidade na direção $\mathrm{x}$ & $\mathrm{m} / \mathrm{s}$ \\
\hline$v$ & Componente da velocidade na direção y & $\mathrm{m} / \mathrm{s}$ \\
\hline $\bar{v}$ & Média da velocidade na direção y & $\mathrm{m} / \mathrm{s}$ \\
\hline$V_{b}$ & Velocidade média de ascensão das bolhas & $\mathrm{m} / \mathrm{s}$ \\
\hline$V_{o l}$ & Volume de uma bolha & $\mathrm{m}^{3}$ \\
\hline$V_{S}$ & Velocidade superficial & $\mathrm{m} / \mathrm{s}$ \\
\hline$V_{x}$ & Componente da velocidade na direção $x$ & $\mathrm{~m} / \mathrm{s}$ \\
\hline$V_{y}$ & Componente da velocidade na direção y & $\mathrm{m} / \mathrm{s}$ \\
\hline$V_{z}$ & Componente da velocidade na direção z & $\mathrm{m} / \mathrm{s}$ \\
\hline VISC & Termos viscosos discretizados da equação de Navier-Stokes & \\
\hline$x$ & Eixo $x$ & $\mathrm{~m}$ \\
\hline $\mathrm{y}$ & Eixo y & $\mathrm{m}$ \\
\hline $\mathrm{z}$ & Eixo z & $\mathrm{m}$ \\
\hline
\end{tabular}

Símbolos Gregos

$\kappa-\varepsilon \quad$ Modelo de turbulência

$\Delta x \quad$ Comprimento de uma célula discreta em $\mathrm{x}$ 


$\begin{array}{lll}\Delta y & \text { Comprimento de uma célula discreta em y } & \mathrm{m} \\ \Delta t & \text { Intervalo de tempo } & \mathrm{s} \\ \pi & \mathrm{Pi} & \mathrm{Kg} / \mathrm{m}^{3} \\ \rho & \text { Massa específica } & \mathrm{Kg} / \mathrm{m}^{3} \\ \rho_{l} & \text { Massa específica do líquido } & \mathrm{N} \cdot \mathrm{m}^{2} \\ \sigma & \text { Tensão superficial do líquido } & \mathrm{N} \cdot \mathrm{s} / \mathrm{m}^{2} \\ \mu & \text { Viscosidade dinâmica } & \mathrm{Kg} /(\mathrm{m} \cdot \mathrm{s}) \\ \mu_{g} & \text { Viscosidade dinâmica da fase gasosa } & \mathrm{Kg} /(\mathrm{m} \cdot \mathrm{s}) \\ \mu_{l} & \text { Viscosidade dinâmica da fase líquida } & \mathrm{m} / \mathrm{s} \\ v & \text { Viscosidade cinemática } & \mathrm{m} / \mathrm{s} \\ v_{t} & \text { Viscosidade cinemática turbulenta } & \\ \varnothing & \text { Fração de vazios } & \end{array}$

\section{Sobrescritos}

$k \quad$ Passo de tempo

n Passo de tempo

\section{Subscritos}

$i \quad$ Posição do ponto discreto no eixo das coordenadas

$j \quad$ Posição do ponto discreto no eixo das abscissas

NX Número de linhas do eixo $\mathrm{x}$

NY Número de linhas do eixo y 


\section{SUMÁRIO}

1 INTRODUÇÃO ............................................................................................................19

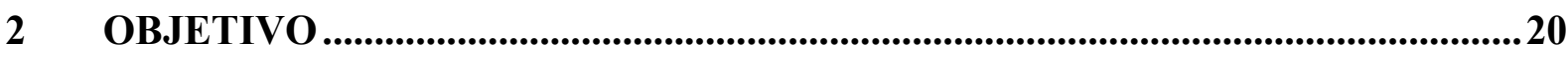

3 REVISÃO DA LITERATURA ..........................................................................21

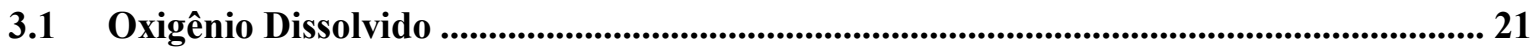

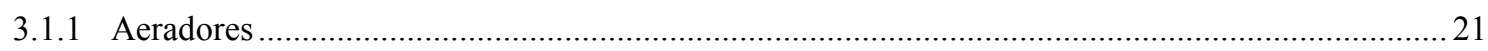

3.2 Equação da Continuidade ................................................................................................... 22

3.3 Transferência de Massa........................................................................................................ 22

3.3.1 Transferência Interfacial de Massa ....................................................................................... 23

3.4 Equação da Conservação de Massa para a Concentração de um Composto em um

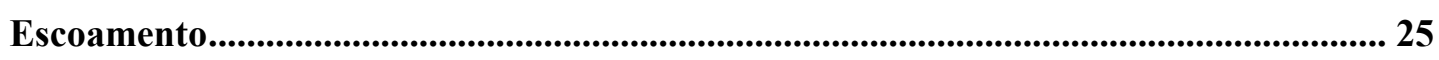

3.5 Equação da Quantidade de Movimento - Navier-Stokes................................................. 25

3.6 Dinâmica dos Fluidos Computacional (DFC).................................................................... 26

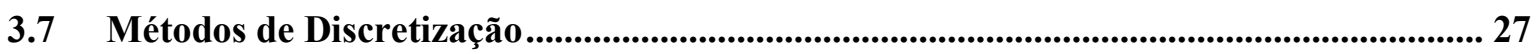

3.8 Método das Diferenças Finitas...................................................................................................... 28

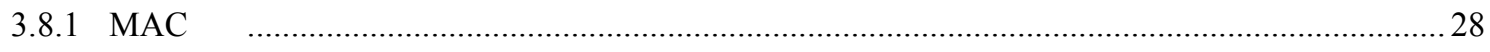

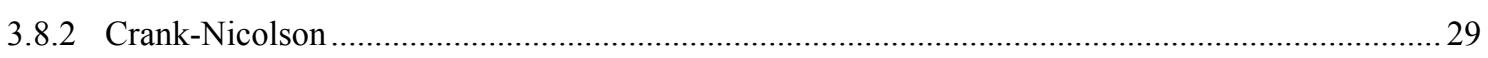

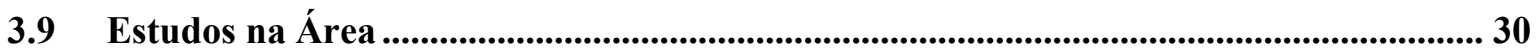

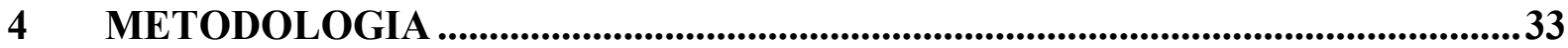

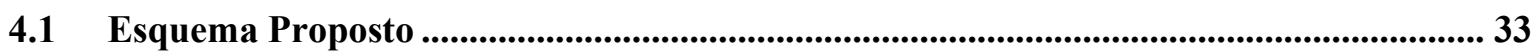

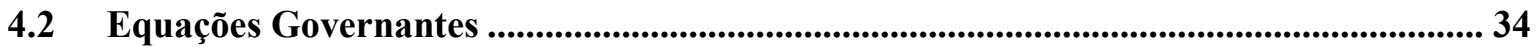

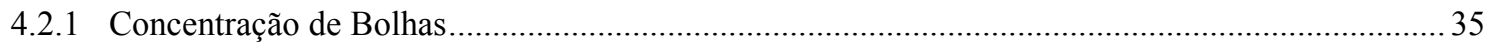

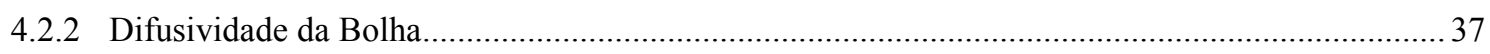

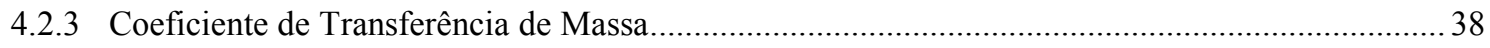

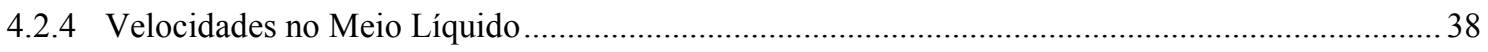

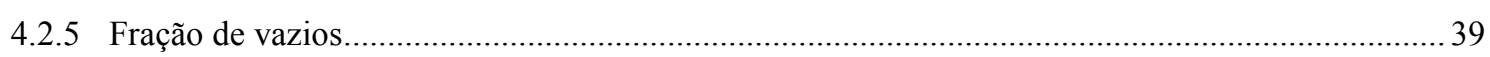

4.2.6 Concentração Média de Oxigênio Dissolvido.............................................................................. 39

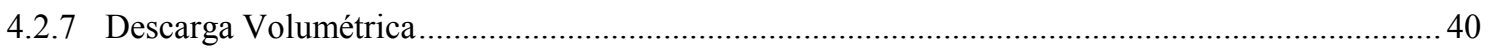

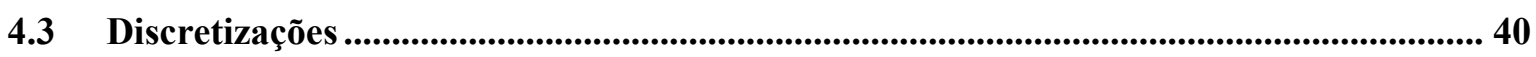

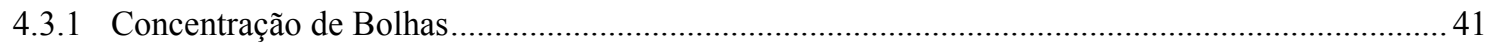

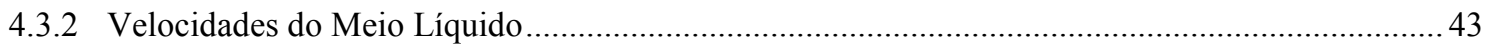

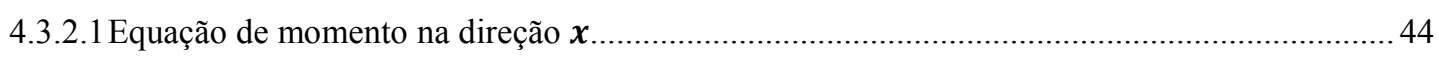

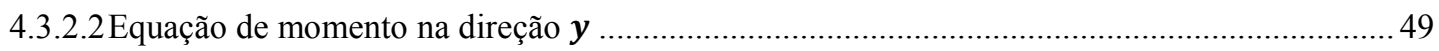

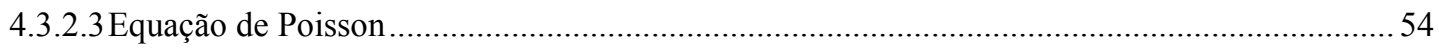

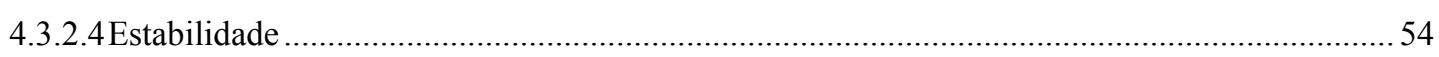

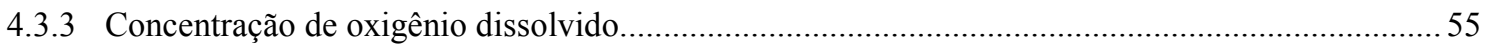

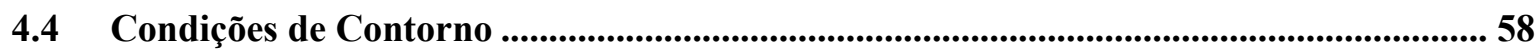


$5 \quad$ RESULTADOS E DISCUSSÕES .............................................................................. 63

6 CONCLUSÕES E RECOMENDAÇÕES ................................................................. 81

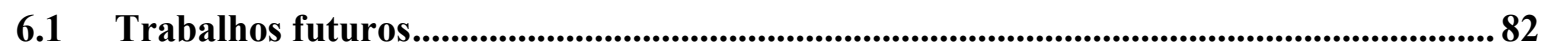

7 REFERÊNCIAS BIBLIOGRÁFICAS ................................................................. 83

APÊNDICE - Programação MATLAB .................................................................................. 86 


\section{INTRODUÇÃO}

Processos de aeração são fundamentais no contexto de hidráulica ambiental e saneamento. Quando a concentração de oxigênio dissolvido é deficiente em um meio, a tendência natural é que o gás passe da fase gasosa para a fase líquida, porém o oxigênio é um gás com baixa solubilidade no meio líquido. Desta forma, processos de aeração artificial são utilizados com o propósito de acelerar a taxa de transferência deste gás, equivalente à taxa do seu consumo pelas bactérias (VON SPERLING, 2003), para o caso de tratamento de efluentes por processos aeróbios.

As duas formas principais de produzir aeração artificial são através da aeração por ar difuso e da aeração superficial (ou mecânica), sendo a primeira, objeto de estudo do presente trabalho.

Uma das principais formas de aeração por ar difuso consiste no fornecimento de oxigênio ao líquido através de difusores submersos que formam microbolhas, as quais induzem uma aceleração local vertical, geram uma difusão turbulenta e transferem seu oxigênio à medida que ascendem no tanque de aeração. Desta forma a grande área de contato entre as fases e as taxas de transferência de massa favorecem reações químicas e biológicas.

Em geral, os equipamentos utilizados são de simples operação, porém apresentam uma fluidodinâmica complexa. O contato entre as fases apresenta instabilidade, o comportamento das interfaces em função das variáveis de campo, como pressão, velocidades, temperatura, requerem grandes estudos. Atualmente, através de técnicas computacionais, é possível simular fenômenos relacionados com o movimento dos fluidos e as simulações numéricas desempenham um papel fundamental para o entendimento e quantificação do fenômeno. A modelagem de um sistema de aeração forçada por bolhas auxiliará a análise do fenômeno de transferência de oxigênio em si. Além disto, o emprego de uma modelagem com maiores simplificações ajuda em procedimentos de simulações mais rápidas, como no caso do controle do processo. 


\section{OBJETIVO}

O presente trabalho visa à obtenção de um modelo simplificado para a simulação da transferência de oxigênio de um sistema bifásico ar-água, no qual a transferência do oxigênio se dá por meio de aeração forçada por bolhas.

Avaliar o método explícito MAC para resolução das equações de Navier-Stokes e o método implícito de Crank-Nicolson para resolução da transferência de oxigênio. 


\section{REVISÃO DA LITERATURA}

Este capítulo traz uma breve revisão sobre trabalhos pertinentes ao problema estudado e a fundamentação teórica necessária para a realização das atividades.

\subsection{Oxigênio Dissolvido}

O Oxigênio Dissolvido (OD) é um parâmetro primordial e limitante em processos de autodepuração em sistemas aquáticos, estações de tratamento de esgoto e manutenção da vida aquática, pois oxida compostos nocivos e minimiza a toxicidade de alguns elementos. Alguns organismos decompõem a matéria orgânica por meio do consumo do oxigênio.

A aeração se dá naturalmente pela interface ar-água, por mecanismos de transporte devido aos movimentos do corpo hídrico, no entanto a eficiência deste processo pode ser baixa quando há lançamentos de esgotos domésticos e industriais em lagos e rios. Frente a isto, aerar um meio deficiente de oxigênio se faz necessário para aumentar a transferência de OD no meio.

\subsubsection{Aeradores}

A aeração mecânica introduz oxigênio no sistema por meio de aeradores superficiais, os quais quebram a superfície da água com um misturador ou turbina, provocando agitação e correntes favorecendo o contato com o ar atmosférico, produz uma nuvem de pequenas bolhas sobre a superfície da água, em um raio de vários metros.

A aeração por ar difuso introduz o oxigênio no meio líquido por meio de microbolhas, originárias de difusores instalados no fundo dos tanques, alimentados por sopradores de ar comprimido.

Berzin (2001) realizou um estudo para um caso particular, o qual foi examinado vantagens e desvantagens técnico-econômicas de um sistema de aeração por ar difuso e sistema de aeração mecânica para o tratamento de águas residuárias. Foi verificado que a eficiência de transferência de oxigênio foi maior no sistema de ar difuso devido ao contato das microbolhas processadas em toda a profundidade do tanque; a redução foi de até $60 \%$ do consumo de energia elétrica ao optar pelo ar difuso em relação à aeração mecânica; o ar difuso possibilita operar o sistema com vazão de ar reduzida em períodos de menor demanda, 
e assim reduzir os gastos operacionais e ao considerar os custos totais entre os dois sistemas, com o ar difuso há uma redução de $27 \%$ do custo por volume de esgoto tratado.

Simular a transferência de oxigênio em sistemas por ar difuso pode trazer benefícios em relação ao custo do processo além de haver melhor eficiência na aeração do sistema.

Ao levar em consideração a formação inicial de bolhas formadas pelos difusores de ar, estas podem ser analisadas, em seu caso mais simples, ao considerá-las com um formato simétrico esférico, a simplicidade da análise revela uma série de fenômenos importantes que ocorrem e devem ser analisados separadamente.

O diâmetro médio das bolhas é um parâmetro de estudo muito importante, pois quanto menor o diâmetro das bolhas, maior será a área interfacial de contato com a água e mais eficiente será a transferência de massa. Salla (2006) estudou o diâmetro médio de bolhas em uma coluna e verificou que o diâmetro da bolha aumenta linearmente com o aumento da vazão. Ao fixar-se uma vazão, foi verificado o aumento do diâmetro da bolha com o aumento da altura da coluna, justificável pela pressão que a coluna d'água exerce sobre as bolhas.

\subsection{Equação da Continuidade}

A Equação da Continuidade (Equação 3.1) expressa à conservação de massa aplicada a um elemento de fluido, em uma região limitada do espaço (SCHULZ, 2003).

$\frac{\partial V_{x}}{\partial x}+\frac{\partial V_{y}}{\partial y}+\frac{\partial V_{z}}{\partial z}=0$

\subsection{Transferência de Massa}

O movimento de um elemento específico num sistema de vários componentes referese à transferência de massa. Em regiões com concentrações distintas ocorrerá a transferência de massa no sentido das zonas de maior concentração para zonas de menor concentração.

Esta transferência pode advir pelo mecanismo da difusão molecular, da convecção ou por ambos. Os movimentos aleatórios de partículas (moléculas) do meio no sentido de maior para menor concentração é chamado de difusão molecular, já quando o fluido que compõe o meio está em movimento, a transferência de massa se dá por convecção.

A Equação 3.2, reconhecida como Lei de Fick, representa o fluxo de massa como proporcional à derivada da concentração em relação ao espaço (no caso, direção $x$ ). A 
difusividade molecular representada pela letra $D$ é de importante quantificação para resolver problemas de transferência de massa.

$\dot{m}=-D_{A B} \frac{d C_{A}}{d x}$

Sendo $\dot{m}$ o fluxo de massa $\left(\mathrm{Kg} / \mathrm{m}^{2}\right), D_{A B}$ a difusividade molecular de uma substância A no meio B $\left(\mathrm{m}^{2} / \mathrm{s}\right), C_{A}$ a concentração de uma substância A qualquer $\left(\mathrm{Kg} / \mathrm{m}^{3}\right)$ e $x$ o eixo das abscissas.

O sinal negativo nessa expressão indica que a direção da difusão se dá contra o gradiente de concentração, isto é, da concentração mais alta para a concentração mais baixa. A difusividade molecular ou coeficiente de difusão indica a facilidade com que um constituinte pode avançar através de outro.

Já a transferência de massa por convecção para regimes turbulentos, em que ocorre presença de vórtices ou turbilhões, adiciona-se ao transporte difusivo uma parcela de transporte convectivo. É um modelo aceito e incorpora o coeficiente de transporte turbulento somado ao coeficiente difusivo, como segue na Equação 3.3 (ROMA, 2006).

$\dot{m}=-\left(D_{A B}+D_{t}\right) \frac{d C_{A}}{d x}$

Sendo $D_{t}$ a difusividade turbulenta $\left(\mathrm{m}^{2} / \mathrm{s}\right)$.

No caso deste trabalho, cujo tratamento é bidimensional, considerou-se $D_{t} \gg D_{A B}$, portanto a transferência de massa se dá pela Equação 3.4.

$\dot{m}=-\left(D_{t_{x}} \cdot \frac{d C_{A}}{d x}+D_{t_{y}} \cdot \frac{d C_{A}}{d y}\right)$

Em escoamentos altamente turbulentos o termo difusivo é totalmente desprezado e a equação, considerando-se $C_{A}$ média temporal, tem similaridade com a equação de Boussinesq para viscosidade turbulenta (BIRD; STEWART; LIGHTFOOT, 2006).

\subsubsection{Transferência Interfacial de Massa}

A transferência de massa entre sistemas bifásicos gás-líquido envolve diversas pesquisas ao longo dos anos por ser um problema de difícil solução. O conceito de camada- 
limite é em geral aceito para representar a taxa de transferência interfacial de massa (Equação 3.5). (SCHULZ, 2003)

$\dot{m}=h_{m}\left(C_{s}-C_{\infty}\right)$

Sendo $h_{m}$ um parâmetro de coeficiente de transferência de massa, $C_{S}$ é a concentração na superfície $\left(\mathrm{Kg} / \mathrm{m}^{3}\right)$ e $C_{\infty}$ concentração no seio líquido distante da interface $\left(\mathrm{Kg} / \mathrm{m}^{3}\right)$.

A Teoria dos Dois Filmes (LEWIS; WHITMAN, 1924) diz respeito à situação física da interface entre duas fases fluidas (líquido e gás). Na interface são formados dois filmes, um filme para a fase líquida e outro para a fase gasosa, sendo estes estruturas de resistência à passagem de moléculas de gás entre as fases gasosa e líquida. O transporte de oxigênio através deles é considerado como um processo de difusão molecular, por considerar apenas movimentos laminares no interior dos filmes. A Equação 3.6 apresenta o termo $K_{L}$, denominado de coeficiente de transferência global de massa. (SCHULZ, 2003).

$\dot{m}=K_{L}\left(C_{s}-C_{\infty}\right)$

O $K_{L}$ é escrito em função do coeficiente de transferência de massa no filme gasoso $\left(k_{g}\right)$ e do coeficiente de transferência de massa no filme líquido $\left(k_{l}\right)$, no entanto em problemas com gases de baixa solubilidade comumente $k_{l}<<k_{g}$, de forma que o $K_{L}$ seja aproximadamente o próprio $k_{l}$.

O coeficiente volumétrico de transferência de massa $K_{L} a$ é o produto do coeficiente de transferência de massa líquida $k_{l}$ e da área interfacial $a$ da bolha. Bouaifi et al. (2001) constataram em seu estudo que o coeficiente de transferência de massa $k_{l}$ variou de acordo com o tamanho da bolha e fluxo em torno das bolhas. Para bolhas maiores, os valores de $k_{l}$ foram consideravelmente superiores aos registrados para as bolhas menores.

Vuitik (2013) estudou 12 correlações para $K_{L} a$ encontradas na literatura e avaliou a melhor correlação aderida aos dados experimentais, a correlação proposta por Hikita et al. (1981) foi a que apresentou maior aderência e selecionada como mais adequada para descrever o processo proposto em sua pesquisa. 


\subsection{Equação da Conservação de Massa para a Concentração de um Composto em um Escoamento}

O princípio da conservação de massa diz que a variação da massa de um composto em um elemento de volume será igual à diferença entre a massa de composto que sai e aquela que entra no elemento mais a massa gerada neste elemento, como ilustrado na Figura 1.

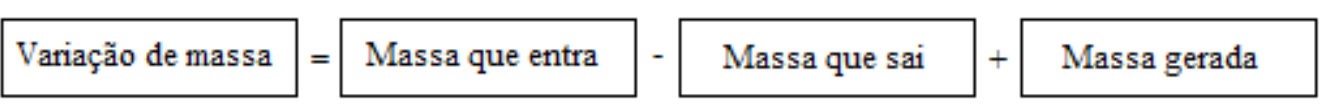

Figura 1 - Esquema geral do principio da conservação de massa.

Comumente a equação da conservação é apresentada em termos de concentração volumétrica do composto. A massa de cada elemento varia de acordo com a posição do volume nas três dimensões $(\mathrm{x}, \mathrm{y}, \mathrm{z})$ e com o tempo, $\mathrm{t}$.

A forma diferencial da Figura 1 pode ser apresentada pela Equação 3.7.

$\frac{\partial C_{A}}{\partial t}+V_{x} \frac{\partial C_{A}}{\partial x}+V_{y} \frac{\partial C_{A}}{\partial y}+V_{z} \frac{\partial C_{A}}{\partial z}=D_{A B}\left(\frac{\partial^{2} C_{A}}{\partial x^{2}}+\frac{\partial^{2} C_{A}}{\partial y^{2}}+\frac{\partial^{2} C_{A}}{\partial z^{2}}\right)+\dot{g}$

Sendo $t$ o tempo (normalmente expresso em segundo), $V_{x}$ a componente da velocidade na direção $x(\mathrm{~m} / \mathrm{s}), V_{y}$ a componente da velocidade na direção $y(\mathrm{~m} / \mathrm{s}), V_{z}$ a componente da velocidade na direção $Z(\mathrm{~m} / \mathrm{s})$ e $\dot{g}$ é a taxa de produção de massa no elemento.

A primeira parcela do primeiro membro representa a taxa de variação temporal da concentração no elemento de estudo. As três próximas parcelas representam a taxa de variação da concentração ao longo das coordenadas espaciais, provocadas pelo movimento do fluido. No segundo membro as três primeiras parcelas representam a difusão de massa nas três direções coordenadas e a última parcela é a taxa de produção de massa no elemento ou incorporação de massa por interfaces (SCHULZ, 2003).

\subsection{Equação da Quantidade de Movimento - Navier-Stokes}

As equações de Navier-Stokes (N-S) visam esclarecer problemas envolvendo qualquer tipo de escoamento compreendendo vários tipos de fluidos. $\mathrm{O}$ desenvolvimento das equações N-S parte da aplicação da segunda lei de Newton para um elemento de volume de um fluido, 
no qual são considerados esforços de contato e de massa sobre este elemento, tais como forças de pressão, tensões viscosas e normais e forças de campos externos.

A Equação 3.8 apresenta a Equação de N-S válida para escoamentos incompressíveis na direção $x$. Para as direções $y$ e $z$ as equações são apresentadas de formas análogas nas Equações 3.9 e 3.10 .

$\rho\left(\frac{\partial V_{x}}{\partial x} V_{x}+\frac{\partial V_{x}}{\partial y} V_{y}+\frac{\partial V_{x}}{\partial z} V_{z}+\frac{\partial V_{x}}{\partial t}\right)=\mu\left(\frac{\partial^{2} V_{x}}{\partial x^{2}}+\frac{\partial^{2} V_{x}}{\partial y^{2}}+\frac{\partial^{2} V_{x}}{\partial z^{2}}\right)+\frac{\partial p}{\partial x}+\rho B_{x}$

$\rho\left(\frac{\partial V_{y}}{\partial x} V_{x}+\frac{\partial V_{y}}{\partial y} V_{y}+\frac{\partial V_{y}}{\partial z} V_{z}+\frac{\partial V_{y}}{\partial t}\right)=\mu\left(\frac{\partial^{2} V_{y}}{\partial x^{2}}+\frac{\partial^{2} V_{y}}{\partial y^{2}}+\frac{\partial^{2} V_{y}}{\partial z^{2}}\right)+\frac{\partial p}{\partial y}+\rho B_{y}$

$\rho\left(\frac{\partial V_{z}}{\partial x} V_{x}+\frac{\partial V_{z}}{\partial y} V_{y}+\frac{\partial V_{z}}{\partial z} V_{z}+\frac{\partial V_{z}}{\partial t}\right)=\mu\left(\frac{\partial^{2} V_{z}}{\partial x^{2}}+\frac{\partial^{2} V_{z}}{\partial y^{2}}+\frac{\partial^{2} V_{z}}{\partial z^{2}}\right)+\frac{\partial p}{\partial z}+\rho B_{z}$

Sendo $\rho$ a massa específica do fluido $\left(\mathrm{Kg} / \mathrm{m}^{3}\right), \mu$ a viscosidade dinâmica $\left(\mathrm{N} \cdot \mathrm{s} / \mathrm{m}^{2}\right)$ e $B$ a força que aparece no elemento de volume devido à ação de um campo.

São equações exploratórias que dão a ideia de como as parcelas de variação de tensão estão relacionadas com o campo de velocidades, sendo assim base de um grande número de resultados úteis obtidos em mecânica dos fluidos.

\subsection{Dinâmica dos Fluidos Computacional (DFC)}

Fluidodinâmica computacional é uma área que consiste em obter soluções numéricas de problemas da mecânica dos fluidos utilizando métodos numéricos.

A DFC integra análises teóricas e técnicas experimentais da mecânica dos fluidos para obtenção de modelos, a fim de esclarecer ou prever fenômenos em escoamento de fluidos. De acordo com Fortuna (2000), DFC é a área da computação científica que estuda métodos computacionais para simulação de fenômenos que envolvem fluidos em movimento com ou sem trocas de calor.

Fenômenos relacionados com o movimento de fluidos podem ser bastante complexos. Análises teóricas, somente, ainda não conseguem descrever esses fenômenos de forma adequada, principalmente nos escoamentos encontrados nos problemas de engenharia (FORTUNA, 2000). 
O uso de técnicas numéricas para a solução de problemas complexos da engenharia e da física é hoje uma realidade, graças ao desenvolvimento de computadores de alta velocidade e de grande capacidade de armazenamento (MALISKA, 2004).

Para resolver um problema característico utilizando DFC é necessário discretizar o domínio físico em que ocorre o escoamento. Os métodos mais empregados são os Métodos das Diferenças Finitas (MDF), o Método dos Volumes Finitos (MVF) e o Método dos Elementos Finitos (MEF).

Em problemas comuns dessa área são associadas geralmente de 3 a 20 variáveis - tais como pressão, três componentes de velocidade, densidade, temperatura, entre outras - para cada elemento da malha gerada. Em fenômenos físicos turbulentos é necessário trabalhar com malhas bastante refinadas dentro do domínio (DIONÍSIO, 2008).

\subsection{Métodos de Discretização}

Por ser um método categórico e tradicional, uma maior ênfase será dada no MDF, pois faz parte do estudo do presente trabalho, no entanto um breve comentário sobre os outros já citados métodos se faz necessário.

Historicamente o MDF foi empregado na área de mecânica dos fluidos, devido a não linearidade envolvendo as equações de N-S (MALISKA, 2004). O MDF expõe as incógnitas do problema de fluxo por meio de pontos tomados em nós da malha de coordenadas lineares, as equações derivadas governantes são substituídas por Diferenças Finitas (DF), através de equações algébricas em cada ponto da malha (MOCROSKY, 2007).

Já o MEF é mais utilizado para a área de engenharia estrutural na solução de problemas de elasticidade, pois estes não possuem termos advectivos e assemelham-se a problemas difusivos de transferência de calor, de característica linear (MALISKA, 2004). O MEF pode fazer uso de malha não estruturada, o que permite a solução de problemas com geometrias complexas, empregando um conjunto de variáveis simples para descrever o local de variação de um fluxo (MOCROSKY, 2007).

Com relação ao MVF, as equações aproximadas são obtidas através de balanços de conservação em um volume elementar (MALISKA, 2004). O MVF permite criar equações aproximadas com balanço das propriedades em nível de volumes simples, para qualquer tamanho de malha. Os algoritmos numéricos permitem uma integração das equações governantes em todo o volume de controle e do domínio da solução, assim a discretização é 
feita pela substituição das variáveis de diferença finitas, através de equações integradas dentro de um sistema de equações algébricas que representam o fluxo (MOCROSKY, 2007).

\subsection{Método das Diferenças Finitas}

O Método das Diferenças Finitas aproxima as derivadas por expressões algébricas válidas para pontos discretos, diferentemente dos modelos analíticos, cujas funções são válidas para qualquer ponto do domínio. Assim sendo, a equação diferencial parcial que descreve o problema é substituída por um número finito de equações algébricas, escritas em termos dos valores da variável dependente nos pontos selecionados. O sistema de equações algébricas deve então ser solucionado.

O ponto de partida é a conservação da equação na forma diferencial. O domínio de solução é representado por uma malha e, em cada ponto dela, a equação é aproximada, substituindo as derivadas (totais ou parciais, a depender do problema em análise) por aproximações em termos de valores das funções nos nós da malha. O resultado é uma equação algébrica para cada nó da malha, na qual o valor da variável num certo número de nós vizinhos aparece como incógnita.

Em princípio, o MDF pode ser aplicado a qualquer tipo de malha, contudo o mesmo tem sido aplicado a malhas estruturadas em que as linhas da malha servem como coordenadas locais.

Para obter aproximações para a primeira e segunda derivadas da variável em função das coordenadas são usadas expansões baseadas na série de Taylor ou regressões polinomiais. Quando necessário estes métodos são também aplicados para obter os valores das variáveis em locais que não há nós (por interpolação).

Em malhas estruturadas, o MDF é muito simples e eficaz. São especialmente fáceis de obter os métodos para uma elevada ordem em malhas regulares. Algumas desvantagens do MDF são o fato de a conservação não ser inerente ao método, a não ser que sejam tomadas medidas especiais e as restrições às geometrias simples, significativa em problemas complexos (GONÇALVES, N. D. F., 2007).

\subsubsection{MAC}

O método MAC (Marker and Cell) foi inicialmente proposto por Harlow e Welch (1965) para a solução de problemas de escoamento em superfícies livres, e tornou-se um dos 
esquemas explícitos mais populares para a solução das equações de N-S. O método pode ser empregado para escoamentos transientes e estacionários, é comumente implementado em uma malha deslocada.

No MAC, a discretização dos termos que envolvem velocidade é realizada no instante $n$ enquanto que o termo envolvendo pressão é discretizado em $n+1$, de forma que após o cálculo das velocidades em $n+1$, todas as variáveis do escoamento são avançadas no tempo. A aproximação do termo transiente no método MAC é baseada no método de Euler explícito. Assim, todos os termos que envolvem derivadas parciais espaciais de velocidades sendo discretizados no nível de tempo $n$, de forma que, após a aplicação do integrador temporal, determinamos o campo de velocidade no nível temporal $n+1$.

A modelagem de escoamentos incompressíveis por meio das Equações de N-S necessita envolver em seus cálculos a equação de Poisson para a pressão a cada incremento no tempo, entretanto existem algumas dificuldades para solucionar estes tipos de sistemas. A equação da continuidade deve ser satisfeita a cada passo de tempo, o que gera a necessidade da solução de um conjunto de equações acopladas para a determinação do campo de velocidades em $n+1$. O segundo é que não há condições de fronteiras físicas para a pressão, deste modo se deve utilizar condições de fronteira apropriadas à solução numérica da equação de Poisson para a pressão. (FORTUNA, 2000).

\subsubsection{Crank-Nicolson}

O método de Crank-Nicolson propõe um esquema implícito alternativo para melhorar a acurácia da derivada de segunda ordem no espaço e possibilitar a discretização central da derivada temporal de primeira ordem, evitando tempos negativos para as equações de transporte. Para alcançar esse objetivo, aproximações para as diferenças são implementadas no ponto médio do incremento de tempo,

Com esta técnica, para que não haja inconsistência com tempos negativos e por permitir um menor desvio com relação às parcelas desprezadas na aproximação discreta (arredondamento), coloca-se o ponto de referência da malha discreta centrado na metade do intervalo de tempo $\Delta t$ estipulado, ou seja, $k+1 / 2$ conforme Figura 2. Este ponto não será contabilizado nos cálculos, mas faz-se uma aproximação por média aritmética das equações avaliadas nos instantes $k$ e $k+1$. 


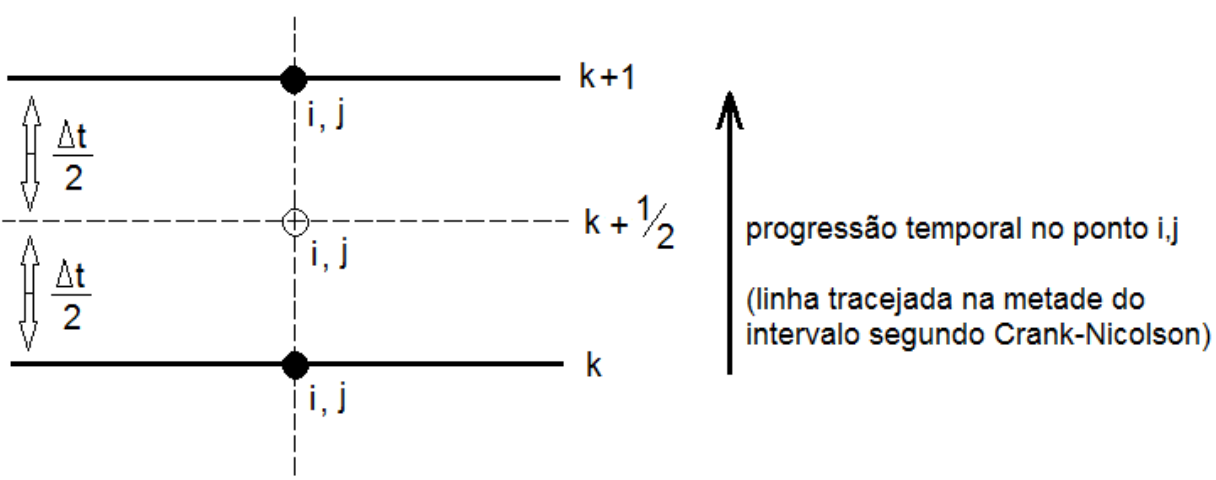

Figura 2 - Esquema de malha temporal conforme a técnica de Crank-Nicolson. Considera-se um ponto na metade do intervalo como referência para os cálculos.

Oishi (2008) estudou o método de Crank-Nicolson na construção de métodos de projeção para escoamentos com superfície livre. Na análise de estabilidade, o principal resultado mostrou que o método de Crank-Nicolson torna-se incondicionalmente estável quando aplicado para uma malha deslocada com a discretização explícita das condições de contorno do tipo Dirichlet, porém o mesmo método com condições de contorno implícitas é condicionalmente estável.

\subsection{Estudos na Área}

Horvath et al. (2009) simularam uma coluna de bolhas utilizando DFC e compararam com resultados experimentais. As simulações fizeram uso de duas implementações disponíveis de modelo de Volume de Fluido. As comparações mostraram que ambas produziram boa previsão da fração volumétrica de gás na coluna de bolhas, sendo medidas pela altura do nível do líquido, mesmo com a velocidade de ascensão das bolhas principais exagerada. Ao usar o OpenFOAM foi possível simular alguns segundos de tempo real para a coluna de bolhas com duas taxas de fluxo de gás diferentes, produzindo resultados semelhantes aos dos experimentos. A fração volumétrica de gás na coluna é prevista corretamente, no entanto a simulação das bolhas menores precisaria de uma grade de maior densidade e de um refinamento em torno de interfaces.

Dionísio (2008) analisou a influência de parâmetros e aproximações geométricas usualmente feitas em simulações por DFC do escoamento bifásico gás-líquido em colunas de bolhas em escala de laboratório. Foram utilizadas equações de conservação de massa e quantidade de movimento, levando em conta as interações relevantes entre as fases, incluindo a força de arraste na modelagem matemática. $\mathrm{O}$ modelo de turbulência utilizado para a fase 
contínua é o modelo $\kappa-\varepsilon$, o qual se baseia na hipótese da viscosidade turbulenta, que sugere que a turbulência consiste de pequenos turbilhões que estão constantemente se formando e se dissipando, e das Tensões de Reynolds, que são consideradas como sendo proporcionais aos gradientes de velocidades médias. Além disso, foi utilizado o software comercial CFX/ANSYS $11^{\mathrm{tm}}$ para resolução numérica e visualização dos resultados do sistema de equações gerado, no qual o MVF é usado para a discretização do domínio da solução do problema.

Ainda de acordo com Dionísio (2008), a abordagem euleriana apresenta uma boa aproximação para os sistemas estudados, havendo necessidade de modelos de arraste que considerem deformações na geometria das bolhas. Já os sistemas de médias temporais são a forma atual mais útil para comparar dados relevantes em colunas de bolhas, já que é sabido o comportamento altamente oscilatório/transitório dos perfis de velocidade axial da fase líquida e fração volumétrica.

Ekambara, Dhotre e Joshi (2005) utilizaram a DFC para descrever a hidrodinâmica dos reatores de coluna de bolhas. O comportamento do fluxo da coluna de bolhas foi previsto utilizando modelos unidimensional, bidimensional e tridimensional. Os modelos de DFC estimaram a fração volumétrica de gás, velocidade axial do líquido, intensidades de turbulência, viscosidade turbulenta e característica de dispersão da fase líquida e foram comparados com dados experimentais.

Para um fluxo bifásico gás-líquido em uma coluna de bolhas, os autores utilizaram equações de movimento e continuidade para coordenadas cilíndricas tridimensionais, obtidas a partir de procedimentos similares a Stewart e Wendroff (1984), Jakobsen et al. (1997), Joshi (2001) e Sokolichin et al. (2004), nos quais os autores deram detalhes pertinentes às equações governantes para formulação dos escoamentos bidimensionais. O método dos volumes finitos foi empregado para solução das equações. $O$ arranjo de grade escalonada utilizado foi o mesmo proposto por Patankar e Spalding (1972) e o algoritmo Semi Implicit Linked Equations (SIMPLE) foi usado para determinar o termo acoplado de velocidade e pressão na modelagem bidimensional e tridimensional. O conjunto de equações algébricas obtido após a discretização foi, então, resolvido por Algoritmo Tridiagonal (TDMA).

Os resultados dos modelos foram comparados com dados experimentais de Vitankar et al. (2002) para modelo unidimensional, Ekambara e Joshi (2003a) para modelo bidimensional e Ekambara e Joshi, (2003b) para modelo tridimensional. As simulações foram realizadas com sucesso. Todos os modelos tiveram boa concordância com os dados experimentais para velocidade axial e fração volumétrica de gás na coluna. No entanto, no que diz respeito ao 
coeficiente de difusão, apenas as previsões do modelo tridimensional concordam em estreita colaboração com os dados experimentais. 


\section{METODOLOGIA}

O processo de aeração realizado através de difusores de gás apresenta, em geral, um mecanismo muito simples de aplicação, que consiste na introdução de um gás no meio líquido, o qual transfere seu oxigênio e supre a deficiência deste no meio. Entretanto, os fenômenos que regem este processo são complexos e exigem um estudo detalhado. Diversos parâmetros precisam ser analisados separadamente para chegar a um resultado satisfatório que represente fielmente o processo de aeração por ar difuso e isto requer a construção de experimentos e estudos aprofundados sobre o tema.

Exemplos de parâmetros e equações são: velocidades do fluido, viscosidades cinemáticas e turbulentas, dispersão de uma pluma de bolhas, fração de vazios, velocidade ascensional de bolhas, coeficiente volumétrico de transferência de massa, difusividade do componente estudado no meio, entre outros.

A modelagem matemática é realizada através da definição de um conjunto de equações diferenciais parciais e condições de fronteira, de forma que melhor represente ou interprete de maneira simplificada a realidade. No entanto para evitar cometer erros graves se deve ter atenção ao determinar simplificações e ao escolher parâmetros que representem a realidade, de forma que os resultados não sejam influenciados negativamente. As equações em suas formas discretas foram implementadas no software MATLAB. A licença do software foi concedida pela Universidade de São Paulo através do link $<$ http://www.cce.usp.br/atendimento/software/matlab/2012a/win/>.

\subsection{Esquema Proposto}

O esquema escolhido para a simulação do trabalho foi um canal aberto, de acrílico, sem agitação mecânica, ajustado para aerador. O canal adaptado está instalado em planta piloto, utilizada para ensaios de cavitação e aeração (OLIVEIRA, 2008). Encontra-se no laboratório de Hidráulica Ambiental, localizado no CRHEA-SHS-EES-USP (Broa, Itirapina, SP).

O fluido utilizado foi água e sua entrada se dá pelo lado esquerdo, por meio de uma pequena abertura na parte inferior do canal e sua saída se dá pela parte superior direita. Os aeradores estão inseridos na linha central do fundo, dispostos longitudinalmente (Figura 3). 


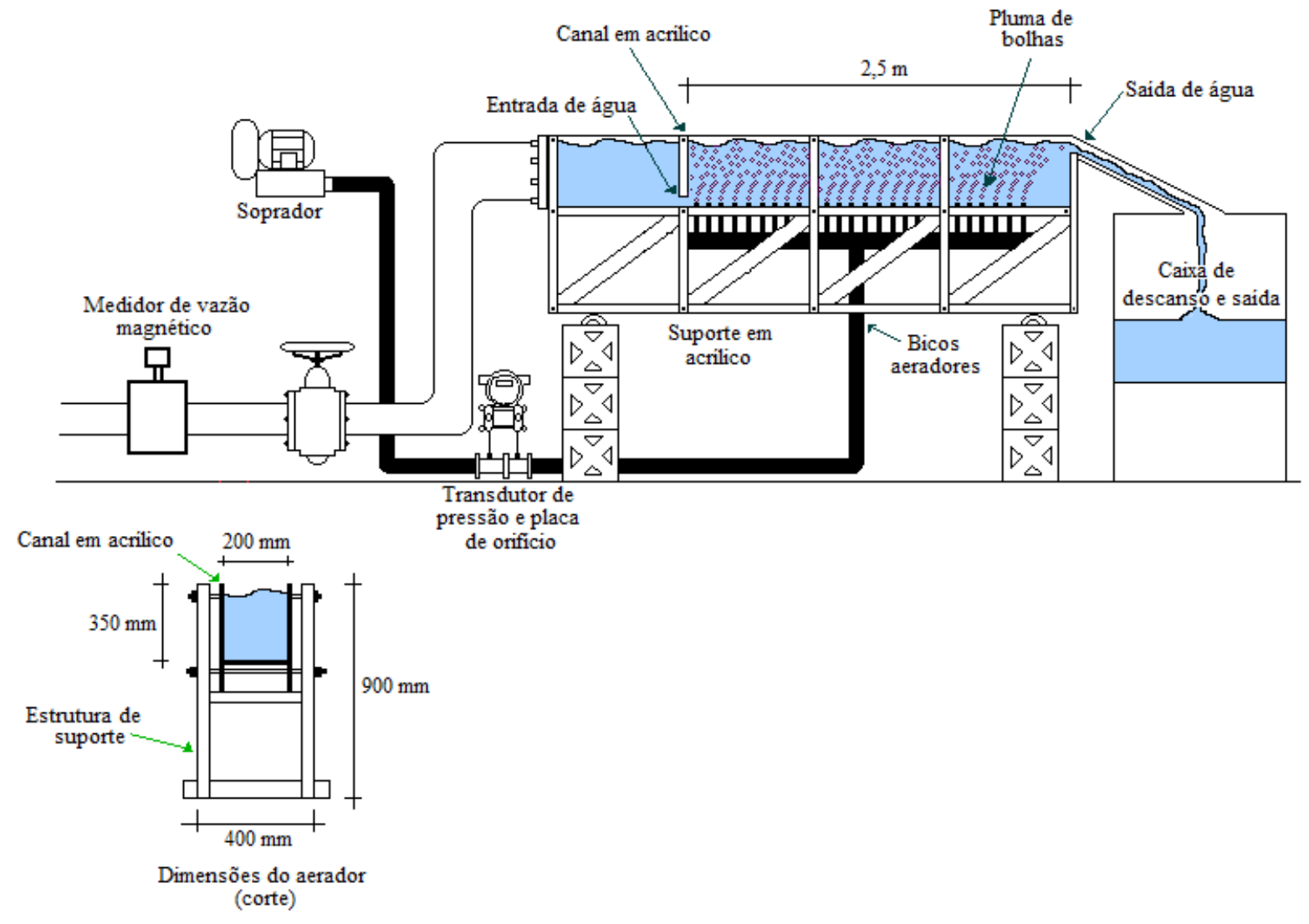

Figura 3 - Aparato experimental. Adaptado de Oliveira (2008).

O canal possui dimensões de $5 \mathrm{~m}$ (comprimento) x $0,35 \mathrm{~m}$ (altura) x $0,20 \mathrm{~m}$ (largura). As simulações foram realizadas apenas em duas dimensões $(x, y)$ e a parte do canal simulada possui $2,5 \mathrm{~m}$ de comprimento por $0,30 \mathrm{~m}$ de altura. A escolha deste intervalo para realizar as simulações foi pelo fato de ser este o trecho que conta com a injeção de oxigênio por meio dos bicos injetores. A Figura 3 não está em escala e serve apenas para elucidar o leitor.

Foram realizadas simulações das velocidades $V_{x}$ e $V_{y}$ da água no tanque, dos perfis estacionários das plumas de bolhas, da concentração de oxigênio dissolvido dentro do tanque, para 1 bico injetor de ar, 5, 10 e 24 bicos injetores de ar, espaçados igualmente entre si, e ainda simulação da pressão no canal.

\subsection{Equações Governantes}

A simulação da transferência de oxigênio por ar difuso procura, através de conceitos teóricos de estudos realizados anteriormente, representar de forma satisfatória o processo ocorrido. Para isso, equações que representem os fenômenos advindos no processo foram 
utilizadas. Vale ressaltar que outras equações podem ser inseridas na modelagem, a fim de complementar a simulação.

\subsubsection{Concentração de Bolhas}

Um modelo de dispersão descreve matematicamente o processo de difusão turbulenta e transporte de um elemento que ocorre em um sistema. Para tratar da modelagem da concentração de bolhas no presente trabalho, foi considerado o modelo de dispersão gaussiana para a pluma.

Simiano (2005) realizou um estudo a respeito da hidrodinâmica em plumas de bolhas. Técnicas de medição como Velocimetria por Imagem de Partículas (PIV), Sondas Ópticas de Dupla Ponta (OP) e técnicas fotográficas foram utilizadas. Estudos estatísticos determinaram que os vazios formados pela pluma de bolhas apresentam um perfil de ajuste gaussiano (Figura 4).

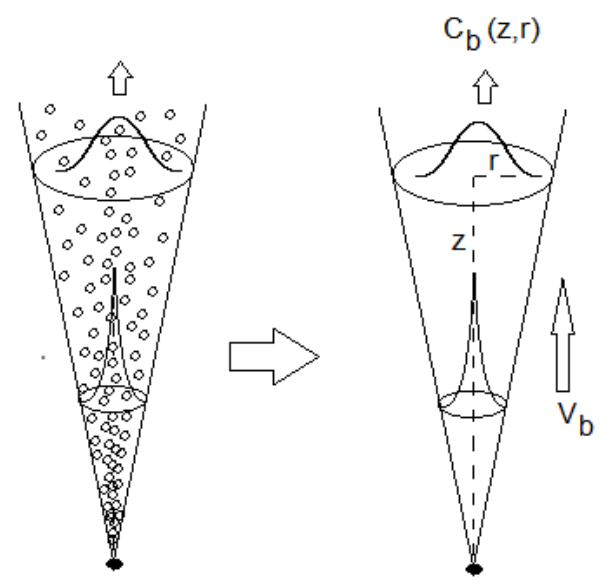

Figura 4 - Espalhamento gaussiano das bolhas, assumido com diâmetro uniforme e velocidade constante. Fonte: Vuitik (2013).

A dispersão das bolhas se dá a partir de um ponto de massa central, o qual sobe numa linha central a uma velocidade média ascensional constante. A equação que descreve uma função Gaussiana de dispersão para concentração de bolhas é abordada por Vuitik (2013), apresentada pela Equação 4.1.

$C_{b}(x, y, z)=\frac{n_{b}}{\left(4 \cdot \pi \cdot z \cdot D_{\text {bolha }}\right)} \cdot \exp \left(\frac{-x^{2}}{4 \cdot D_{\text {bolha }} \cdot \frac{Z}{V_{z}}}\right) \cdot \exp \left(\frac{-y^{2}}{4 \cdot D_{\text {bolha }} \cdot \frac{Z}{V_{z}}}\right)$ 
Sendo $C_{b}$ a concentração de bolhas ( $\mathrm{n}^{\mathrm{o}}$ de bolhas $\left./ \mathrm{m}^{3}\right), n_{b}$ a quantidade de bolhas formadas pela vazão de ar na injeção ( $\mathrm{n}^{\mathrm{o}}$ de bolhas/s), $D_{\text {bolha }}$ a difusividade das bolhas na água $\left(\mathrm{m}^{2} / \mathrm{s}\right)$. A vazão de ar $\left(Q_{a r}\right)$ injetada no aerador e o volume médio da bolha $\left(\operatorname{Vol}_{b}\right)$ interferem na quantidade de bolhas que é formada.

Adaptando a Equação 4.1 para este estudo, tem-se a Equação 4.2.

$C_{b}(x, y)=\frac{n_{b}}{\left(4 \cdot \pi \cdot y \cdot D_{\text {bolha }}\right)} \cdot \exp \left(\frac{-x^{2}}{4 \cdot D_{\text {bolha }} \cdot \frac{y}{V_{b}}}\right)$

Sendo $V_{b}$ a velocidade média de ascensão das bolhas $(\mathrm{m} / \mathrm{s})$.

Ao considerar o caso bidimensional, as direções $z$ e $y$ da Equação 4.1 passam a ser a direção $y$ e zero, respectivamente, para esta metodologia, por se tratar de um estudo bidimensional. Assim sendo a terceira parcela do segundo membro da Equação 4.1 é igual a 1.

A fim de saber a $C_{b}$ em função do raio a partir da linha central de uma pluma de bolhas, a Equação 4.2 ainda pode ser reescrita por fazer-se necessário compatibilizar para posições cartesianas, de modo a possibilitar o cálculo do sistema algébrico discreto (Equação 4.3).

$C_{b}(x, y)=\frac{n_{b}}{\left(4 \cdot \pi \cdot y \cdot D_{\text {bolha }}\right)} \cdot \exp \left(\frac{-r^{2}}{4 \cdot D_{\text {bolha }} \cdot \frac{y}{V_{b}}}\right)$

Sendo $r$ o raio de espalhamento ao redor da linha central da pluma (m).

Vuitik (2013) ainda insere um coeficiente de ajuste para o cálculo da concentração de bolhas. Este coeficiente reduz o termo disperso a uma ordem de grandeza apropriada à realidade observada e é utilizado neste trabalho. O coeficiente tem valor de 0,2 e é multiplicado pela concentração de bolhas calculada.

Além disto, a equação diz respeito a apenas uma pluma de um bico injetor e ao haver mais de um, que é o caso do presente trabalho, é necessário sobrepor os efeitos, conforme Figura 5. 


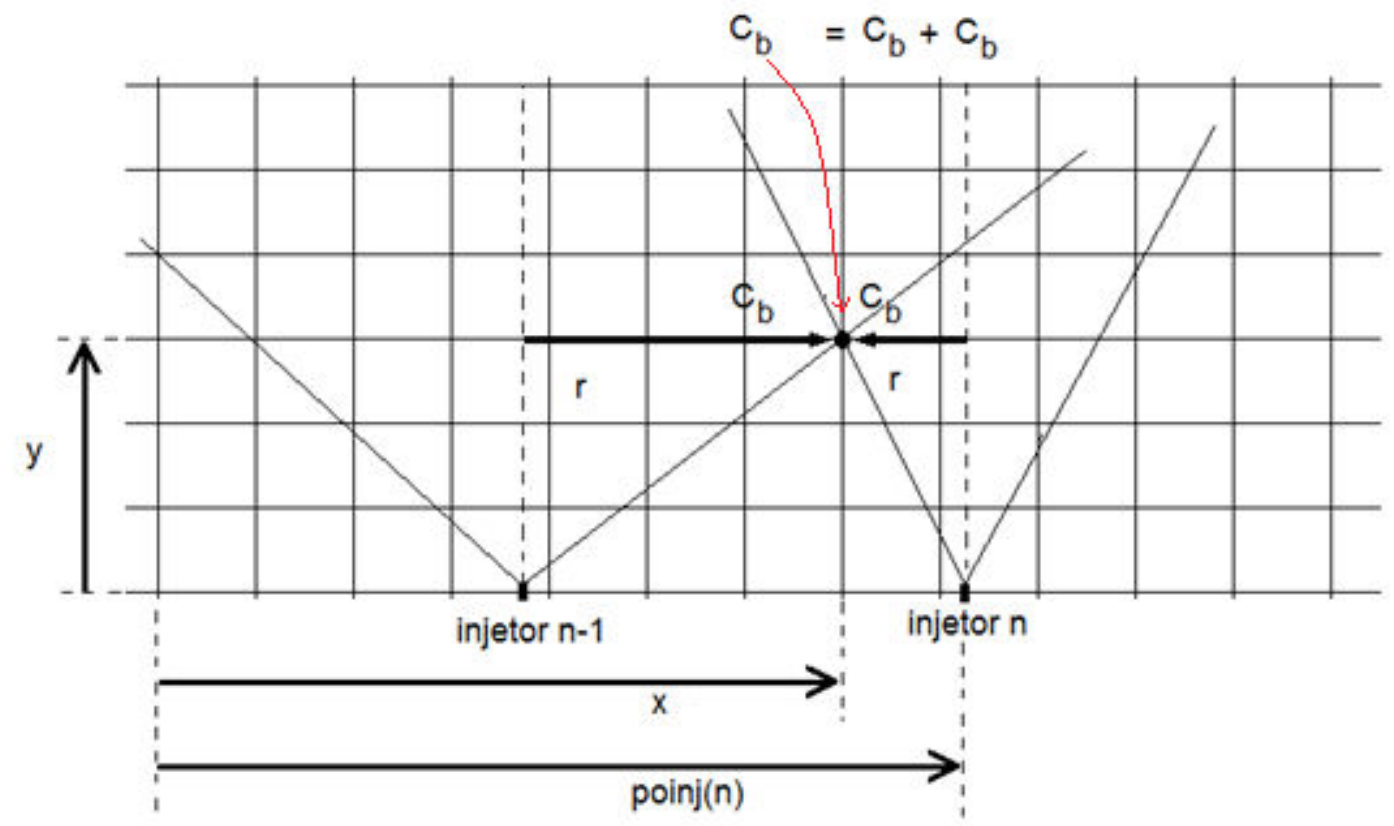

Figura 5 - Observação do raio da pluma e da sobreposição da $C_{b}$. Fonte: Arquivo pessoal.

O assunto será abordado mais adiante no item 4.3.1.

\subsubsection{Difusividade da Bolha}

Para o cálculo da difusividade da bolha, foi empregada a Equação 4.4 de Vuitik (2013), o qual realizou um estudo que abordou os parâmetros envolvidos na transferência de oxigênio em meio hídrico aerado por bolhas, com os símbolos adaptados, onde $y$ corresponde à cota da seção e $V_{b}$ à velocidade ascensional média das bolhas na mesma seção.

$D_{\text {bolha }}=0,000055 \cdot\left(y \cdot V_{b}\right)^{-0,544}$

De acordo com a Equação 4.4, a difusividade da bolha varia com a altura e com a velocidade ascensional média da bolha. Neste estudo a altura $y$ do tanque foi considerada constante $(0,30 \mathrm{~m})$ e conforme estudo realizado por Oliveira (2008) a velocidade ascensional média de uma bolha pode variar de $0,13 \mathrm{~m} / \mathrm{s}$ a $0,26 \mathrm{~m} / \mathrm{s}$, neste trabalho foi utilizado o valor de $0,19 \mathrm{~m} / \mathrm{s}$. 


\subsubsection{Coeficiente de Transferência de Massa}

A Equação 4.5, proposta por Hikita et al. (1981) foi utilizada para o cálculo do $K_{L}$ no presente trabalho, por representar um ajuste satisfatório para este cálculo de acordo com Vuitik (2013).

$\frac{K_{L} \cdot a \cdot V_{S}}{g}=14,9 \cdot\left(\frac{V_{S} \cdot \mu_{l}}{\sigma}\right)^{1,76} \cdot\left(\frac{\mu_{l}^{4} \cdot g}{\rho_{l} \cdot \sigma^{3}}\right)^{-0,248} \cdot\left(\frac{\mu_{g}}{\mu_{l}}\right)^{0,243} \cdot\left(\frac{\mu_{l}}{\rho_{l} \cdot D_{A B}}\right)$

Sendo $V_{S}$ a velocidade superficial $(\mathrm{m} / \mathrm{s}) ; g$ a aceleração devida à ação da gravidade $\left(\mathrm{m} / \mathrm{s}^{2}\right) ; \mu_{l}$ a viscosidade dinâmica na fase líquida $\left(\mathrm{N} \cdot \mathrm{s} / \mathrm{m}^{2}\right) ; \sigma$ a tensão superficial do líquido $\left(\mathrm{N} \cdot \mathrm{m}^{2}\right) ; \rho_{l}$ a massa específica do líquido $\left(\mathrm{Kg} / \mathrm{m}^{3}\right)$ e $\mu_{g}$ a viscosidade dinâmica da fase gasosa $\left(\mathrm{N} \cdot \mathrm{s} / \mathrm{m}^{2}\right)$.

\subsubsection{Velocidades no Meio Líquido}

As velocidades médias de um meio líquido em turbulência, $V_{x}$ e $V_{y}$, nas direções $x$ e $y$ respectivamente, são variáveis importantes no escoamento. Para acoplar essas variáveis ao fenômeno, têm-se as Equações de N-S nas direções $x$ (Equação 4.6) e $y$ (Equação 4.7). As velocidades já são as velocidades médias do escoamento segundo o equacionamento de Reynolds.

$\frac{\partial u}{\partial t}+\frac{\partial u^{2}}{\partial x}+\frac{\partial u v}{\partial y}=-\frac{1}{\rho} \frac{\partial p}{\partial x}+v_{t}\left(\frac{\partial^{2} u}{\partial x^{2}}+\frac{\partial^{2} u}{\partial y^{2}}\right)$, em $x$

$\frac{\partial v}{\partial t}+\frac{\partial v^{2}}{\partial y}+\frac{\partial u v}{\partial x}=-\frac{1}{\rho} \frac{\partial p}{\partial y}+v_{t}\left(\frac{\partial^{2} v}{\partial x^{2}}+\frac{\partial^{2} v}{\partial y^{2}}\right)$, em $y$

Sendo $u$ a componente da velocidade na direção $x(\mathrm{~m} / \mathrm{s}), v$ a componente da velocidade na direção $y(\mathrm{~m} / \mathrm{s}), p$ a pressão $(\mathrm{Pa})$ e $v_{t}$ a velocidade cinemática turbulenta $\left(\mathrm{m}^{2} / \mathrm{s}\right)$.

No meio aquoso com alto grau de agitação por bolhas, é possível usar valores de viscosidades cinemáticas turbulentas médias (em qualquer direção) na faixa de 5 a 30 Pa.s para efeito de cálculos e estimativas rápidas sem significantes degenerações dos resultados (OLIVEIRA, 2008). 


\subsubsection{Fração de vazios}

Ao considerar um sistema bifásico ar-água, a fração de vazios $(\varnothing)$ neste estudo foi entendida como segue na Equação 4.8.

$\emptyset=1-\left(\operatorname{Vol}_{b} * C_{b}\right)$

A cada posição $(i, j)$ da malha foi calculado um valor para a fração de vazios $(\emptyset)$, segundo o volume da bolha $\left(V o l_{b}\right)$ e a concentração de bolhas na mesma posição. Caso o espaço tenha sido preenchido somente com líquido, o valor de $\emptyset$ foi igual a 1 .

Para simplificação dos cálculos, o volume de uma bolha foi calculado considerando uma bolha esférica de diâmetro médio de $0,005 \mathrm{~m}$.

\subsubsection{Concentração Média de Oxigênio Dissolvido}

Para calcular a concentração de oxigênio dissolvido na água foi inserida no modelo a Equação 4.9, baseada na Equação 3.7 do item 3.4.

$\frac{\partial \emptyset C_{O D}}{\partial t}+V_{x} \frac{\partial \emptyset C_{O D}}{\partial x}+V_{y} \frac{\partial \emptyset C_{O D}}{\partial y}=\frac{\partial}{\partial x}\left(D_{t_{x}} \frac{\partial \emptyset C_{O D}}{\partial x}\right)+\frac{\partial}{\partial y}\left(D_{t_{y}} \frac{\partial \emptyset C_{O D}}{\partial y}\right)+\dot{m}_{O D}$

Sendo $C_{O D}$ a concentração de oxigênio dissolvido na água $\left(\mathrm{Kg} / \mathrm{m}^{3}\right) ; t$ o tempo $(\mathrm{s}), D_{t_{x}}$ é a difusividade turbulenta do OD na direção $x\left(\mathrm{~m}^{2} / \mathrm{s}\right), D_{t}$ é a difusividade turbulenta do OD na direção $y\left(\mathrm{~m}^{2} / \mathrm{s}\right)$ e $\dot{m}_{O D}$ a descarga volumétrica que atravessa a interface da bolha por convenção de massa $\left(\mathrm{Kg} /\left(\mathrm{m}^{3} \cdot \mathrm{s}\right)\right)$.

As difusividades turbulentas serão consideradas de iguais magnitudes das viscosidades cinemáticas turbulentas $v_{t}$, de modo que a transferência de massa ocorra simultaneamente com movimento do fluido.

O número de Schmidt $(S c)$ representa a razão entre a difusão de momento e a difusão de massa (Equação 4.10).

$S c=\frac{v}{D}$

Sendo $v$ a viscosidade cinemática do fluido $\left(\mathrm{m}^{2} / \mathrm{s}\right)$ e $D$ a difusividade $\left(\mathrm{m}^{2} / \mathrm{s}\right)$. 
Ao considerar o número de $S c=1$, por hipótese, $D_{t_{x}}=v_{t_{x}}$ e $D_{t_{y}}=v_{t_{y}}$.

\subsubsection{Descarga Volumétrica}

A taxa $\dot{m}_{O D}$ é quantificada pela Equação 4.11 constituinte da convecção de massa.

$\dot{m}_{O D}=k_{L} \cdot a \cdot\left(C_{O D S}-C_{O D}\right)$

Sendo $C_{O D S}$ a concentração de oxigênio dissolvido junto à superfície da bolha, assume-se o valor de saturação nesta região, junto à interface, em certa temperatura $\left(\mathrm{Kg} / \mathrm{m}^{3}\right)$.

Com relação à concentração de saturação do $\mathrm{OD}, C_{O D S}$, ela é uma propriedade termodinâmica do sistema binário oxigênio-água e varia com a temperatura. Para a temperatura ambiente de aproximadamente $27^{\circ} \mathrm{C}$ tem-se uma concentração próxima de 8mg/L. A área superficial da interface gás-líquido presente no volume diferencial é a superfície total das bolhas no volume em questão $\left(\mathrm{m}^{2}\right)$.

Usualmente, o produto $K_{L} a$ pode ser predito por correlações empíricas, assim como o valor de $K_{L}$. Também é típico associar esse parâmetro ao número de Sherwood $(S h)$, encontrado em diversas equações. Painmanakul et al. (2009), por exemplo, apresentam diversas correlações da literatura, mas correlacionam melhor os dados nas Equações de Higbie (Teoria da Penetração) (Equação 4.12), Frossling (Equação 4.13) e a Equação 4.5 de Hikita (1981) analisada por Vuitik (2013).

$$
\begin{aligned}
& K_{L}=2 \sqrt{\frac{D_{O D} \cdot V_{b}}{\pi \cdot y}} \\
& K_{L}=\frac{D_{O D}}{d_{b}}\left(2+0,6 \operatorname{Re}^{1 / 2 S C} C^{1 / 3}\right)
\end{aligned}
$$

Sendo $d_{b}$ o diâmetro da bolha (m); Re o número de Reynolds e $S c$ o número de Schimdt.

\subsection{Discretizações}

Para calcular a solução das equações governantes e implementá-las no software MATLAB foi necessário discretizar a região (domínio) computacional e as equações, ou seja, 
dividi-las em pontos, pois não se pode obter soluções numéricas sobre uma região contínua com infinitos pontos. Somente nestes pontos numéricos as soluções foram obtidas, e ao conjunto de pontos dá-se o nome de "malha" (Figura 6). O resultado numérico obtido será mais fiel ao modelo, quanto mais "fina" for a malha, ou seja, quanto maior for o número de pontos discretos. (FORTUNA, 2000)

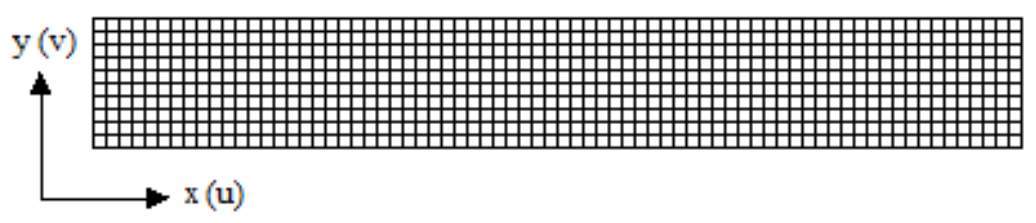

Figura 6 - Malha computacional, $i$ varia de 1 até 10 e $j$ varia de 1 até 72.

A malha computacional deste trabalho (Figura 6) apresenta dimensão $(i, j)$, onde $i$ representa o número de linhas do eixo $y$ e varia de 1 à $N Y$, sendo $N Y=10$ e $j$ representa o número de linhas do eixo $x$ e varia de 1 à $N X$, sendo $N X=72$.

\subsubsection{Concentração de Bolhas}

A $C_{b}$ foi armazenada no centro da célula discreta de acordo com a Figura 7.

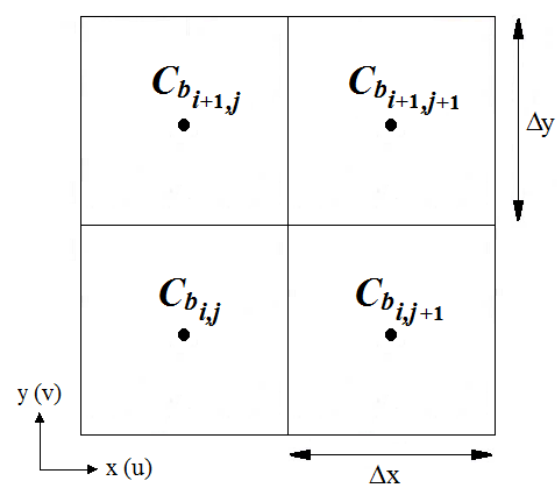

Figura 7 - Malha discretizada para o cálculo da concentração de bolhas.

A concentração de bolhas foi calculada para cada ponto discreto da malha, primeiramente, em relação ao primeiro injetor. Em seguida para cada ponto discreto da malha novamente, porém, para a posição do segundo injetor, e assim sucessivamente até o último bico injetor de oxigênio. As concentrações foram sobrepostas de acordo com a Figura 8. 


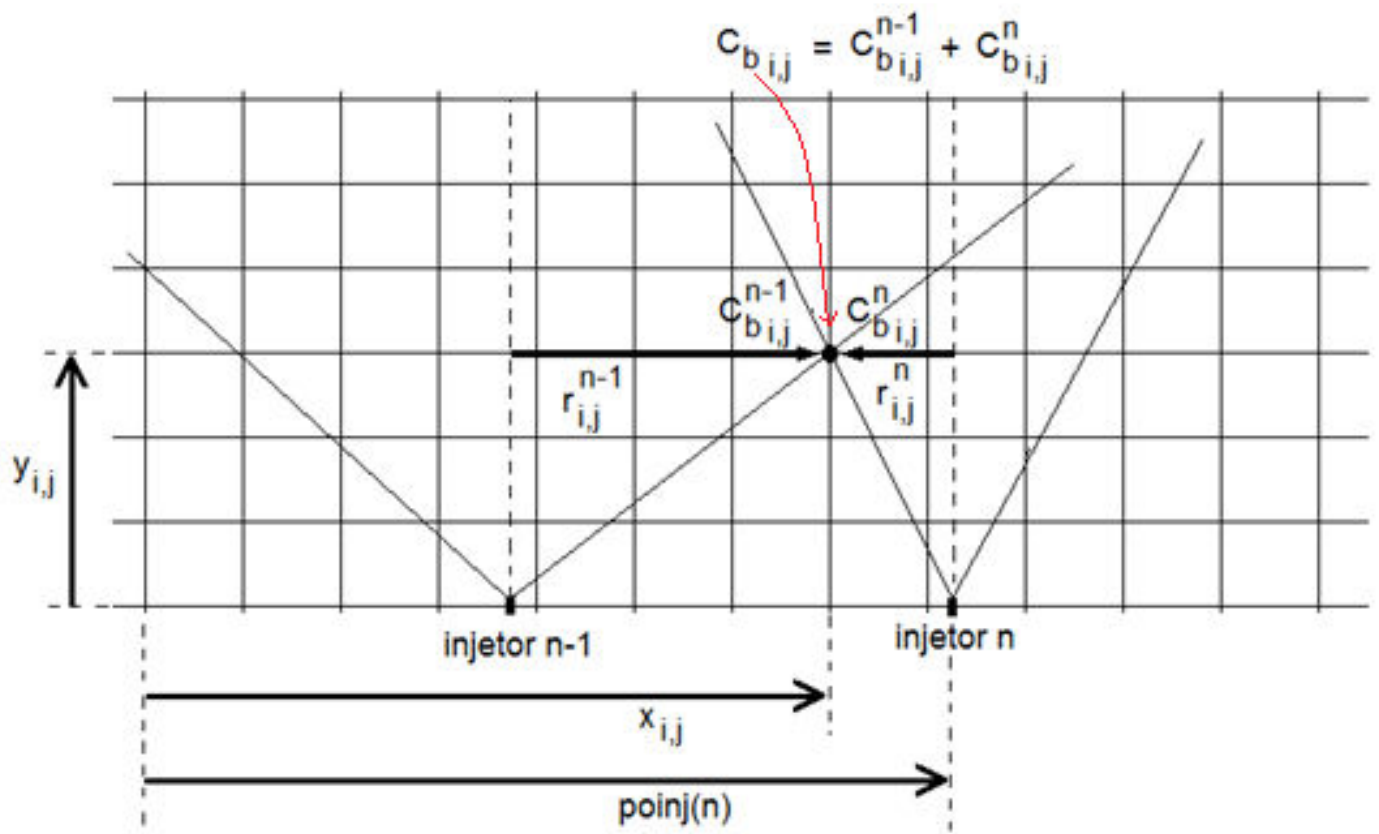

Figura 8 - Observação do raio da pluma com relação ao ponto $i, j$ e superposição de efeitos dos bicos injetores. Fonte: Arquivo pessoal.

Com a introdução da medida do raio para um ponto discreto situado em $x_{i j}$ (e $\left.y_{i j}\right)$ a partir da linha de posição do $n$-ésimo bico injetor $\operatorname{poinj(n)}$ conforme Figura 8 , tem-se a Equação 4.14 .

$r_{i, j}^{n}=\left|\operatorname{poinj}(n)-x_{i, j}\right|$

Sendo $\operatorname{poinj}(n)$ a posição do bico injetor de gás dentro do tanque (m) e $x$ a distância do local onde se deseja encontrar a $C_{b}$.

Após a substituição da Equação 4.14 na Equação 4.3 obtém-se a Equação 4.15.

$C_{b_{i, j}}^{n}=\frac{n_{b}}{\left(4 \cdot \pi \cdot D_{\text {bolha }} \cdot \frac{y_{i, j}}{V_{b}}\right)^{3 / 2}} \cdot \exp \left(-\frac{\left|\operatorname{poinj}(n)-x_{i, j}\right|}{4 \cdot D_{b o l h a} \cdot \frac{y_{i, j}}{V_{b}}}\right)$

Esta Equação 4.15 permite calcular de antemão o perfil estacionário de distribuição de bolhas, $C_{b}$, para o sistema de aeração.

De acordo com o esquema suposto na Figura 8, para obter a concentração de bolhas $C_{b}$ total, faz-se o somatório das contribuições de cada bico injetor (Equação 4.16). 
$C_{b_{i, j}}=\sum_{n-1}^{N_{i n j}} C_{b_{i, j}}^{n}$

Sendo $N_{i n j}$ o número de injetores existentes no tanque.

Dessa forma, a equação representa o perfil radial de espalhamento das bolhas a uma dada altura (Figura 4). Com esse perfil é possível quantificar a área interfacial de troca de oxigênio entre bolha e água em uma dada célula da malha discretizada representativa do meio.

\subsubsection{Velocidades do Meio Líquido}

As velocidades no meio fluido foram calculadas por meio do MDF e do MAC apresentado em Fortuna (2000).

Para realizar o cálculo das Equações de N-S (Equações 3.8 à 3.10), as incógnitas $u, v$ e $p$ são distribuídas em malha deslocada (Figura 9) de forma que elas não fiquem nas mesmas posições. Isso evita a formação de conjuntos desacoplados de equações que pode levar a erros grosseiros. É usual colocar a pressão $p$ no centro da célula e $u$ e $v$ nas faces. A pressão $p$ fica no centro da célula, a componente $u$ da velocidade fica na direção $x$ nas faces laterais, que distam $\pm \Delta x / 2$ do centro e a componente $v$ da velocidade na direção $y$ nas faces superior e inferior, que distam $\pm \Delta y / 2$ do centro.

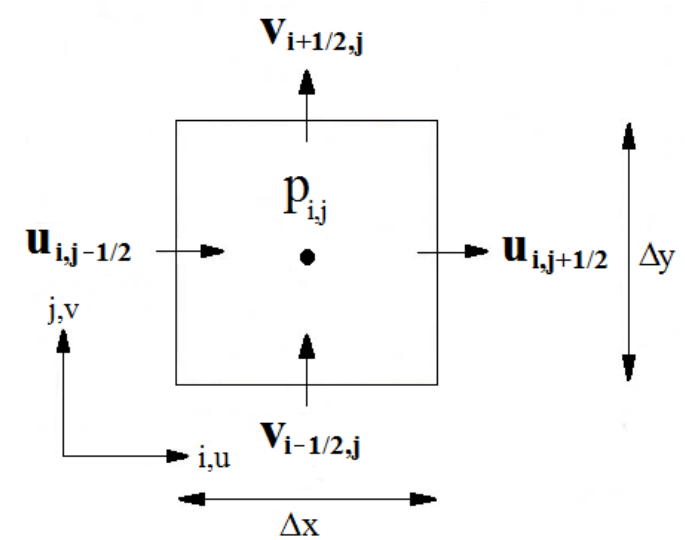

Figura 9 - Célula da malha deslocada. A pressão é armazenada no centro, enquanto que as velocidades são armazenadas nas faces.

As Equações de N-S (Equações 4.17 e 4.18$)$ em $x$ são discretizadas em $\left(i, j+\frac{1}{2}\right)$ e em $y$, em $\left(i+\frac{1}{2}, j\right)$ 
$\frac{\partial u}{\partial t}+\frac{\partial u^{2}}{\partial x}+\frac{\partial(u v)}{\partial y}=-\frac{1}{\rho} \frac{\partial p}{\partial x}+v\left(\frac{\partial^{2} u}{\partial x^{2}}+\frac{\partial^{2} u}{\partial y^{2}}\right)$

$\frac{\partial v}{\partial t}+\frac{\partial v^{2}}{\partial y}+\frac{\partial(u v)}{\partial x}=-\frac{1}{\rho} \frac{\partial p}{\partial y}+v\left(\frac{\partial^{2} v}{\partial x^{2}}+\frac{\partial^{2} v}{\partial y^{2}}\right)$

\subsubsection{Equação de momento na direção $x$}

Seguem abaixo as discretizações realizadas para a equação de momento na direção $x$ (Equação 4.17).

\subsection{Discretização Temporal}

A derivada temporal da equação de N-S na direção $x$ é discretizada de acordo com a Equação 4.19 .

$\left.\frac{\partial u}{\partial t}\right|_{i, j+1 / 2}=\frac{u_{i, j+1 / 2}^{n+1}-u_{i, j+1 / 2}^{n}}{\Delta t}$

\subsection{Aproximação dos termos convectivos}

Os termos convectivos foram discretizados utilizando diferenças centrais de segunda ordem (Equações 4.20 e 4.21) e estão representados na Figura 10.

$\left.\frac{\partial u^{2}}{\partial x}\right|_{i, j+1 / 2} \cong \frac{u^{2}{ }_{i, j+1}-u^{2}{ }_{i, j}}{\Delta x}$

$\left.\frac{\partial(u v)}{\partial y}\right|_{i, j+1 / 2} \cong \frac{(u v)_{i-1 / 2, j+1 / 2}-(u v)_{i+1 / 2, j+1 / 2}}{\Delta y}$ 


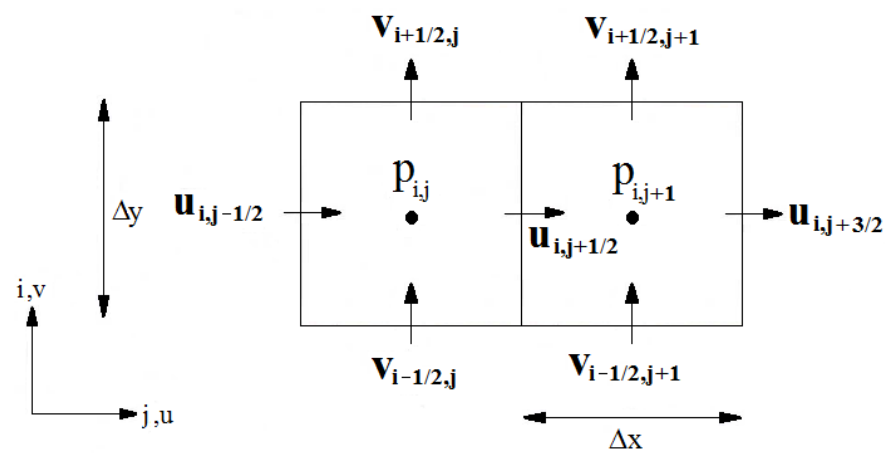

Figura 10 - A discretização das derivadas presentes na equação de momento na direção $x$ é feita no ponto $(i, j+1 / 2)$.

Porém termos $u_{i, j+1}^{2}, u_{i, j}^{2}, u v_{i-1 / 2, j+1 / 2}$ e $u v_{i+1 / 2, j+1 / 2}$, não estão definidos nas células e as parcelas convectivas podem ser reescritas conforme Equações 4.22 e 4.23.

$\frac{\partial u^{2}}{\partial x}=u \frac{\partial u}{\partial x}$

$\frac{\partial(u v)}{\partial y}=v \frac{\partial u}{\partial y}$

No entanto $u$ e $v$ são velocidades de convecção conhecidas pela média e $\frac{\partial u}{\partial x}$ e $\frac{\partial u}{\partial y}$ são propriedades de transporte, as quais precisam ser interpoladas. Desta forma têm-se as Equações 4.24 e 4.25 .

$\left.\frac{\partial u^{2}}{\partial x}\right|_{i, j+1 / 2} \cong \frac{\bar{u}_{i, j+1} \cdot u_{i, j+1}-\bar{u}_{i, j} \cdot u_{i, j}}{\Delta x}$

$\left.\frac{\partial(u v)}{\partial y}\right|_{i, j+1 / 2} \cong \frac{\bar{v}_{i+1 / 2, j+1 / 2} \cdot u_{i+1 / 2, j+1 / 2}-\bar{v}_{i-1 / 2, j+1 / 2} \cdot u_{i-1 / 2, j+1 / 2}}{\Delta y}$

Os valores $\bar{v}$ e $\bar{u}$ são médias dos pontos vizinhos, definidos nas faces, definidas pelas Equações 4.26 à 4.29 .

$\bar{u}_{i, j+1}=\frac{u_{i, j+3 / 2}+u_{i, j+1 / 2}}{2}$ 
$\bar{u}_{i, j}=\frac{u_{i, j+1 / 2}+u_{i, j-1 / 2}}{2}$

$\bar{v}_{i+1 / 2, j+1 / 2}=\frac{v_{i+1 / 2, j}+v_{i+1 / 2, j+1}}{2}$

$\bar{v}_{i-1 / 2, j+1 / 2}=\frac{v_{i-1 / 2, j}+v_{i-1 / 2, j+1}}{2}$

As velocidades transportadas $u$ são obtidas por interpolação. A direção local do escoamento é muito importante em determinado ponto $(i, j)$ da malha, pois isto reflete o comportamento que o escoamento tem à montante deste ponto, bem como as propriedades transportadas para este ponto.

O método utilizado para obter esta velocidade transportada é o método Híbrido, que combina o método Upwind e o método das Diferenças Centrais.

O método Upwind de discretização determina que a aproximação da derivada espacial dependa da direção de propagação das características, ou seja, a propriedade em um ponto $\mathrm{P}$ qualquer depende fortemente das características transportadas de pontos à montante de $\mathrm{P}$. Desta forma, o método Upwind verifica a direção do fluxo médio e atribui uma função sinal (Equação 4.32) para determinar esta direção. As equações 4.30 e 4.31 verificam essas direções e a Equação 4.33 calcula a velocidade interpolada.

$u_{i, j}=\left\{\begin{array}{l}u_{i, j+1 / 2} \text { se } \bar{u}_{i, j}<0 \\ u_{i, j-1 / 2} \text { se } \bar{u}_{i, j} \geq 0\end{array}\right.$

$u_{i, j+1}=\left\{\begin{array}{l}u_{i, j+3 / 2} \text { se } \bar{u}_{i, j+1}<0 \\ u_{i, j+1 / 2} \text { se } \bar{u}_{i, j+1} \geq 0\end{array}\right.$

$S_{j}=\left\{\begin{array}{c}1 \text { se } \bar{u}_{i, j} \geq 0 \\ -1 \text { se } \bar{u}_{i, j}<0\end{array}\right.$

$u_{i, j}=\left[\frac{1+s_{j}}{2}\right] u_{i, j-1 / 2}+\left[\frac{1-s_{j}}{2}\right] u_{i, j+1 / 2}$

O esquema Upwind não é recomendado, em geral, pois apresenta problemas práticos por gerar uma forte difusão numérica na solução. 
$\mathrm{O}$ número de Péclet $(\mathrm{Pe})$ mede a razão entre as intensidades dos processos de convecção e difusão (Equação 4.34). Quanto maior o número de $P e$, maior a intensidade da convecção. O método de discretização por Diferenças Centrais pode originar soluções oscilatórias quando o número de $P e$ é maior do que 2, porém quando $P e<2$, gera-se bons resultados.

$P e_{i, j}=\frac{\left|\bar{u}_{i, j}\right| \cdot \Delta x}{v}($ Péclet $)$

Caso o $P e$ tenha sido menor que dois, a velocidade transportada $u_{i, j}$ manteve-se igual a $\bar{u}_{i, j}$ (Equação 4.35).

$u_{i, j}=\bar{u}_{i, j}, \quad$ se $P e_{i, j}<2$

O método utilizado no presente estudo, Híbrido, agrupa a precisão nas regiões do escoamento por Diferenças Centrais onde $P e_{i, j}<2$ e Upwind para $P e_{i, j} \geq 2$. A transição de um para outro deve ser suave, para isso utiliza-se a Equação 4.36.

$u_{i, j}=\underbrace{\left(1-F P_{j}\right) u_{i, j}}_{\text {Diferenças Centrais }}+\underbrace{F P_{j} u_{i, j}}_{\text {Upwind }}$

Sendo FP uma função apresentada por Wesseling (1992), calculada pela Equação 4.37.

$F P_{j}=\left\{\begin{array}{c}0, \text { se } P e_{i, j}<1,9 \\ \frac{P e_{i, j}-1,9}{0,1}, \quad \text { se } 1,9 \leq P e_{i, j}<2 \\ 1, \text { se } P e_{i, j} \geq 2\end{array}\right.$

Ao somarem-se os termos convectivos, tem-se $C O N V$ discretizado no nível de tempo $n$ (Equação 4.38).

$\operatorname{CONV}_{i, j+1 / 2}^{n}=\frac{\left(u^{2}\right)_{i, j+1}^{n}-\left(u^{2}\right)_{i, j}^{n}}{\Delta x}+\frac{(u v)_{i-1 / 2, j+1 / 2}^{n}-(u v)_{i+1 / 2, j+1 / 2}^{n}}{\Delta y}$ 


\subsection{Cálculo dos termos viscosos}

Os termos viscosos da Equação 4.17, também são discretizados em malha deslocada e estão apresentados nas Equações 4.39 e 4.40.

$$
\begin{aligned}
& \left.\frac{\partial^{2} u}{\partial x^{2}}\right|_{i, j+1 / 2} \cong \frac{u_{i, j-1 / 2}-2 u_{i, j+1 / 2}+u_{i, j+3 / 2}}{\left(\Delta x^{2}\right)} \\
& \left.\frac{\partial^{2} u}{\partial y^{2}}\right|_{i, j+1 / 2} \cong \frac{u_{i-1, j+1 / 2}-2 u_{i, j+1 / 2}+u_{i+1, j+1 / 2}}{\left(\Delta y^{2}\right)}
\end{aligned}
$$

Todos os termos acima estão definidos na malha e não precisam ser interpolados.

Ao somarem-se os termos viscosos, tem-se VISC discretizado no nível de tempo $n$ (Equação 4.41).

$$
\begin{aligned}
\operatorname{VISC}_{i, j+1 / 2}^{n}= & v \frac{u_{i, j-1 / 2}^{n}-2 u_{i, j+1 / 2}^{n}+u_{i, j+3 / 2}^{n}}{\left(\Delta x^{2}\right)} \\
& +v \frac{u_{i-1, j+1 / 2}^{n}-2 u_{i, j+1 / 2}^{n}+u_{i+1, j+1 / 2}^{n}}{\left(\Delta y^{2}\right)}
\end{aligned}
$$

\subsection{Cálculo da pressão}

A equação de Poisson discretizada também relaciona valores de $p$ adjacentes entre si. e sua aproximação é descrita na Equação 4.42 .

$\left.\frac{\partial p}{\partial x}\right|_{i, j+1 / 2}=\frac{p_{i, j+1}-p_{i, j}}{\Delta x}$

Após a discretização de todos estes termos, a versão discreta da Equação 4.17 pode ser reescrita pela Equação 4.43:

$\frac{u_{i, j+1 / 2}^{n+1}-u_{i, j+1 / 2}^{n}}{\Delta t}+\operatorname{CON} V_{i, j+1 / 2}^{n}=-\frac{1}{\rho} \frac{p_{i, j+1}^{n}-p_{i, j}^{n}}{\Delta x}+V I S C_{i, j+1 / 2}^{n}$

Ao rearranjar os termos, foi obtida a Equação 4.44 . 
$u_{i, j+1 / 2}^{n+1}=u_{i, j+1 / 2}^{n}-\frac{\Delta t}{\rho} \frac{p_{i, j+1}^{n}-p_{i, j}^{n}}{\Delta x}+\Delta t\left(-\operatorname{CON} V_{i, j+1 / 2}^{n}+V I S C_{i, j+1 / 2}^{n}\right)$

Por conveniência, foi definido $F_{i, j+1 / 2}^{n}$ como sendo a soma dos termos convectivos, viscosos e da velocidade $u_{i, j+1 / 2}^{n}$ (Equação 4.45).

$F_{i, j+1 / 2}^{n}=u_{i, j+1 / 2}^{n}+\Delta t\left(-\operatorname{CONV}_{i, j+1 / 2}^{n}+\operatorname{VISC} C_{i, j+1 / 2}^{n}\right)$

A Equação 4.44 foi reescrita conforme Equação 4.46.

$u_{i, j+1 / 2}^{n+1}=F_{i, j+1 / 2}^{n}-\frac{\Delta t}{\rho} \frac{p_{i, j+1}^{n}-p_{i, j}^{n}}{\Delta x}$

\subsubsection{Equação de momento na direção $y$}

Analogamente obteve-se a discretização da equação de momento na direção $y$ (Equação 4.18) na posição $(i+1 / 2, j)$.

\subsection{Discretização temporal}

A derivada temporal da equação de N-S na direção $y$ é discretizada de acordo com a Equação 4.47

$\left.\frac{\partial v}{\partial t}\right|_{i+1 / 2, j}=\frac{v_{i+1 / 2, j}^{n+1}-v_{i+1 / 2, j}^{n}}{\Delta t}$

\subsection{Aproximação dos termos convectivos}

Os termos convectivos foram discretizados utilizando diferenças centrais de segunda ordem (Equações 4.48 e 4.49) e estão representados na Figura 11.

$\left.\frac{\partial v^{2}}{\partial y}\right|_{i+1 / 2, j} \cong \frac{v_{i+1, j}^{2}-v_{i, j}^{2}}{\Delta x}$

$\left.\frac{\partial(u v)}{\partial x}\right|_{i+1 / 2, j} \cong \frac{(u v)_{i+1 / 2, j+1 / 2}-(u v)_{i+1 / 2, j-1 / 2}}{\Delta x}$ 


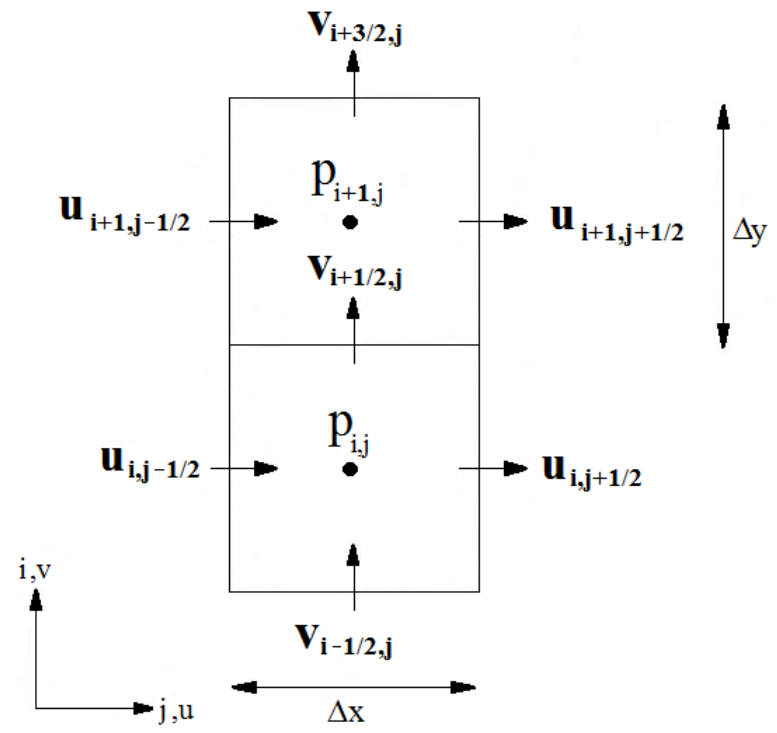

Figura 11 - A discretização das derivadas presentes na equação de momento na direção $y$ é feita no ponto $(i+1 / 2, j)$.

Porém os termos $v_{i+1, j}^{2}, v_{i, j}^{2}, u v_{i+1 / 2, j+1 / 2}$ e $u v_{i+1 / 2, j-1 / 2}$, não estão definidos nas células e as parcelas convectivas podem ser reescritas conforme Equações 4.50 e 4.51 .

$\frac{\partial v^{2}}{\partial y}=v \frac{\partial v}{\partial y}$

$\frac{\partial(u v)}{\partial x}=u \frac{\partial v}{\partial x}$

No entanto $u$ e $v$ são velocidades de convecção conhecidas pela média e $\frac{\partial v}{\partial y}$ e $\frac{\partial v}{\partial x}$ são propriedades de transporte, as quais precisam ser interpoladas. Desta forma têm-se as Equações 4.52 e 4.53.

$\left.\frac{\partial v^{2}}{\partial y}\right|_{i+1 / 2, j} \cong \frac{\bar{v}_{i+1, j} \cdot v_{i+1, j}-\bar{v}_{i, j} \cdot v_{i, j}}{\Delta y}$

$\left.\frac{\partial(u v)}{\partial x}\right|_{i+1 / 2, j} \cong \frac{\bar{u}_{i+1 / 2, j+1 / 2} \cdot v_{i+1 / 2, j+1 / 2}-\bar{u}_{i+1 / 2, j-1 / 2} \cdot v_{i+1 / 2, j-1 / 2}}{\Delta x}$

Os valores $\bar{v}$ e $\bar{u}$ são médias dos pontos vizinhos definidos nas faces, definidas pelas Equações 4.54 à 4.57. 
$\bar{v}_{i+1, j}=\frac{v_{i+3 / 2, j}+v_{i+1 / 2, j}}{2}$

$\bar{v}_{i, j}=\frac{v_{i+1 / 2, j}+v_{i-1 / 2, j}}{2}$

$\bar{u}_{i+1 / 2, j+1 / 2}=\frac{u_{i+1, j+1 / 2}+u_{i, j+1 / 2}}{2}$

$\bar{u}_{i+1 / 2, j-1 / 2}=\frac{v_{i+1 / 2, j}+v_{i+1 / 2, j+1}}{2}$

As velocidades transportadas $v$ são obtidas por interpolação. O método utilizado para obter esta velocidade transportada também foi o método Híbrido.

O cálculo do método Upwind é apresentado nas Equações 4.58 à 4.61.

$v_{i, j}=\left\{\begin{array}{l}u_{i+1 / 2, j} \text { se } \bar{u}_{i, j}<0 \\ u_{i-1 / 2, j} \text { se } \bar{u}_{i, j} \geq 0\end{array}\right.$

$v_{i+1, j}=\left\{\begin{array}{l}u_{i+3 / 2, j} \text { se } \bar{u}_{i+1, j}<0 \\ u_{i+1 / 2, j} \text { se } \bar{u}_{i+1, j} \geq 0\end{array}\right.$

$S_{i}=\left\{\begin{array}{c}1 \text { se } \bar{v}_{i, j} \geq 0 \\ -1 \text { se } v_{i, j}<0\end{array}\right.$

$v_{i, j}=\left[\frac{1+s_{i}}{2}\right] u_{i-1 / 2, j}+\left[\frac{1-s_{i}}{2}\right] u_{i+1 / 2, j}$

O método de discretização por Diferenças Centrais é apresentado nas Equações 4.62 e 4.63 .

$P e_{i, j}=\frac{\left|\bar{v}_{i, j}\right| \cdot \Delta y}{v}($ Péclet $)$

$v_{i, j}=\bar{v}_{i, j}, \quad$ se $P e_{i, j}<2$

O método Híbrido para a direção y está descrito nas Equações 4.64 e 4.65. 
$v_{i, j}=\underbrace{\left(1-F P_{i}\right) v_{i, j}}_{\text {Diferenças Centrais }}+\underbrace{F P_{i} v_{i, j}}_{\text {Upwind }}$

FP é calculada pela Equação 4.65.

$F P_{i}=\left\{\begin{array}{c}0, \text { se } P e_{i, j}<1,9 \\ \frac{P e_{i, j}-1,9}{0,1}, \quad \text { se } 1,9 \leq P e_{i, j}<2 \\ 1, \text { se } P e_{i, j} \geq 2\end{array}\right.$

Ao somarem-se os termos convectivos, tem-se CONV discretizado no nível de tempo $n$ (Equação 4.66).

$\operatorname{CONV}_{i+1 / 2, j}^{n}=\frac{\left(v^{2}\right)_{i+1, j}^{n}-\left(v^{2}\right)_{i, j}^{n}}{\Delta y}+\frac{(u v)_{i+1 / 2, j+1 / 2}^{n}-(u v)_{i+1 / 2, j-1 / 2}^{n}}{\Delta x}$

\subsection{Cálculo dos termos viscosos}

Os termos viscosos da Equação 4.18, também são discretizados em malha deslocada e estão apresentados nas Equações 4.67 e 4.68.

$\left.\frac{\partial^{2} v}{\partial y^{2}}\right|_{i+1 / 2, j} \cong \frac{v_{i-1 / 2, j}-2 v_{i+1 / 2, j}+v_{i+3 / 2, j}}{\left(\Delta y^{2}\right)}$

$\left.\frac{\partial^{2} v}{\partial x^{2}}\right|_{i+1 / 2, j} \cong \frac{v_{i+1 / 2, j-1}-2 v_{i+1 / 2, j}+v_{i+1 / 2, j+1}}{\left(\Delta x^{2}\right)}$

Todos os termos acima estão definidos na malha e não precisam ser interpolados.

Ao somarem-se os termos viscosos, tem-se VISC discretizado no nível de tempo $n$ (Equação 4.69).

$$
\begin{aligned}
V I S C_{i+1 / 2, j}^{n}= & v \frac{v_{i-1 / 2, j}-2 v_{i+1 / 2, j}+v_{i+3 / 2, j}}{\left(\Delta y^{2}\right)} \\
& +v \frac{v_{i+1 / 2, j-1}-2 v_{i+1 / 2, j}+v_{i+1 / 2, j+1}}{\left(\Delta x^{2}\right)}
\end{aligned}
$$




\subsection{Cálculo da pressão}

A equação de Poisson discretizada também relaciona valores de $p$ adjacentes entre si. e sua aproximação é descrita na Equação 4.70.

$\left.\frac{\partial p}{\partial y}\right|_{i+1 / 2, j}=\frac{p_{i+1, j}-p_{i, j}}{\Delta y}$

Após a discretização de todos estes termos, a versão discreta da Equação 4.18 pode ser reescrita pela Equação 4.71:

$\frac{v_{i+1 / 2, j}^{n+1}-v_{i+1 / 2, j}^{n}}{\Delta t}+\operatorname{CONV}_{i+1 / 2, j}^{n}=-\frac{1}{\rho} \frac{p_{i+1, j}^{n}-p_{i, j}^{n}}{\Delta y}+\operatorname{VISC}_{i+1 / 2, j}^{n}$

Ao rearranjar os termos, foi obtida a Equação 4.72.

$v_{i+1 / 2, j}^{n+1}=v_{i+1 / 2, j}^{n}-\frac{\Delta t}{\rho} \frac{p_{i+1, j}^{n}-p_{i, j}^{n}}{\Delta y}+\Delta t\left(-\operatorname{CONV}_{i+1 / 2, j}^{n}+V I S C_{i+1 / 2, j}^{n}\right)$

Por conveniência, foi definido $G_{i+1 / 2, j}^{n}$ como sendo a soma dos termos convectivos, viscosos e da velocidade $v_{i+1 / 2, j}^{n}$ (Equação 4.73).

$G_{i+1 / 2, j}^{n}=v_{i+1 / 2, j}^{n}+\Delta t\left(-\operatorname{CONV}_{i+1 / 2, j}^{n}+\operatorname{VIS} C_{i+1 / 2, j}^{n}\right)$

A Equação 4.72 foi reescrita conforme Equação 4.74.

$v_{i+1 / 2, j}^{n+1}=G_{i+1 / 2, j}^{n}-\frac{\Delta t}{\rho} \frac{p_{i+1, j}^{n}-p_{i, j}^{n}}{\Delta y}$

\subsection{Equação da Continuidade}

A equação da continuidade (Equações 4.75 e 4.76) na célula de Diferenças Finitas foi discretizada no ponto $(i, j)$ e utilizando diferenças centrais de segunda ordem (Equação 4.77). 
$\frac{\partial(\text { Eq.Navier }- \text { Stokes em } x)}{\partial x}+\frac{\partial(\text { Eq. Navier }- \text { Stokes em } y)}{\partial y}=0$

$\frac{\partial u}{\partial x}+\frac{\partial v}{\partial y}=0$

$\left.\frac{\partial u}{\partial x}\right|_{i, j}+\left.\frac{\partial v}{\partial y}\right|_{i, j}=\frac{u_{i, j+1 / 2}-u_{i, j-1 / 2}}{\Delta x}+\frac{v_{i+1 / 2, j}-v_{i-1 / 2, j}}{\Delta y}$

\subsubsection{Equação de Poisson}

A função da pressão no escoamento incompressível é fazer com que o campo de velocidades satisfaça a equação da continuidade. É a Equação de Poisson que faz a ligação entre as equações de momento e da continuidade (FORTUNA, 2000).

A equação de Poisson foi construída substituindo na Equação 4.77 as Equações 4.46 e 4.74, além das equações correspondentes $u_{i, j-1 / 2}^{n+1} e v_{i-1 / 2, j}^{n+1}$. Ao fazer estas substituições foi obtida a Equação 4.78 .

$$
\begin{aligned}
\frac{p_{i, j+1}^{n+1}-2 p_{i, j}^{n+1}+}{(\Delta x)^{2}} & p_{i, j-1}^{n+1}+\frac{p_{i+1, j}^{n+1}-p_{i, j}^{n+1}+p_{i-1, j}^{n+1}}{(\Delta y)^{2}} \\
= & \frac{\rho}{\Delta t}\left[\left(\frac{F_{i, j+1 / 2}^{n}-F_{i, j-1 / 2}^{n}}{\Delta x}\right)+\left(\frac{G_{1+1 / 2, j}^{n}-G_{i-1 / 2, j}^{n}}{\Delta y}\right)\right]
\end{aligned}
$$

Para resolução da pressão no nível de tempo $n+1$ foi utilizado o método iterativo Successive Over-relaxation ou Sobre-relaxação Sucessiva - SOR. O método é baseado no método de Gauss-Seidel. As diferenças entre as sucessivas aproximações diminuem e faz com que o método necessite de muitas iterações para obter uma boa solução. Com o SOR pode-se reduzir o número de iterações extrapolando o valor de $p^{n+1}$ de tal forma que ela se aproxime mais rapidamente da solução numérica.

\subsubsection{Estabilidade}

O critério da estabilidade no método MAC apresenta apenas condições necessárias para a estabilidade das equações não lineares originais. Griebel, Dornseifer e Neunhoeffer (1998), Hirt (1979) e Hirt, Nichols e Romero (1975) apresentam os critérios apresentados nas Equações 4.79 e 4.80. 
$\Delta t_{1}<\min \left(\frac{\Delta x}{|u|_{\max }}, \frac{\Delta y}{|v|_{\max }}\right)$

$\Delta t_{2}<\frac{1}{2 v}\left(\frac{1}{(\Delta x)^{2}}+\frac{1}{(\Delta y)^{2}}\right)^{-1}$

O fluido não pode percorrer uma distância maior que o comprimento de uma célula a cada passo no tempo. Logo, o critério generalizado será conforme Equação 4.81

$\Delta t=c \cdot \min \left(\Delta t_{1}, \Delta t_{2}\right)$

Sendo $c$ o fator de segurança, $0<c \leq 1$.

\subsubsection{Concentração de oxigênio dissolvido}

A principal parte do modelo se baseia na Equação 4.9. O método será o tradicional baseado em Diferenças Finitas com a técnica de Crank-Nicolson, muito usada no equacionamento da parcela transiente. O método implícito de Crank-Nicolson consiste em avaliar a EDP, aproximando a derivada temporal por diferença central e a derivada espacial pela média das diferenças centrais nos níveis de tempo.

Para proceder conforme estabelecido, reescreve-se a Equação 4.9 como segue na Equação 4.82 .

$\frac{\partial \phi C_{O D}}{\partial t}=-V_{x} \frac{\partial \phi C_{O D}}{\partial x}-V_{y} \frac{\partial \phi C_{O D}}{\partial y}+\frac{\partial}{\partial x}\left(D_{t x} \frac{\partial \phi C_{O D}}{\partial x}\right)+\frac{\partial}{\partial y}\left(D_{t y} \frac{\partial \phi C_{O D}}{\partial y}\right)+\dot{m}_{O D}$

Substituindo o segundo membro igualdade da Equação 4.82 por " $E q$ ”, tem-se a Equação 4.83 .

$\frac{\partial \phi C_{O D}}{\partial t}=E q$

Por meio da técnica de Crank-Nicolson com diferença centrada em $k+1 / 2$, a Equação 4.83 pode ser escrita conforme a Equação 4.84. 
$\left.\frac{\partial \phi C_{O D}}{\partial t}\right|_{i, j} ^{k+1 / 2}=\frac{\left(\phi C_{O D}\right)_{i, j}^{k+1}-\left(\phi C_{O D}\right)_{i, j}^{k}}{\Delta t}=\frac{E q_{i, j}^{k+1}+E q_{i, j}^{k}}{2}$

As derivadas espaciais da $C_{O D}$ são discretizadas de acordo com as Equações 4.85 a 4.88 .

$\frac{\partial \phi C_{O D}}{\partial x}=\frac{\left(\phi C_{O D}\right)_{i+1, j}^{k}-\left(\phi C_{O D}\right)_{i-1, j}^{k}}{2 \Delta x}$

$\frac{\partial^{2} \phi C_{O D}}{\partial x^{2}}=\frac{\left(\phi C_{O D}\right)_{i+1, j}^{k}-2\left(\phi C_{O D}\right){ }_{i, j}^{k}+\left(\phi C_{O D}\right){ }_{i-1, j}^{k}}{(\Delta x)^{2}}$

$\frac{\partial \phi C_{O D}}{\partial y}=\frac{\left(\phi C_{O D}\right)_{i, j+1}^{k}-\left(\phi C_{O D}\right)_{i, j-1}^{k}}{2 \Delta y}$

$\frac{\partial^{2} \phi C_{O D}}{\partial y^{2}}=\frac{\left(\phi C_{O D}\right)_{i, j+1}^{k}-2\left(\phi C_{O D}\right)_{i, j}^{k}+\left(\phi C_{O D}\right)_{i, j-1}^{k}}{(\Delta y)^{2}}$

A equação para $\dot{m}_{O D}$ é descrita na Equação 4.11.

Inseridas as formas discretas das derivadas, após a substituição das Equações 4.85 à 4.78, juntamente com a 4.11 na Equação 4.84 e, posteriormente, após um rearranjo dos termos, tem-se uma equação de recursão da seguinte forma $\left(C=C_{O D}\right)$ :

$$
\begin{aligned}
\boldsymbol{\alpha} C_{i, j}^{k+1}+\boldsymbol{\beta} C_{i+1, j}^{k+1} & +\boldsymbol{\gamma} C_{i-1, j}^{k+1}+\lambda C_{i, j+1}^{k+1}+\boldsymbol{\omega} C_{i, j-1}^{k+1} \\
& =a C_{i, j}^{k}+\boldsymbol{b} C_{i+1, j}^{k}+\boldsymbol{c} C_{i-1, j}^{k}+\boldsymbol{d} C_{i, j+1}^{k}+\boldsymbol{e} C_{i, j-1}^{k}+\boldsymbol{f}
\end{aligned}
$$

Onde os coeficientes são avaliados por:

$$
\begin{aligned}
& \alpha=\left[\frac{2 \phi_{i, j}}{\Delta t}+\frac{2 D_{t x} \phi_{i, j}}{(\Delta x)^{2}}+\frac{2 D_{t y} \phi_{i, j}}{(\Delta y)^{2}}+k a_{i, j}\right] \\
& \beta=\left[\frac{V_{x} \phi_{i, j+1}}{2 \Delta x}-\frac{D_{t x} \phi_{i, j+1}}{(\Delta x)^{2}}\right]
\end{aligned}
$$


$\gamma=\left[-\frac{V_{x} \phi_{i, j-1}}{2 \Delta x}-\frac{D_{t x} \phi_{i, j-1}}{(\Delta x)^{2}}\right]$

$\lambda=\left[\frac{V_{y} \phi_{i+1, j}}{2 \Delta y}-\frac{D_{t y} \phi_{i+1, j}}{(\Delta y)^{2}}\right]$

$\omega=\left[-\frac{V_{y} \phi_{i-1, j}}{2 \Delta y}-\frac{D_{t y} \phi_{i,-1 j}}{(\Delta y)^{2}}\right]$

$A=\left[\frac{2 \phi_{i, j}}{\Delta t}-\frac{2 D_{t x} \phi_{i, j}}{(\Delta x)^{2}}-\frac{2 D_{t y} \phi_{i, j}}{(\Delta y)^{2}}-k a_{i, j}\right]$

$b=\left[-\frac{V_{x} \phi_{i, j+1}}{2 \Delta x}+\frac{D_{t x} \phi_{i, j+1}}{(\Delta x)^{2}}\right]$

$c=\left[\frac{V_{x} \phi_{i, j-1}}{2 \Delta x}+\frac{D_{t x} \phi_{i, j-1}}{(\Delta x)^{2}}\right]$

$d=\left[-\frac{V_{y} \phi_{i+1, j}}{2 \Delta y}+\frac{D_{t y} \phi_{i+1, j}}{(\Delta y)^{2}}\right]$

$e=\left[\frac{V_{y} \phi_{i-1, j}}{2 \Delta y}+\frac{D_{t y} \phi_{i-1, j}}{(\Delta y)^{2}}\right]$

$f=2 k a_{i, j} C_{O D S}$

Sendo $C_{O D S}$ a concentração de saturação do $\mathrm{OD}\left(\mathrm{Kg} / \mathrm{m}^{3}\right)$.

A técnica iterativa para resolver o sistema algébrico formado pela Equação 4.89 é o de Gauss-Seidel, pela qual se resolve recursivamente a Equação 4.101 dentro de um mesmo instante de tempo:

$C_{i, j}^{m+1}=\frac{R_{i, j}^{m}-\left(\beta C_{i+1, j}^{m}+\gamma C_{i-1, j}^{m}+\lambda C_{i, j+1}^{m}+\omega C_{i, j-1}^{m}\right)}{\alpha}$ 
A recursão se faz para $m(m=1,2, \ldots)$ crescendo tendo cada concentração $C^{m}$ trocada pelo novo $C^{m+1}$ após cada iteração. Esse procedimento é feito até que o critério do máximo erro relativo seja satisfeito, ou seja:

$E^{m}=\frac{\max \left|C_{i, j}^{m}-C_{i, j}^{m-1}\right|}{\max \left|C_{i, j}^{m}\right|} \leq 1 \cdot 10^{-4}$

Embora a concentração de oxigênio dissolvido $\left(C\right.$ ou $\left.C_{O D}\right)$ seja afetada pelas velocidades do líquido, essas velocidades $V_{x}$ e $V_{y}$ praticamente independem de $C_{O D}$. Entretanto, $V_{x}$ e $V_{y}$ são influenciadas pela movimentação das bolhas, ou seja, são dependentes da sua concentração $C_{b}$ ou $\phi$.

\subsection{Condições de Contorno}

As condições de contorno, ao considerar um sistema retangular do tanque, são colocadas com uma entrada de água à esquerda, uma saída de água à direita, uma superfície sólida ao fundo e uma superfície livre em contato com o ar.

\section{Região de entrada (parede lateral esquerda):}

Para a região de entrada de fluido a condição de contorno para a concentração de oxigênio dissolvido é zero em toda a primeira coluna $(j=1)$ (Equação 4.103).

$C_{O D i, 1}^{k}=0$, para $i=2$ até $N Y$

As velocidades de entrada na direção $y$ para as linhas de 2 até $N Y-2$ (região de parede) são dadas conforme Equação 4.104, por serem regiões de fronteira não-escorregadia (velocidade tangencial do fluido em relação a parede é igual a zero) e poder-se aplicar a técnica da reflexão, a qual é dada pela extrapolação da reta que passa sobre os valores $v_{i, j-1}, v_{i, j}$ e $v_{i, j+1}$.

$v_{i, 1}=-v_{i, 2}$, para $i=2$ até $N Y-2$ 
Para a região de entrada de fluido $(i=N Y-2)$ a velocidade em $y$ é considerada zero até a terceira coluna (Equações 4.105 à 4.107).

$v_{N Y-2,1}=0$

$v_{N Y-2,2}=0$

$v_{N Y-2,3}=0$

A fim de introduzir o fluido no sistema as velocidades de entrada na direção $x$ foram consideradas igual a 0,1 nas primeiras 3 colunas da malha na altura $N Y-2$ (Equações 4.108 à 4.110).

$u_{N Y-2,1}=0,1$

$u_{N Y-2,2}=0,1$

$u_{N Y-2,3}=0,1$

A pressão na coluna 1 foi considerada igual a pressão na coluna 2 nesta mesma região para as linhas 2 até $N Y-1$ (Equação 4.111).

$p_{i, 1}=p_{i, 2}$, para $i=2$ até $N Y-1$

\section{Região de saída (parede lateral direita):}

Para a região de saída de fluido, a condição de contorno para a concentração de oxigênio dissolvido é igual à derivada da concentração de oxigênio dissolvido (Equação 4.112).

$\frac{\partial C_{O D}}{\partial x}=0$, para todo $y$ ou $C_{O D i, N X}^{k}=C_{O D i, N X+2}^{k}$, para $i=2$ até $N Y$ 
As velocidades de saída na direção $y$ para as linhas de 3 até $N Y-2$ (região de parede) são consideradas conforme Equação 4.113. Para região de saída de fluido (linhas 1 e 2) são consideradas igual a zero na penúltima coluna (Equações 4.114 e 4.115).

$v_{1, N X}=-v_{i, N X-1}$, para $i=3$ até $N Y-2$

$v_{1, N X-1}=0$

$v_{2, N X-1}=0$

Para a região de saída, a velocidade do fluido na direção $x(u)$ é considerada igual a zero a partir da terceira linha, região da parede do tanque, conforme (Equação 4.116). Para a região onde o fluido sai do canal - linhas 1 e 2 - as velocidades na direção x são consideradas iguais as suas velocidades no ponto discreto anterior (Equações 4.118 à 4.121).

$u_{i, N X}=0$, para $i=3$ até $N Y$

$u_{1, N X}=u_{1, N X-2}$

$u_{2, N X}=u_{2, N X-2}$

$u_{1, N X+1}=u_{1, N X}$

$u_{2, N X+1}=u_{2, N X}$

As pressões na região de saída de fluido a partir da quarta linha até a penúltima linha (região de parede) foram consideradas iguais à pressão da coluna anterior (Equação 4.121). As pressões nas linhas 2 e 3 da região de saída foram iguais as pressões da linha anterior subtraídas de aproximadamente $10 \mathrm{~Pa}$, que é relativo à diferença de pressão da altura (espessura) de lâmina de água que sai do tanque, uma vez que a água entra pelo fundo e sustenta uma coluna hidrostática maior a montante (Equações 4.122 e 4.123).

$p_{i, N X}=p_{i, N X-1}$, para $i=4$ até $N Y-1$ 
$p_{2, N X}=p_{2, N X-1}-10$

$p_{3, N X}=p_{3, N X-1}-10$

\section{Fundo (parede inferior):}

A concentração de oxigênio dissolvido em relação à $y$ é considerada zero em sua derivada a partir da segunda coluna (Equação 4.124).

$\frac{\partial C_{O D}}{\partial y}=0$, para todo $x$ ou $C_{O D_{N Y+1, j}}^{k}=C_{O D}^{k}{ }_{N Y-1, j}$, para $j=2$ até $N X$

Para o escoamento na direção $x(u)$ no fundo do canal, a técnica de reflexão também é aplicada por se tratar de região de fronteira não-escorregadia (Equação 4.125).

$u_{N Y, j}=-u_{N Y-1, j}$, para $j=3$ até $N X-1$

A pressão nesta região é considerada igual à pressão da linha anterior a partir da segunda coluna até a penúltima coluna (Equação 4.126).

$p_{N Y, j}=p_{N Y-1, j}$, para $j=2$ até $N X-1$

\section{Superfície (região superior):}

Neste trabalho desconsideraram-se os efeitos de superfície, como quebra, ondulações e transferência de oxigênio por esta interface, estudou-se somente a interação com superfície de bolhas. A concentração de oxigênio dissolvido em relação à $y$ também é considerada zero em sua derivada a partir da segunda linha (Equação 4.127).

$\frac{\partial C_{O D}}{\partial y}=0$ para todo $x$ ou $C_{O D}^{k}{ }_{1, j}^{k}=C_{O D}^{k}, j$, para $j=2$ até $N X$

As velocidades na direção $y(v)$ no contorno são consideradas iguais à velocidade da terceira linha (Equação 4.128).

$v_{1, j}=v_{3, j}$, para $j=1$ até $N X$ 
Para a direção $\mathrm{x}(\mathrm{u})$ as velocidades são consideradas iguais às velocidades da segunda linha (Equação 4.129).

$u_{1, j}=u_{2, j}$, para $j=1$ até $N X+1$

As pressões na superfície livre são consideradas iguais as pressões da segunda linha, para a segunda coluna até a penúltima coluna (Equação 4.130).

$p_{1, j}=p_{2, j}$, para $j=2$ até $N X-1$ 


\section{RESULTADOS E DISCUSSÕES}

São apresentados os resultados para o cálculo da dispersão da pluma de bolhas, das velocidades e pressão no meio líquido e do perfil de concentração de oxigênio dissolvido.

O valor da difusividade da bolha calculada pela Equação 4.4 foi de $0,0002613 \mathrm{~m}^{2} / \mathrm{s}$, ao considerar uma altura constante de 0,3m (altura de água no tanque) e uma velocidade de ascensão da bolha de $0,19 \mathrm{~m} / \mathrm{s}$ adotada de acordo com Oliveira, 2008. Outras considerações foram:

- Diâmetro médio da bolha, $d_{B}=0,005 \mathrm{~mm}$;

- Concentração de saturação do oxigênio dissolvido a $25^{\circ} \mathrm{C}, C_{O D S}=0,008 \mathrm{Kg} / \mathrm{m}^{3}$;

- Viscosidade cinemática turbulenta da água, $v_{t}=0,001 \mathrm{~m}^{2} / \mathrm{s}$;

- Viscosidade dinâmica da fase líquida, $\mu_{l}=0,0008684 \mathrm{Kg} / \mathrm{m} \cdot \mathrm{s}$;

- Viscosidade dinâmica da fase gasosa, $\mu_{g}=0,000018444 \mathrm{Kg} / \mathrm{m} \cdot \mathrm{s}$;

- Massa especifica da água, $\rho_{l}=997 \mathrm{Kg} / \mathrm{m}^{3}$;

- Aceleração devida a gravidade, $g=9,81 \mathrm{~m} / \mathrm{s}^{2}$;

- Difusividade turbulenta em $x, D_{t x}=0,001 \mathrm{~m}^{2} / \mathrm{s}$

- Difusividade turbulenta em $x y, D_{t y}=0,001 \mathrm{~m}^{2} / \mathrm{s}$;

- Vazão de ar por bico injetor, $Q_{a r}=0,1 \mathrm{~m}^{3} / \mathrm{h}$;

- Volume da bolha, $\operatorname{Vol}_{b}=6,54 \cdot 10^{-8} \mathrm{~m}^{3}$;

Os valores para o coeficiente de transferência de massa $K_{L}$ foram calculados a partir da Equação 4.5 de Hikita et al. (1981). Os valores calculados para $K_{L}$ são apresentados na Tabela 1.

Tabela 1 - Resultados calculados para os valores do coeficiente de transferência de massa $K_{L}(1 / \mathrm{s})$.

\begin{tabular}{ccccc} 
& $\mathbf{1}$ bico injetor & $\mathbf{5}$ bicos injetores & $\mathbf{1 0}$ bicos injetores & $\mathbf{2 4}$ bicos injetores \\
\hline $\boldsymbol{K}_{\boldsymbol{L}}$ & 0,001138961 & 0,003870135 & 0,006554037 & 0,012748804 \\
\hline
\end{tabular}

Os valores de $K_{L}$ aumentam de acordo com o número de bicos injetores, pois em seus cálculos é utilizada a área interfacial das bolhas, assim, quanto maior a concentração de bolhas no tanque, maior a área interfacial de troca de massa das bolhas para o líquido e consequentemente maior o valor do $K_{L}$. 
As Figuras 13 a 16 representam o perfil estacionário de bolhas segundo a Equação 4.15 , usando o valor obtido para a difusividade da bolha $D_{\text {bolha }}=0,0002613$. As cores e tamanhos dos círculos indicam a ordem de grandeza da concentração de bolhas $C_{b}$, indicadas na Figura 12.

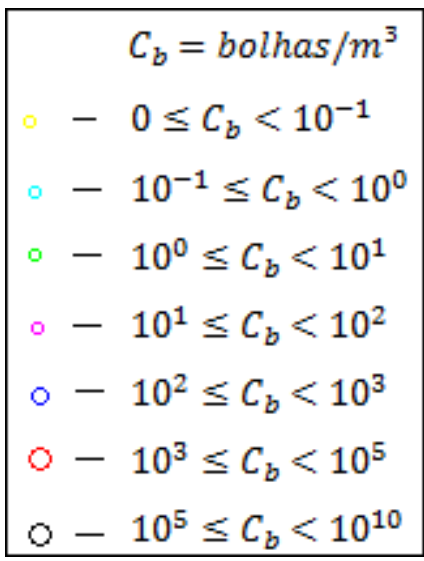

Figura 12 - Ordem de grandeza da concentração de bolhas $C_{b}$.

A Figura 13 mostra uma pluma estacionária de bolhas para 1 injetor somente, localizado na posição $x=1,26 \mathrm{~m}$.

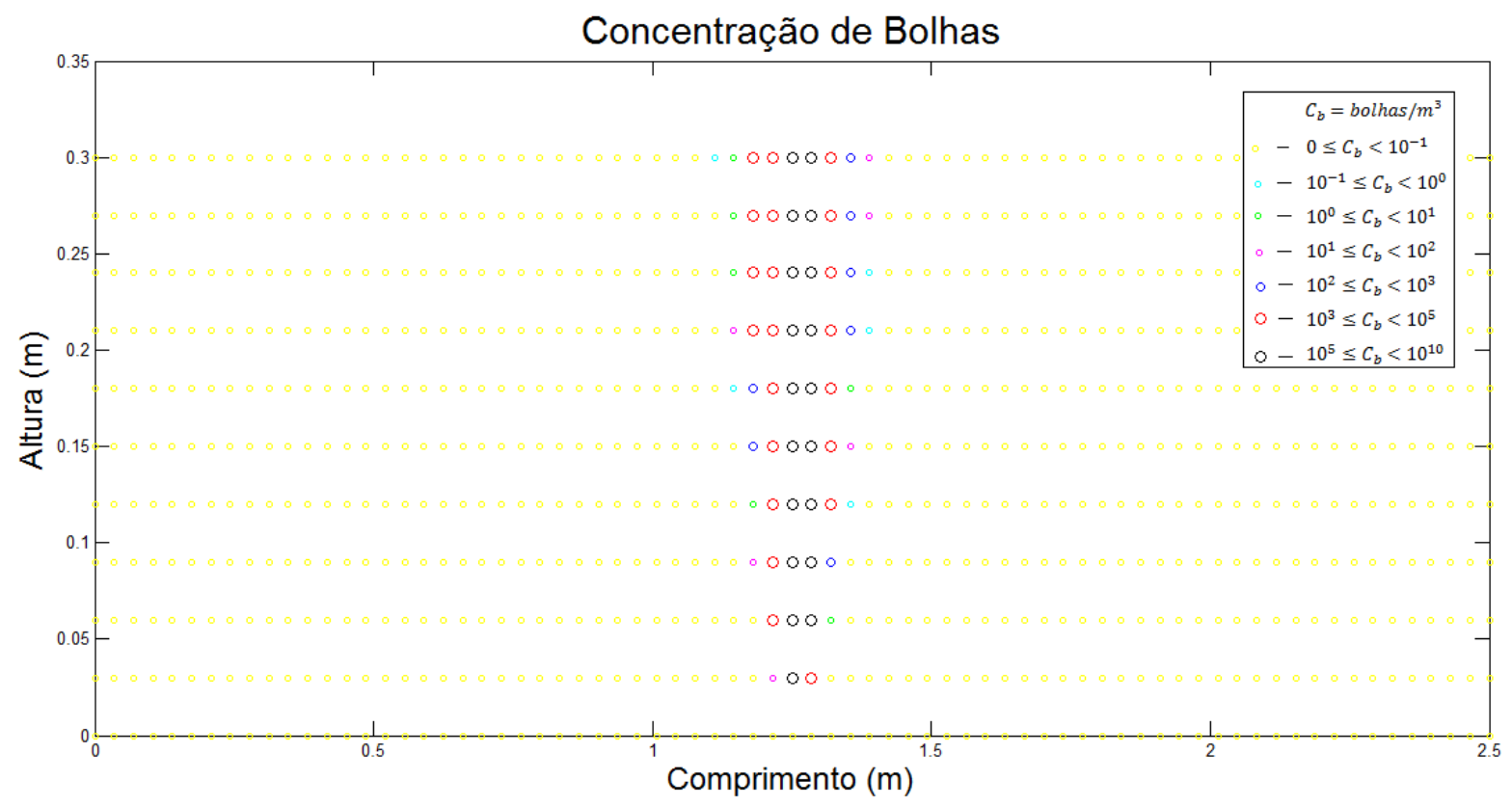

Figura 13 - Perfil da $C_{b}$ (número de bolhas/m3) da pluma para 1 injetor somente. Malha de 10x72.

Verifica-se que a concentração de bolhas é maior na linha central da pluma e esta diminui conforme o raio da pluma se distancia de seu eixo. A concentração de bolhas aumenta 
conforme a altura do tanque devido ao espalhamento das bolhas. $\mathrm{O}$ raio da pluma, em sua altura máxima, chega a aproximadamente $0,30 \mathrm{~m}$.

A Figura 14 mostra o perfil estacionário das plumas de bolhas para 5 bicos injetores. Os bicos injetores foram localizados nas posições $x=0,43,0,84,1,26,1,68$ e 2,09 para os bicos $1,2,3,4$ e 5, respectivamente.

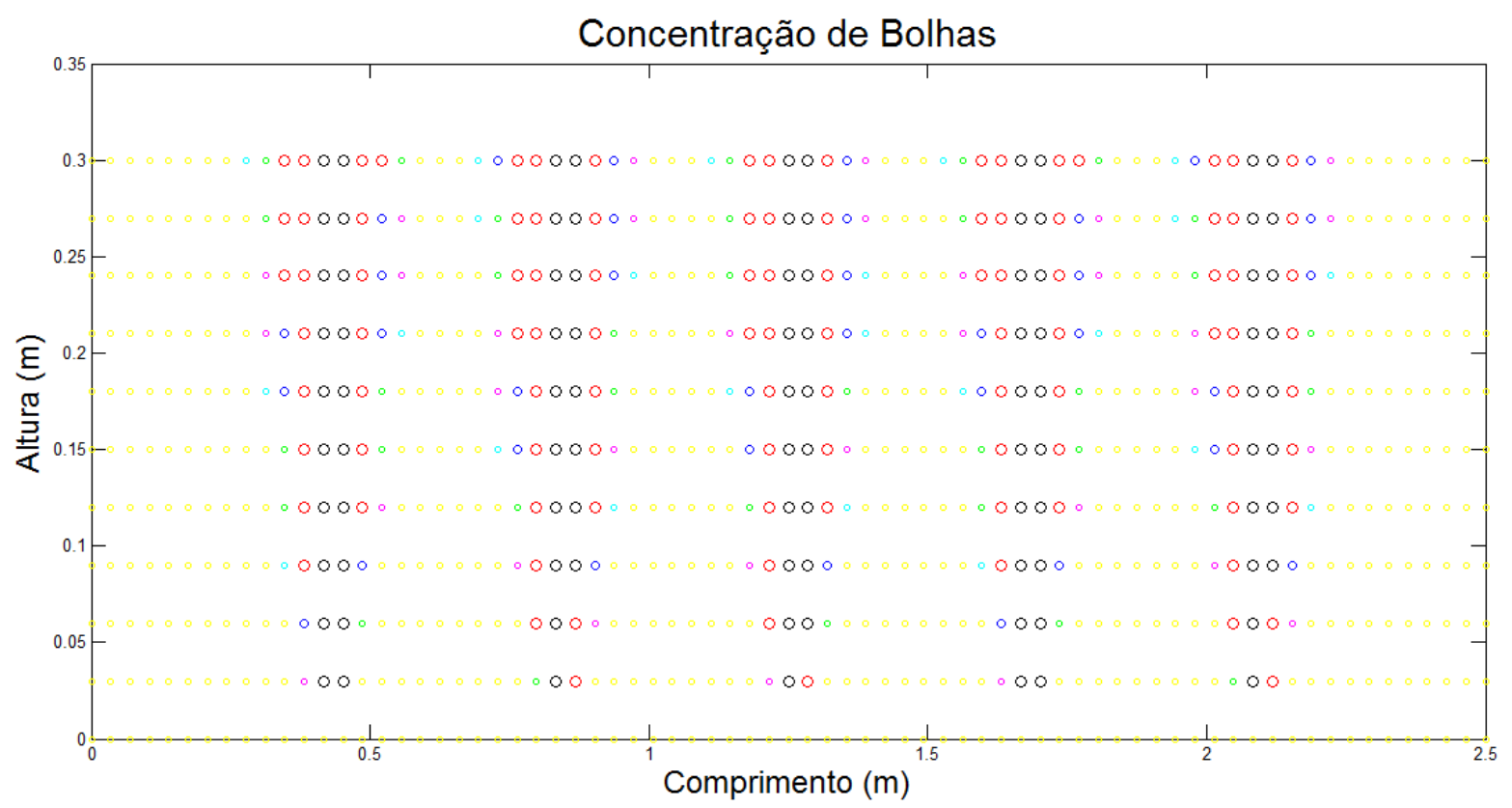

Figura 14 - Perfil da $C_{b}$ (número de bolhas/m³) da pluma para 5 injetores. Malha de $10 x 72$.

Assim como na Figura 13 verificou-se uma maior concentração de bolhas na linha central da pluma e um aumento gradual de acordo com a altura do tanque. Não foi verificada a superposição das bolhas devido ao espaçamento dos bicos injetores, desta maneira, uma pluma de bolha não interferiu nas demais.

A Figura 15 mostra o perfil estacionário das plumas de bolhas para 10 bicos injetores. Os bicos injetores foram espaçados igualmente entre si, distando aproximadamente $0,23 \mathrm{~m}$ um do outro. 


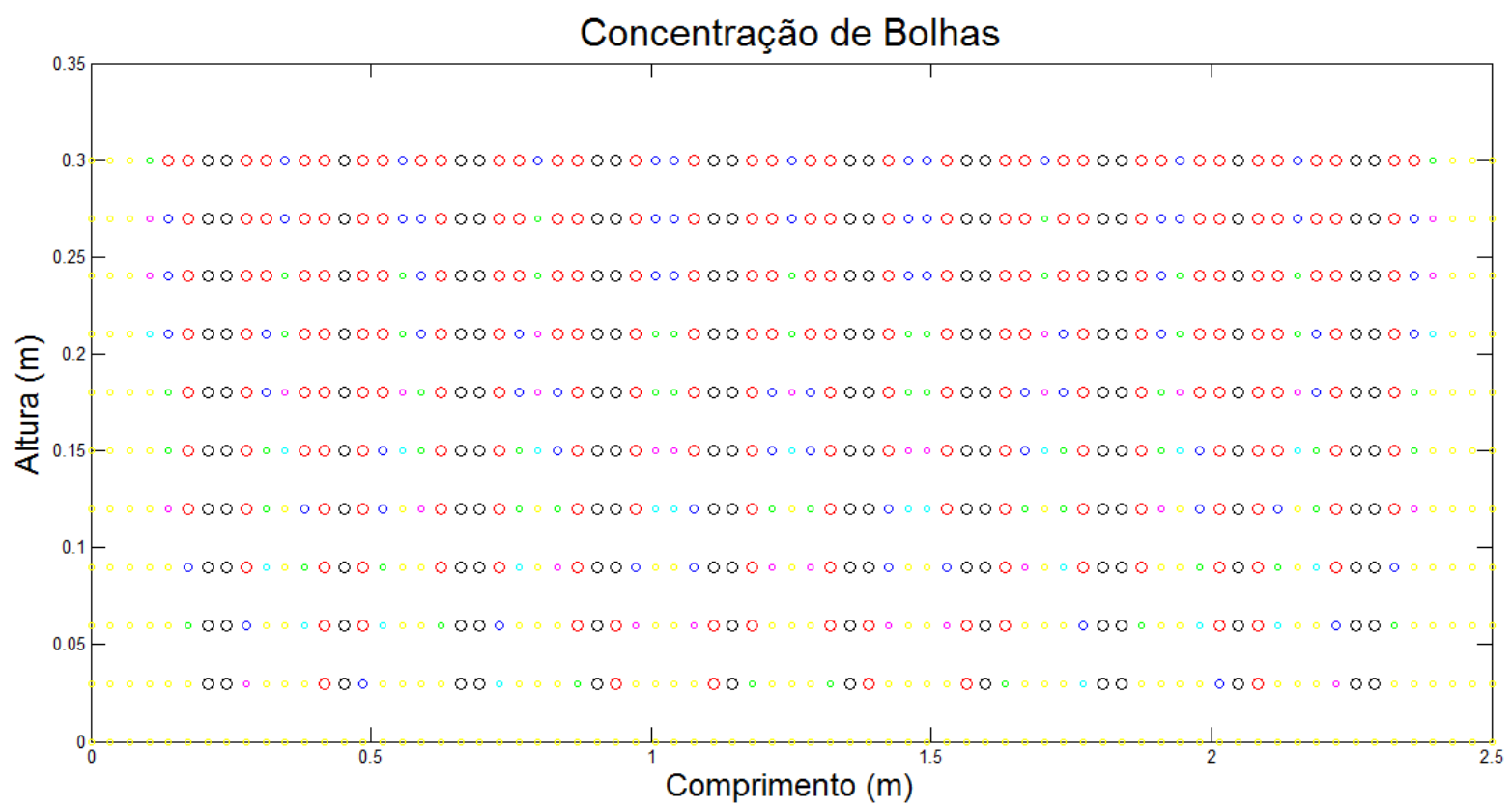

Figura 15 - Perfil da $C_{b}$ (número de bolhas/m³) da pluma para 10 injetores. Malha de $10 \times 72$.

Observa-se também que a concentração de bolhas foram maiores nos eixos centrais de cada pluma e nas posições mais altas do tanque, porém neste caso, as concentrações de bolhas foram superpostas de acordo com a Equação 4.16, pois a quantidade de bicos injetores fez com que a concentração de bolhas de uma pluma em determinada altura e raio se somasse com a concentração de bolhas da pluma vizinha.

A Figura 16 representa o perfil estacionário das plumas de bolhas para 24 injetores no tanque. Os bicos foram distanciados entre si por $0,10 \mathrm{~m}$.

Verifica-se a homogeneidade da concentração de bolhas devido ao elevado número de bicos injetores. A superposição das bolhas fez com que a concentração de bolhas no tanque ficasse homogênea ao longo do tanque. As menores concentrações são encontradas na parte mais funda do tanque e entre os bicos injetores. 


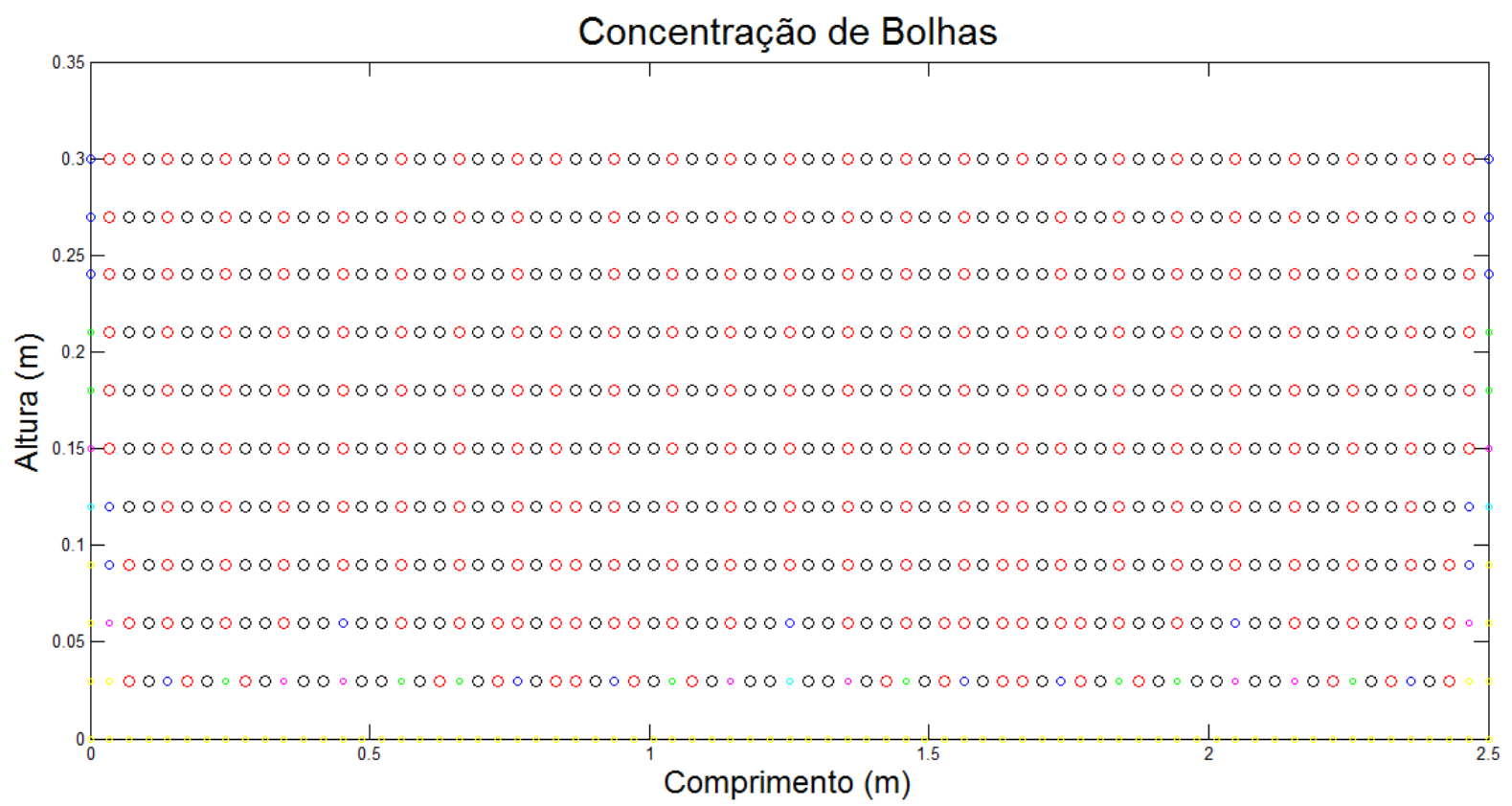

Figura 16 - Perfil da $C_{b}$ (número de bolhas/m³) da pluma para 24 injetores. Malha de $10 x 72$.

A Figura 17 mostra vetores que indicam a direção do escoamento dentro do tanque, com a região de entrada na parte inferior direita e região de saída na parte superior esquerda. As velocidades médias $u$ e $v$ foram, em módulo, de 0,01 a $0,06 \mathrm{~m} / \mathrm{s}$ e 0,02 a $0,09 \mathrm{~m} / \mathrm{s}$, respectivamente.

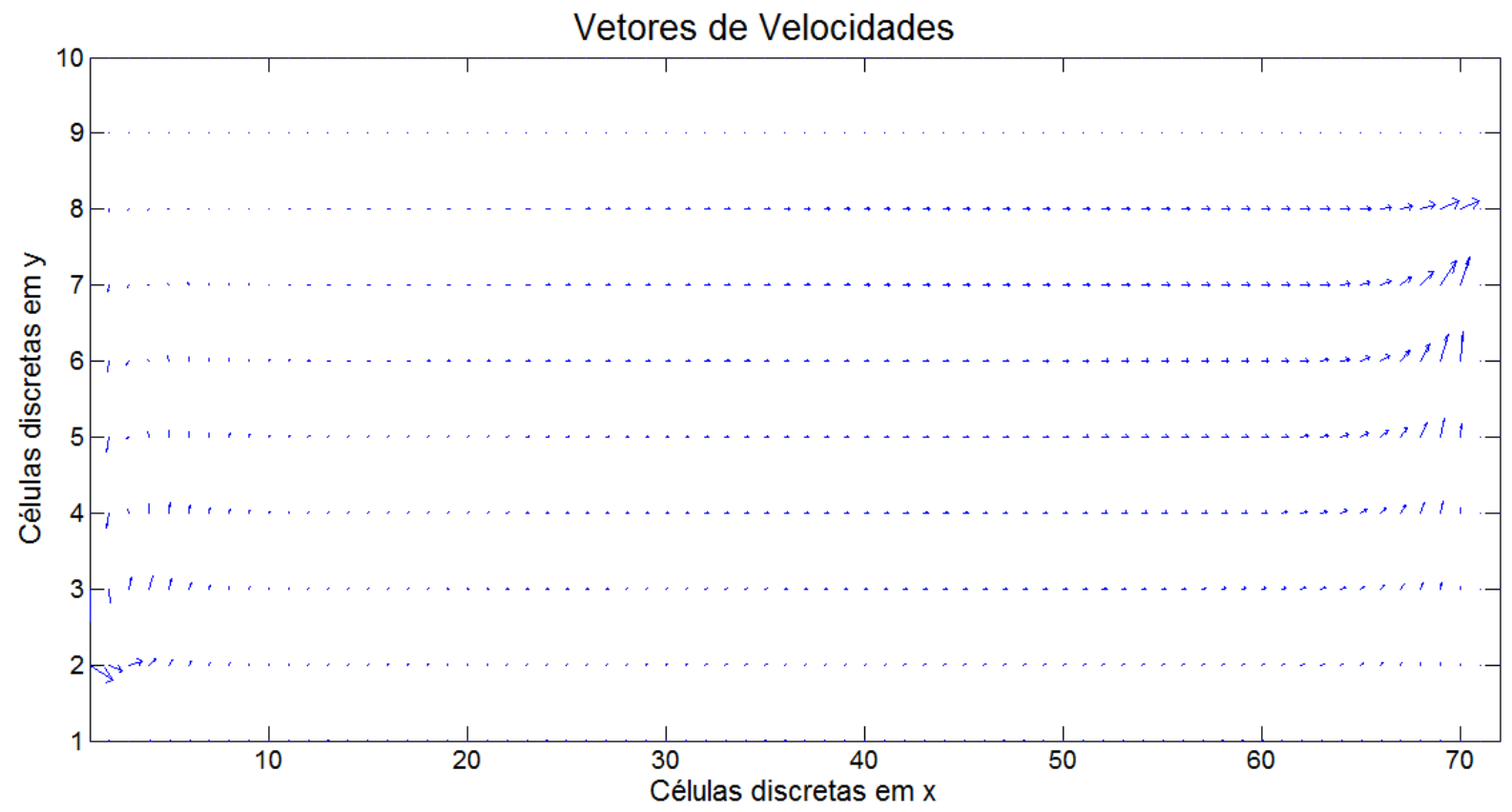

Figura 17 - Gráfico dos vetores das velocidades no tanque. Malha 10x72. 
A Figura 18 apresenta de modo aproximado o campo de velocidades para a região de entrada do fluido. Observa-se a formação de um pequeno turbilhão nesta região de entrada de fluido.

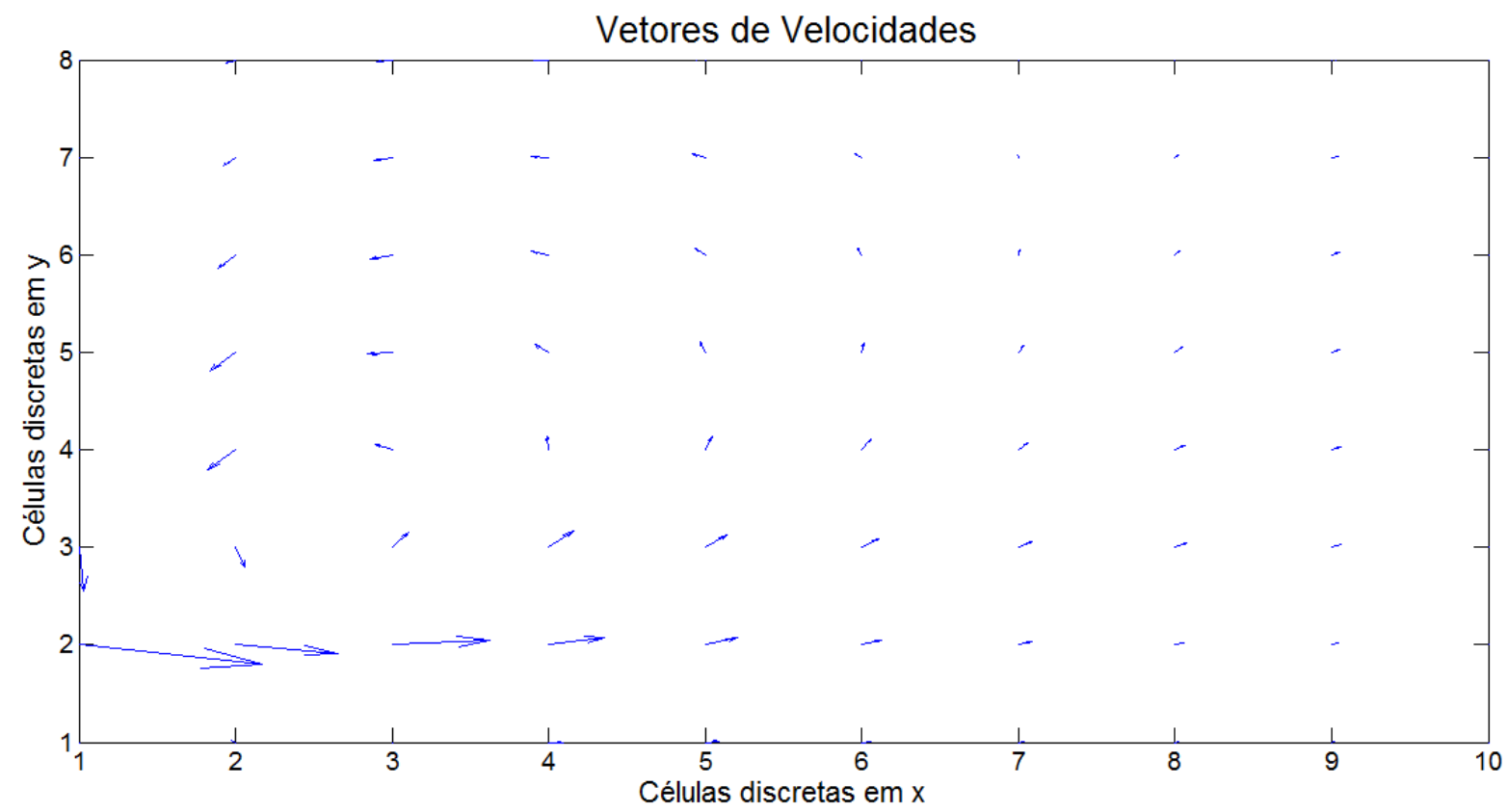

Figura 18 - Gráfico dos vetores de velocidades na região de entrada do canal.

A Figura 19 apresenta de modo aproximado o campo de velocidades na região de saída de fluido do canal.

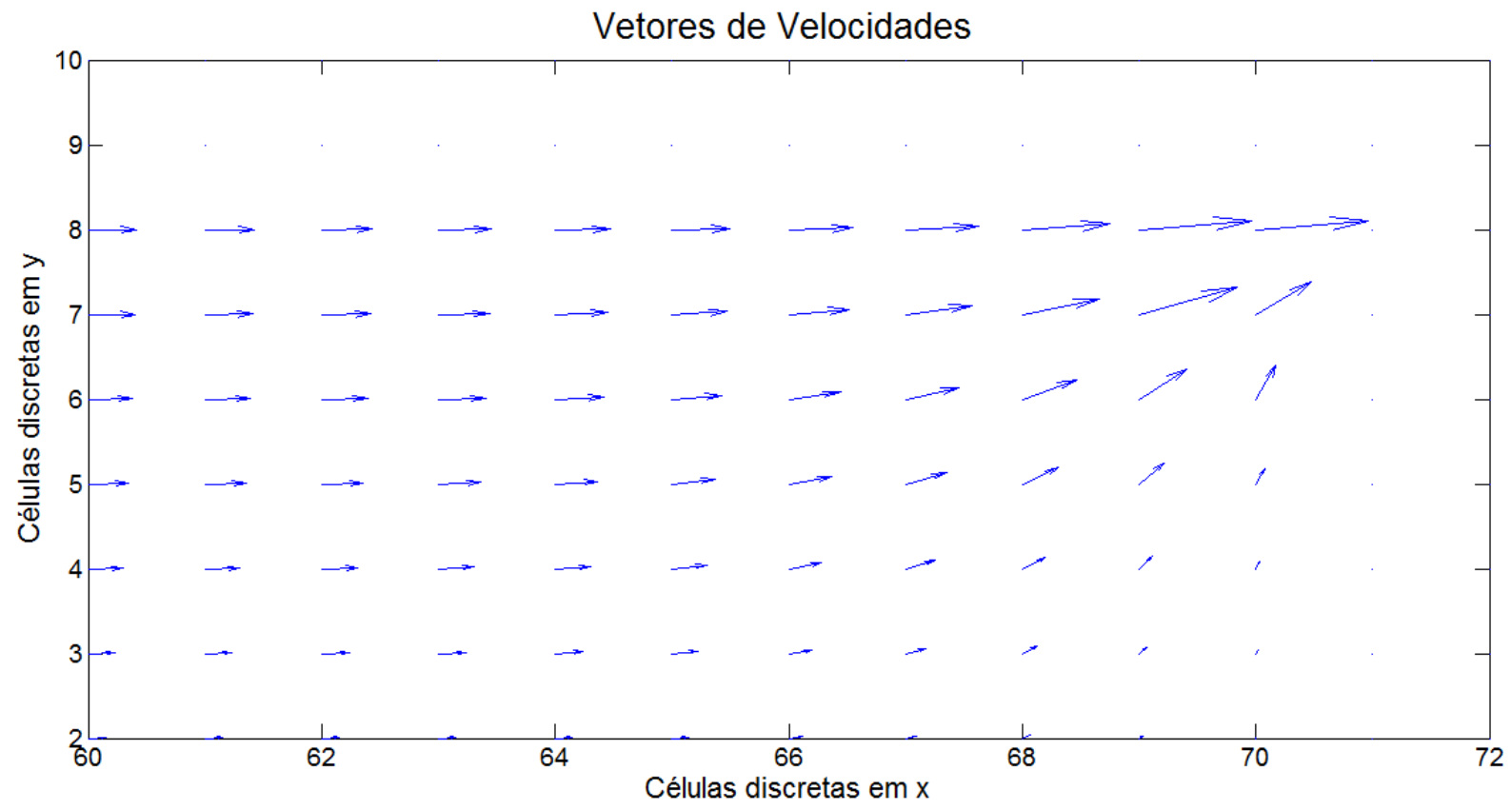

Figura 19 - Gráfico dos vetores de velocidade na região de saída do canal. 
A Figura 20 apresenta o gráfico de pressões relativas ao longo do tanque.

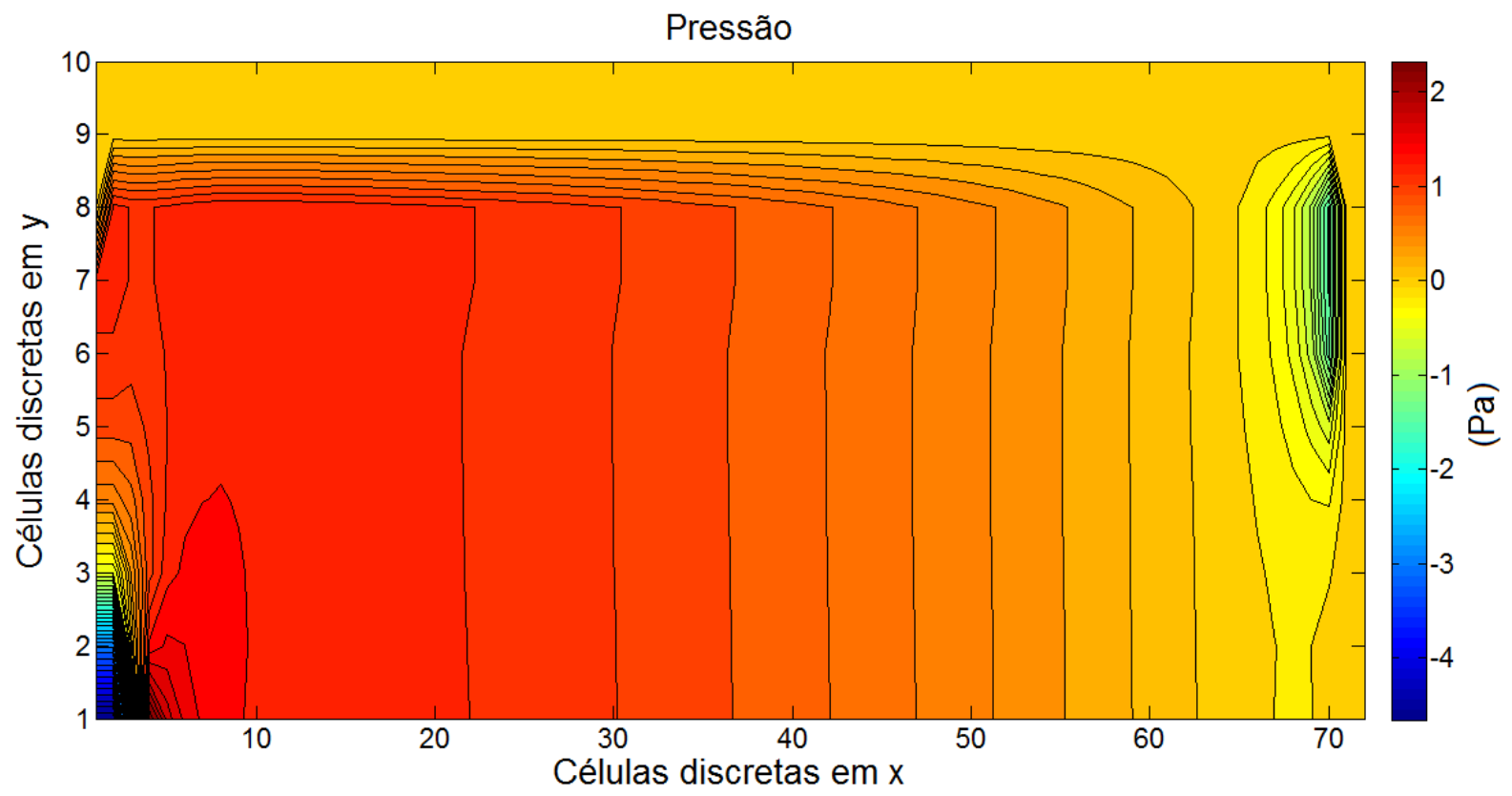

Figura 20 - Gráfico da pressão no tanque. Malha 10x72.

Os valores de maior pressão são encontrados logo na entrada do tanque, diminuindo ao longo do canal na direção do escoamento da água. Na superfície do canal a pressão do tanque é zero (pressão relativa).

Na região de entrada do fluido há pressões relativas negativas bem perto da entrada devido a grande velocidade do fluido, ao desacelerar nas proximidades, a pressão relativa aumenta. Na região de saída do fluido, devido a grande movimentação para sair, a velocidade aumenta e a pressão diminui como se ocorresse um efeito de sucção.

As Figuras 21 a 37 apresentam os perfis de concentração de oxigênio dissolvido, $C_{O D}$, no tanque com domínio computacional bidimensional em malha 10x72 para água fluindo pelo canal. As velocidades da água utilizadas para os cálculos foram àquelas calculadas pelo método MAC.

O valor utilizado para intervalo de tempo foi de 1 segundo. As Figuras 21 a 24 apresentam o resultado da concentração de OD para 1 injetor somente. O coeficiente de transferência de massa utilizado para estes cálculos foi de $0,001138961 \mathrm{~m} / \mathrm{s}$, conforme apresentado na Tabela 1. 


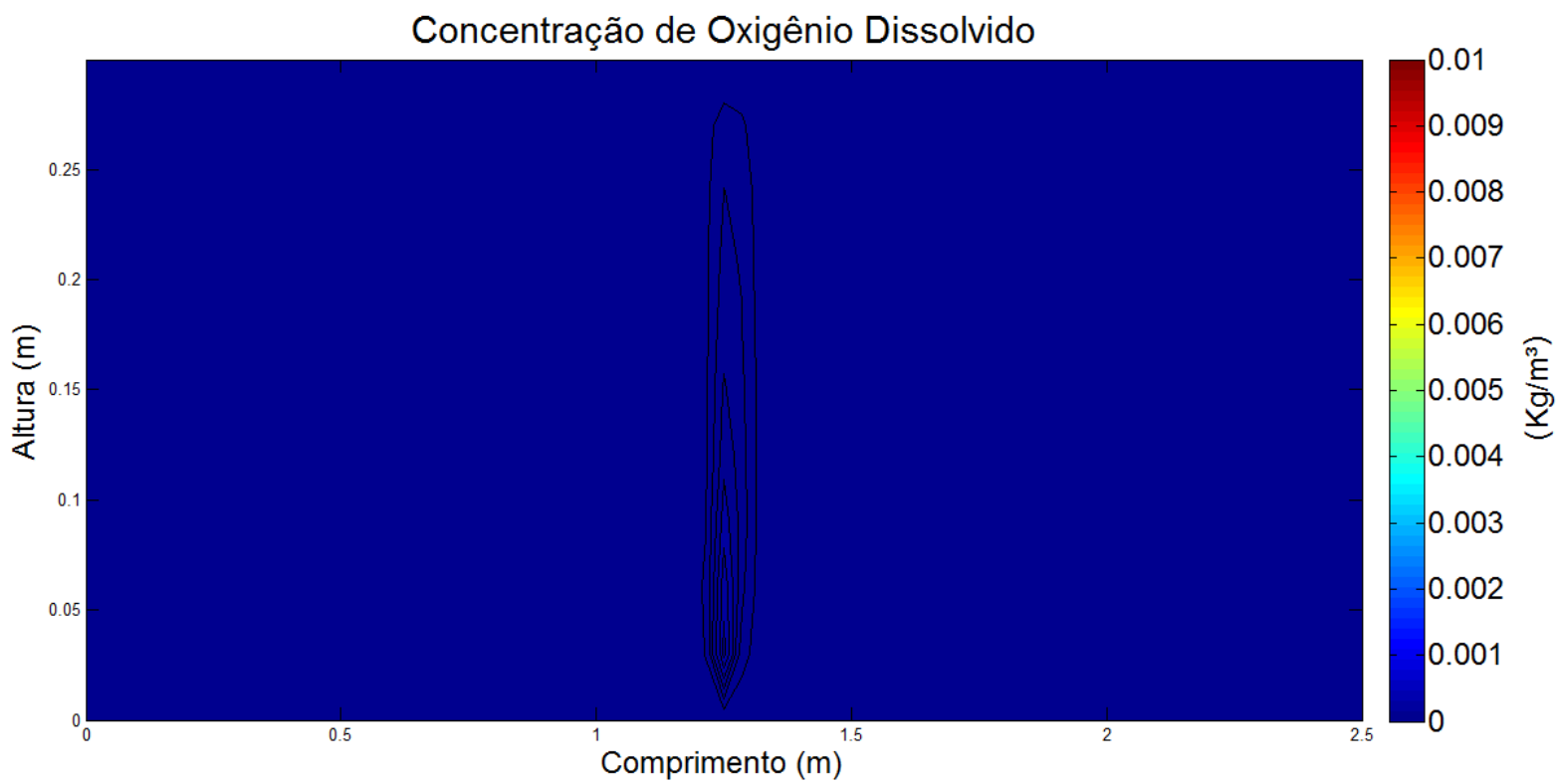

Figura 21 - Perfil de concentração de oxigênio dissolvido $C_{O D}\left(K g / \mathrm{m}^{3}\right)$ no tanque para 1 injetor localizado em $x=1,26 \mathrm{~m}$. Malha de 10x72. Tempo simulado: $1 \mathrm{~s}$.

O perfil da Figura 21 é para o primeiro instante de tempo da injeção de bolhas com apenas 1 segundo de simulação. A $C_{O D}$ foi colocada como sendo inicialmente igual a zero conforme se pode observar na figura.

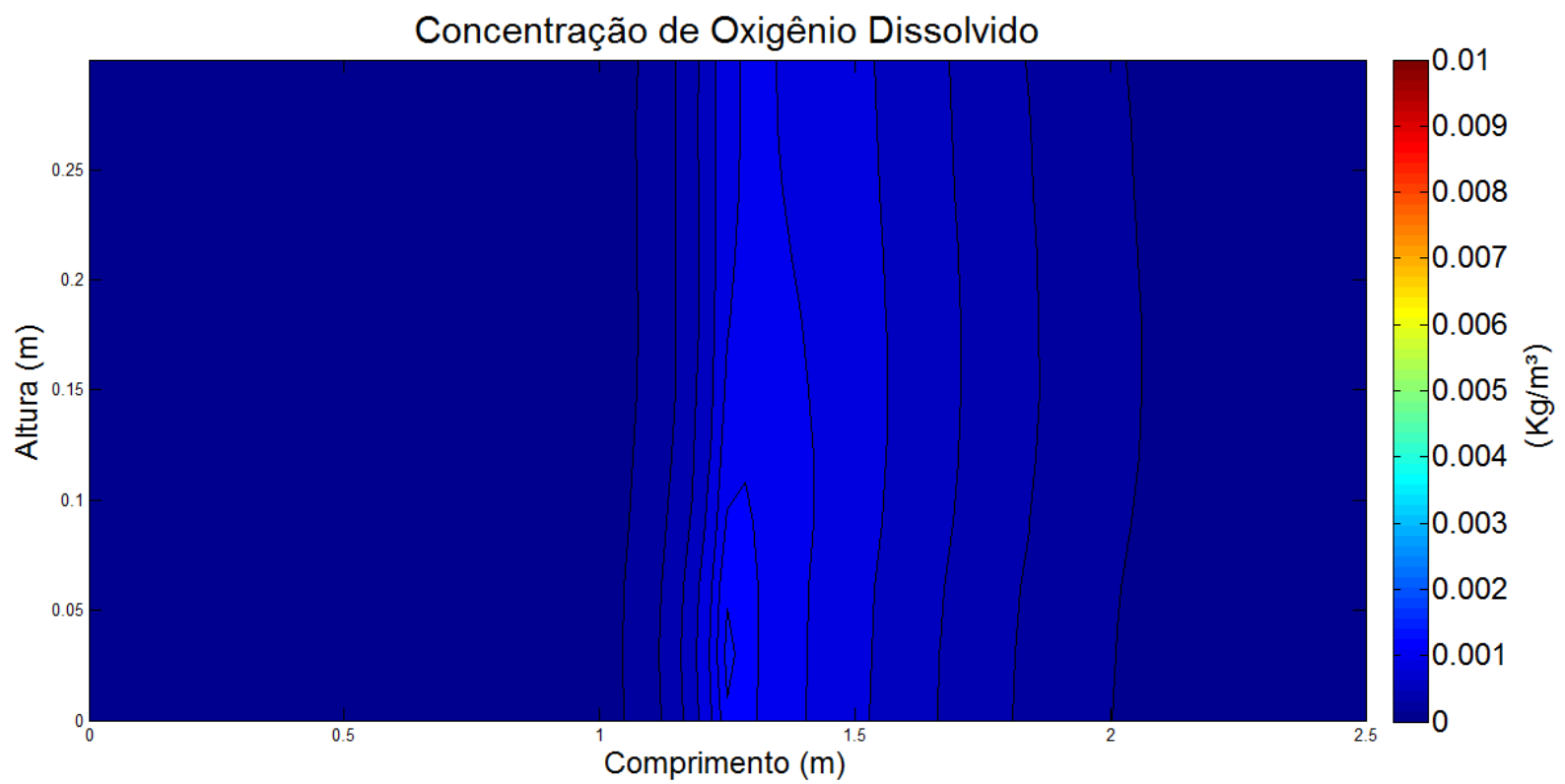

Figura 22 - Perfil $C_{O D}\left(\mathrm{Kg} / \mathrm{m}^{3}\right)$ no tanque para 1 injetor localizado em $\mathrm{x}=1,26 \mathrm{~m}$. Malha de 10x72. Tempo simulado: $50 \mathrm{~s}$.

Após 50 segundos simulados já é possível observar na Figura 22 o processo de transferência de OD para o meio líquido. A coluna que apresenta maior $C_{O D}$, ainda que baixa, 
é próxima ao eixo vertical do bico injetor com aproximadamente $0,0015 \mathrm{Kg} / \mathrm{m}^{3}$ de OD. A componente da velocidade $V_{x}$, na direção do escoamento, faz com que o OD se difunda mais facilmente também na direção de saída do tanque.

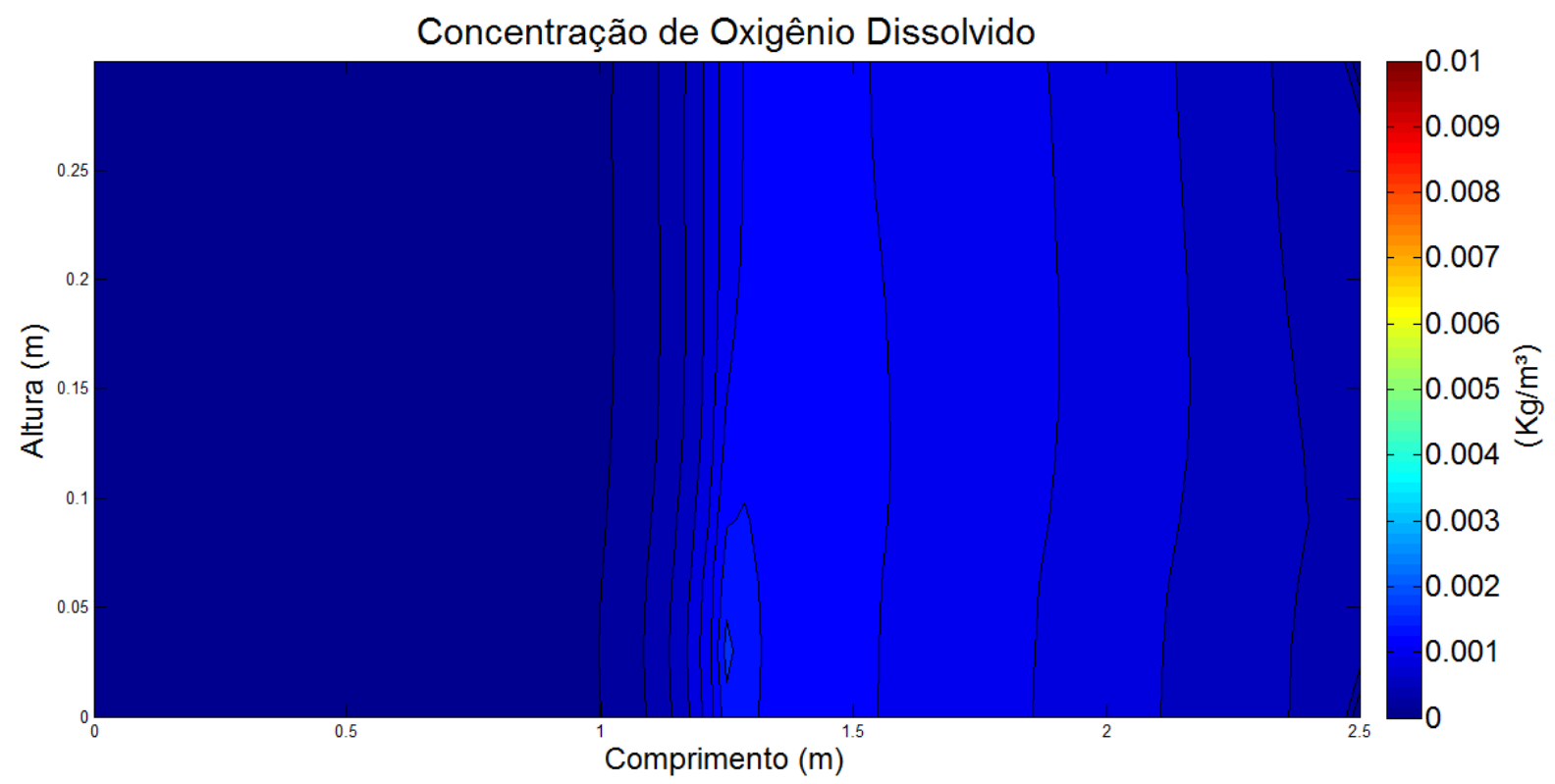

Figura 23 - Perfil da $C_{O D}\left(\mathrm{Kg} / \mathrm{m}^{3}\right)$ no tanque para 1 injetor localizado em $x=1,26 \mathrm{~m}$. Malha de $10 x 72$. Tempo simulado: $100 \mathrm{~s}$.

A Figura 23 representa 100 segundos de simulação. A concentração de oxigênio dissolvido ainda encontra-se baixa, porém o processo já ocorre até as distâncias próximas à região de saída.

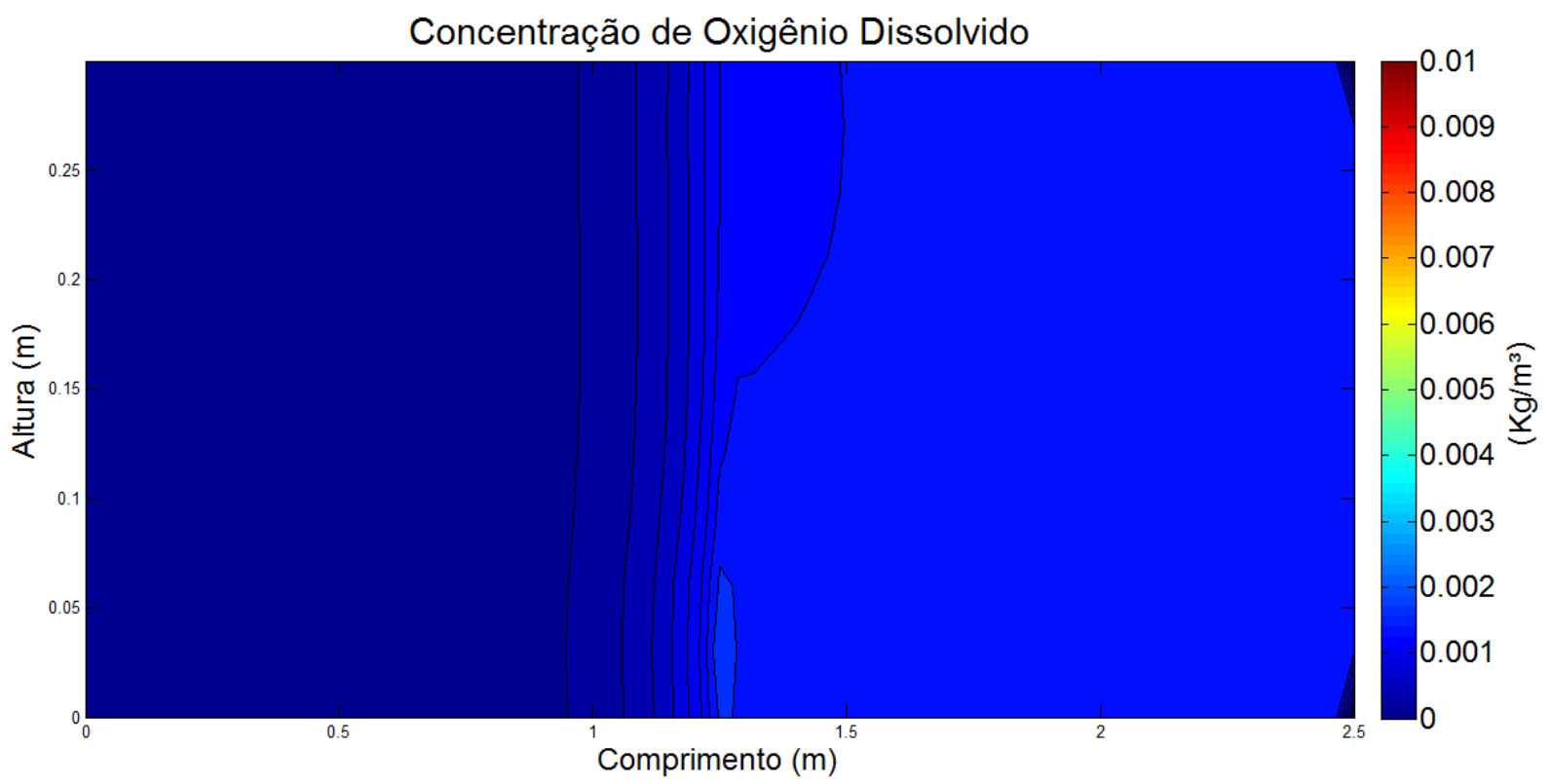

Figura 24 - Perfil da $\mathrm{C}_{\mathrm{OD}}\left(\mathrm{Kg} / \mathrm{m}^{3}\right)$ no tanque para 1 injetor localizado em $\mathrm{x}=1,26 \mathrm{~m}$. Malha de $10 \times 72$. Tempo simulado: $1000 \mathrm{~s}$. 
Passados 1000 segundos de simulação observa-se uma homogeneização a partir do meio do tanque, onde está localizado o bico injetor. A $C_{O D}$ ainda é baixa e a aproximadamente $0,002 \mathrm{Kg} / \mathrm{m}^{3}$ de OD. Foi realizada uma simulação de 2000 segundos e a diferença desta simulação para a simulação da Figura 24 foi mínima. Desta forma observa-se que este é o perfil de $C_{O D}$ para 1 bico injetor.

As Figuras 25 a 29 apresentam o perfil de $C_{O D}$ para 5 bicos injetores no tanque. $O$ valor para $K_{L}$ utilizado foi de 0,003870135 de acordo com a Tabela 1.

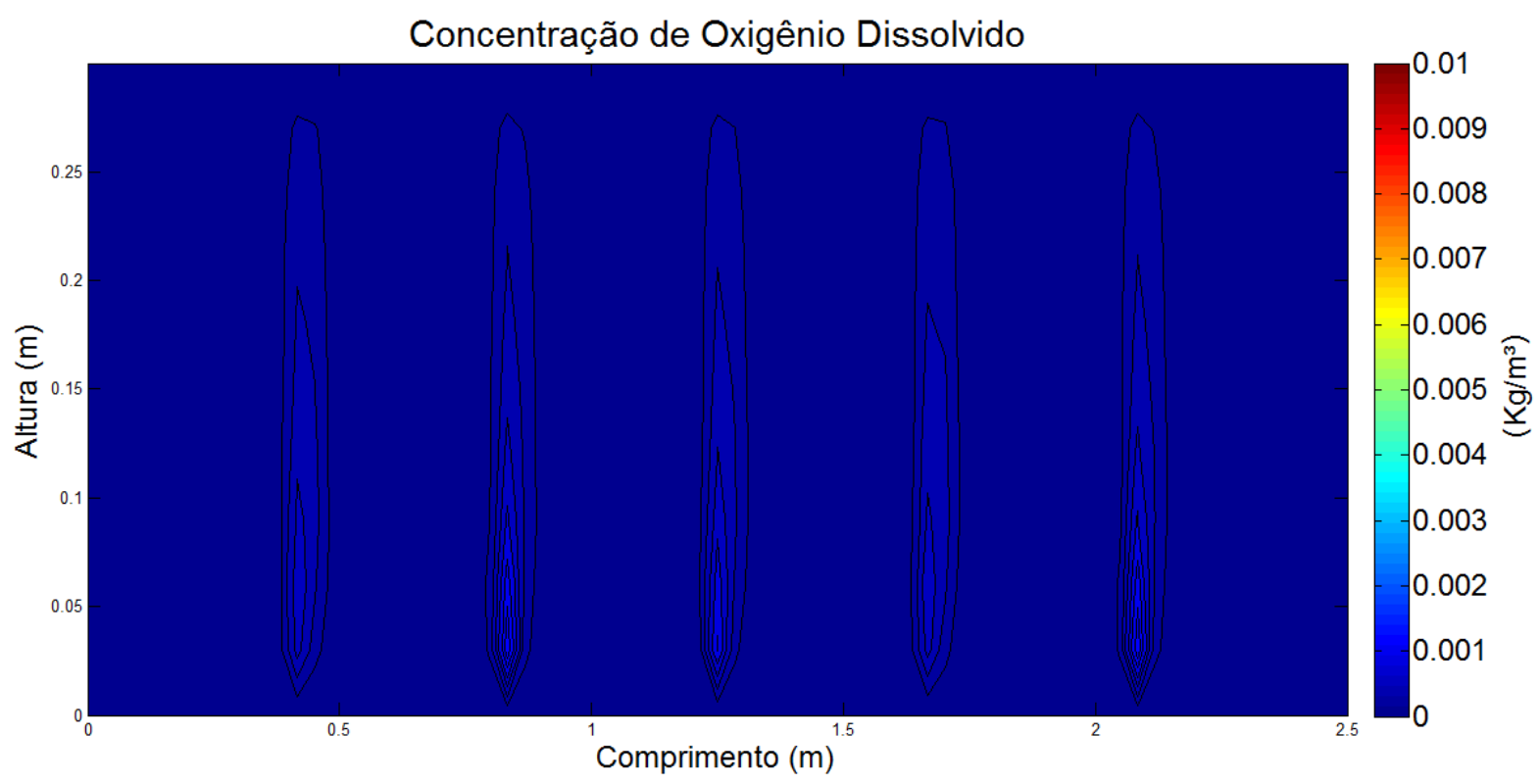

Figura 25 - Perfil da $C_{O D}\left(K g / m^{3}\right)$ no tanque para 5 injetores localizados em $x=0,43 m, 0,84 m, 1,26 m, 1,68 m$ e 2,09m respectivamente. Malha de $10 \times 72$. Tempo simulado: $1 \mathrm{~s}$.

A Figura 25 apresenta o tempo inicial do cálculo, 1 segundo de simulação. Como esperado, a $C_{O D}$ é zero praticamente para o tanque todo, porém quando comparado a Figura 21 percebe-se uma levíssima alteração na coloração dos eixos centrais da pluma devido ao maior valor para $K_{L}$ quando se tratou de 5 bicos injetores. 


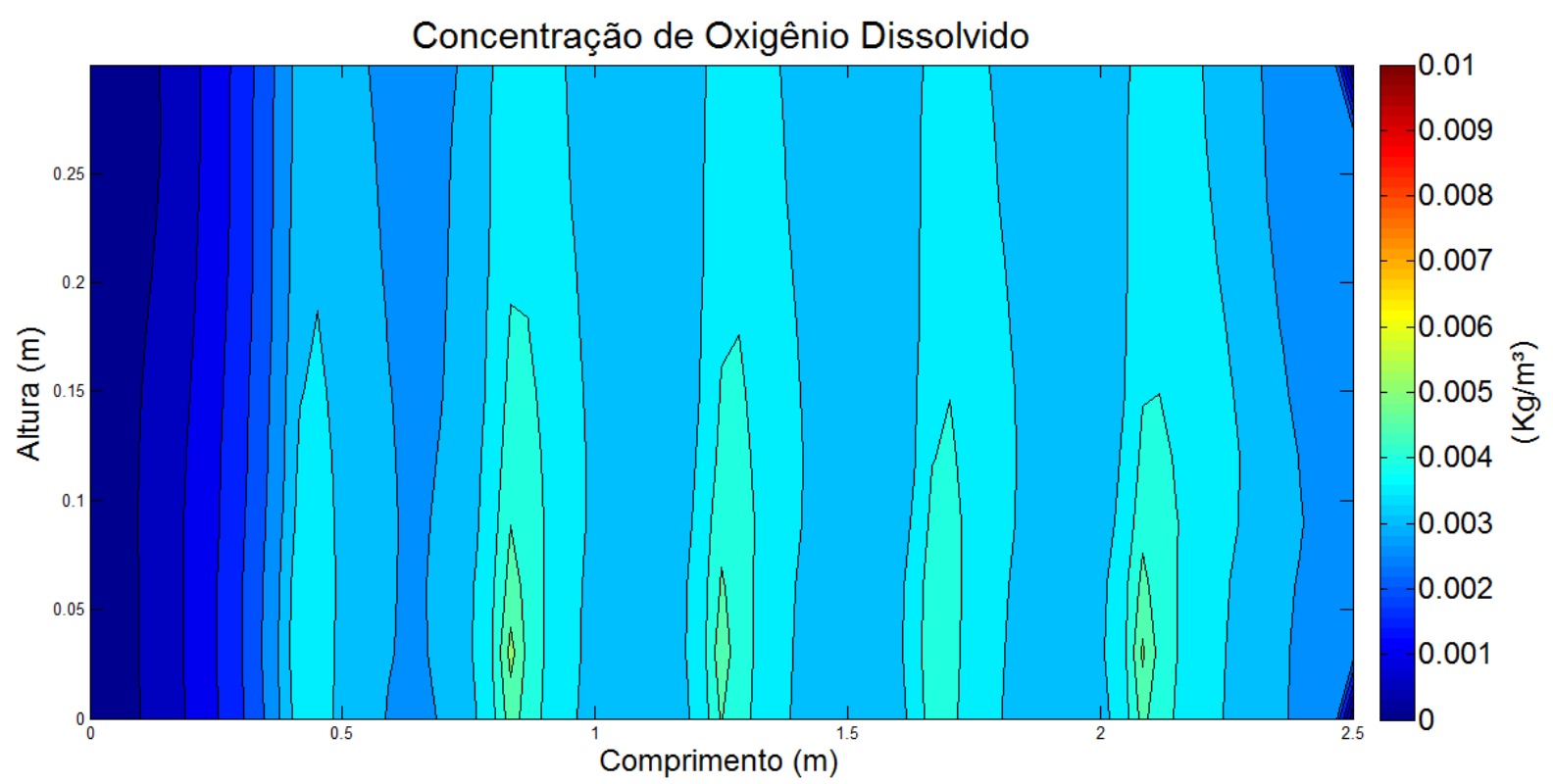

Figura 26 - Perfil da $C_{O D}\left(K g / m^{3}\right)$ no tanque para 5 injetores localizados em $x=0,43 m, 0,84 m, 1,26 m, 1,68 m$ e 2,09m respectivamente. Malha de 10x72. Tempo simulado: $50 \mathrm{~s}$.

Após 50 segundos de simulação é possível observar na Figura 26 o aumento da $C_{O D}$, principalmente nos eixos centrais dos bicos injetores, onde o fluxo de bolhas é mais elevado.

Com 100 segundos de simulação (Figura 27) a concentração de OD aparece de forma mais homogênea ao longo do tanque, diferente da simulação para 50 segundos.

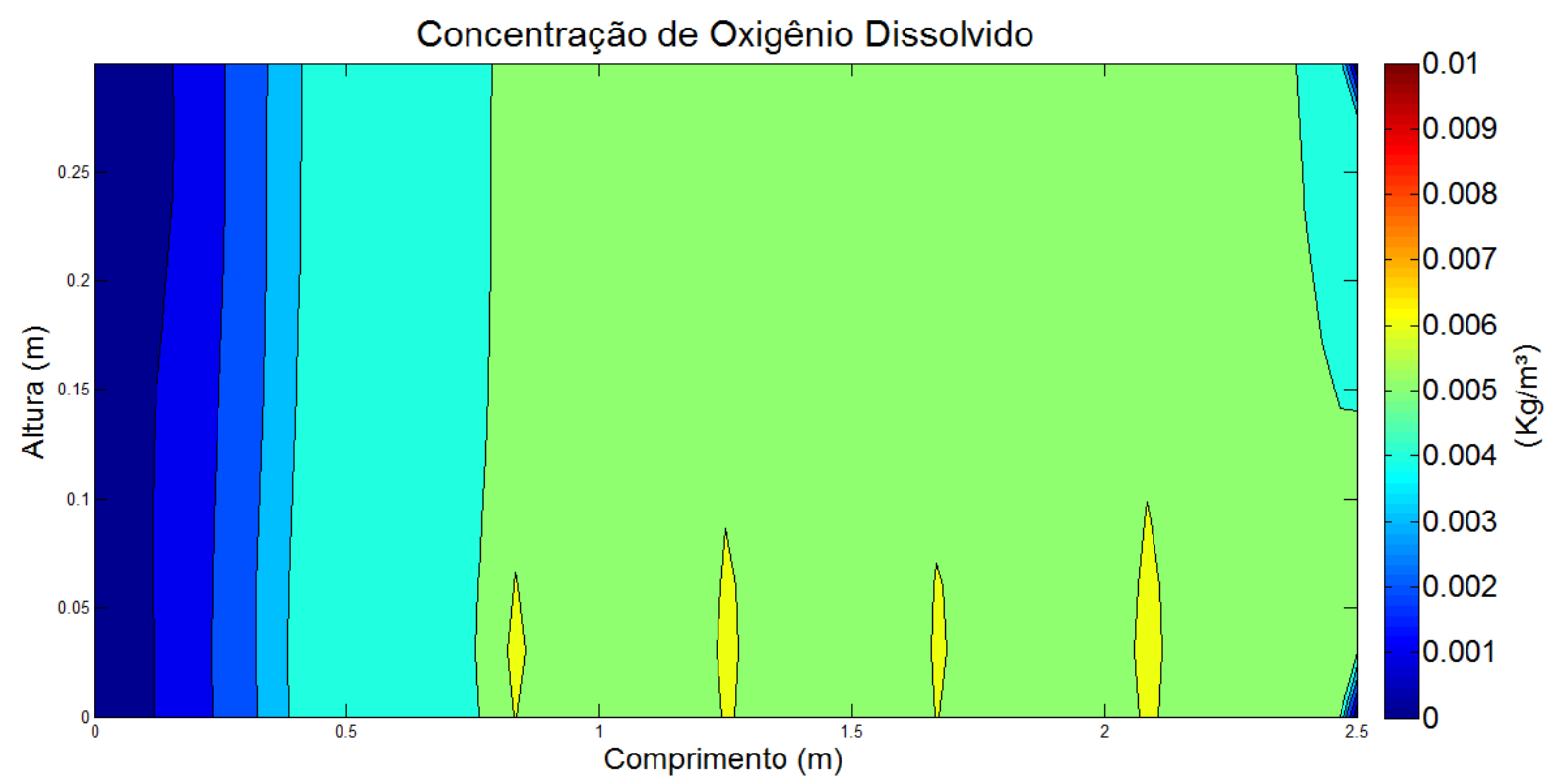

Figura 27 - Perfil da $C_{O D}\left(K g / \mathrm{m}^{3}\right)$ no tanque para 5 injetores localizados em $x=0,43 \mathrm{~m}, 0,84 \mathrm{~m}, 1,26 \mathrm{~m}, 1,68 \mathrm{~m}$ e 2,09m respectivamente. Malha de 10x72. Tempo simulado: $100 \mathrm{~s}$. 
A velocidade na entrada do tanque faz com que não seja possível, em termos de $C_{O D}$, a visualização o primeiro bico injetor localizado na posição $x=0,43 \mathrm{~m}$ (Figura 27).

É interessante observar na Figura 28 a influência da velocidade e da direção do escoamento. Isto também pode ser percebido nas figuras anteriores, mas na Figura 28 a diferença das concentrações próxima à região de entrada fica bem nítida quando comparada à região de saída. A segunda metade do tanque apresenta concentrações próximas a concentração de saturação de OD.

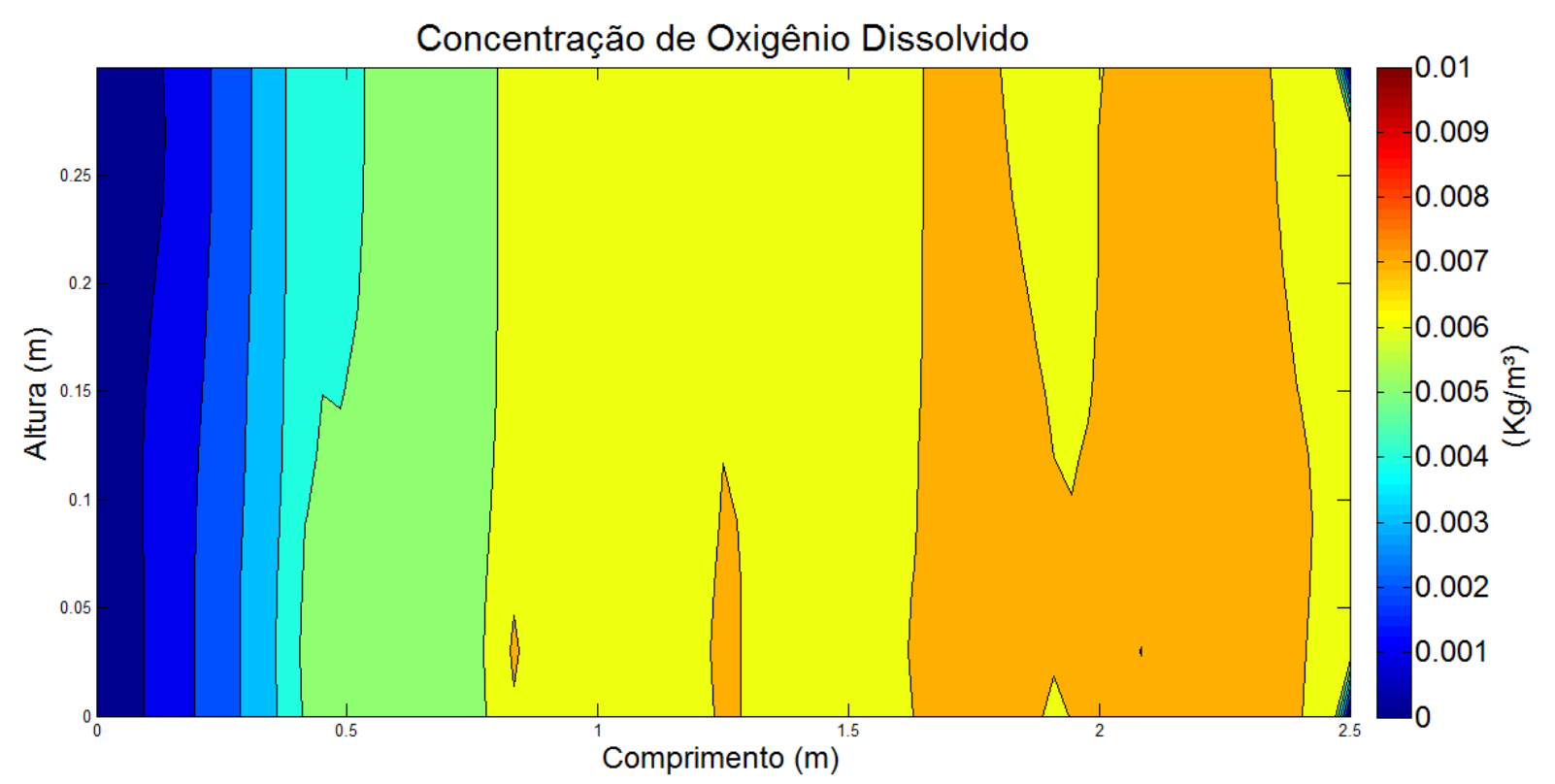

Figura 28 - Perfil da $C_{O D}\left(\mathrm{Kg} / \mathrm{m}^{3}\right)$ no tanque para 5 injetores localizados em $\mathrm{x}=0,43 \mathrm{~m}, 0,84 \mathrm{~m}, 1,26 \mathrm{~m}, 1,68 \mathrm{~m}$ e 2,09m respectivamente. Malha de 10x72. Tempo simulado: $200 \mathrm{~s}$

Finalizando os 5 bicos injetores, a Figura 29 mostra, com 300 segundo simulados, o perfil final para a $C_{O D}$. Simulações foram feitas até 1000 segundo e o perfil se mostrou praticamente o mesmo. Diferente do perfil final para 1 bico injetor, a $C_{O D}$ neste caso foi mais elevada com valor aproximado de $0,007 \mathrm{Kg} / \mathrm{m}^{3}$. 


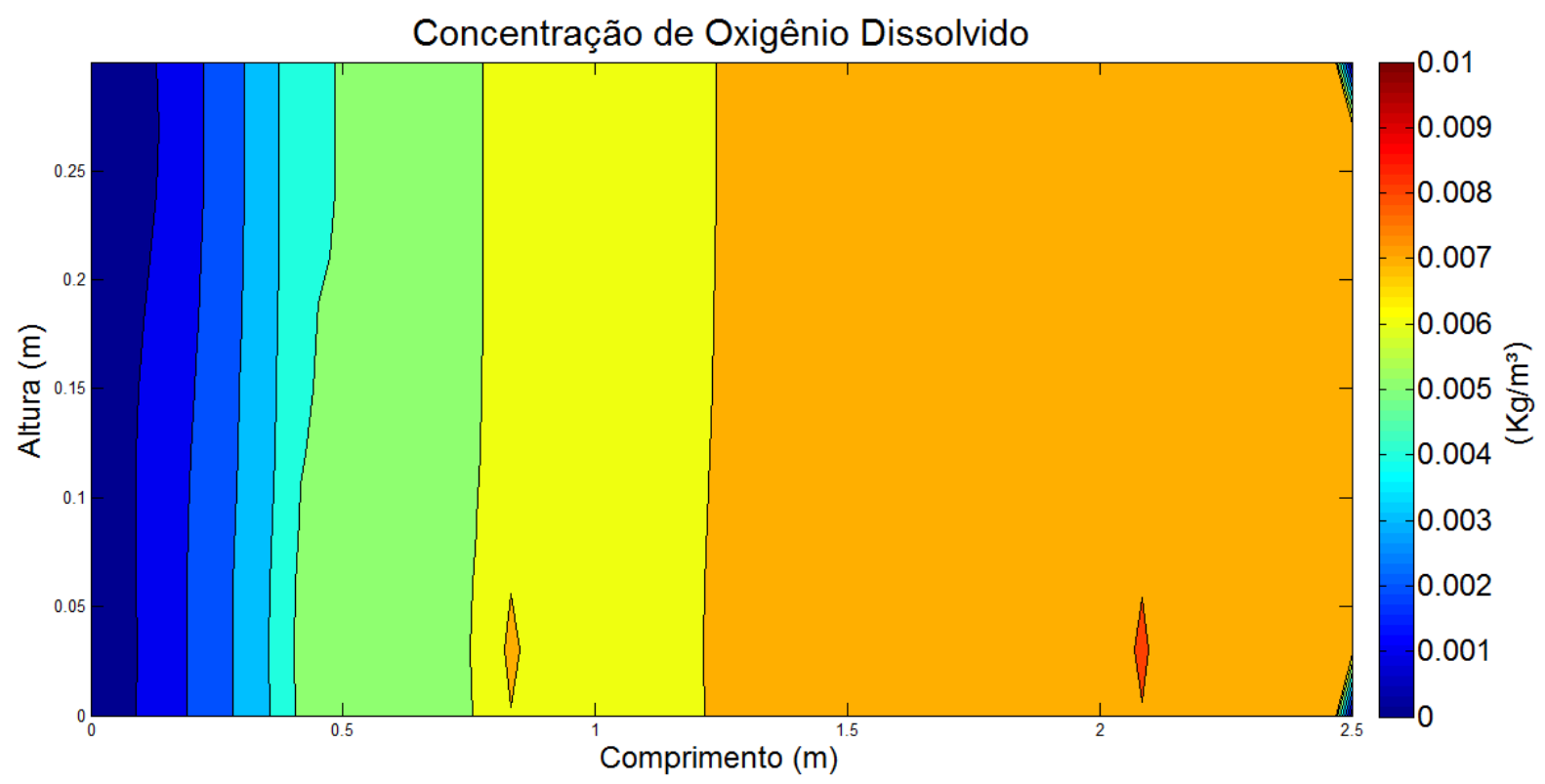

Figura 29 - Perfil da $C_{O D}\left(K g / m^{3}\right)$ no tanque para 5 injetores localizados em $x=0,43 m, 0,84 m, 1,26 m, 1,68 m$ e 2,09m respectivamente. Malha de 10x72. Tempo simulado: $300 \mathrm{~s}$

As Figuras 30 a 33 apresentam os perfis de $C_{O D}$ no tanque para 10 bicos injetores. $\mathrm{O}$ valor do $K_{L}$ é de 0,006554037 de acordo com a Tabela 1.

A simulação para 10 bicos injetores inicia-se com o perfil de tempo simulado de 1 segundo na Figura 30, na qual é possível a visualização de 10 perfis de OD ocasionados pela transferência de OD das bolhas das plumas.

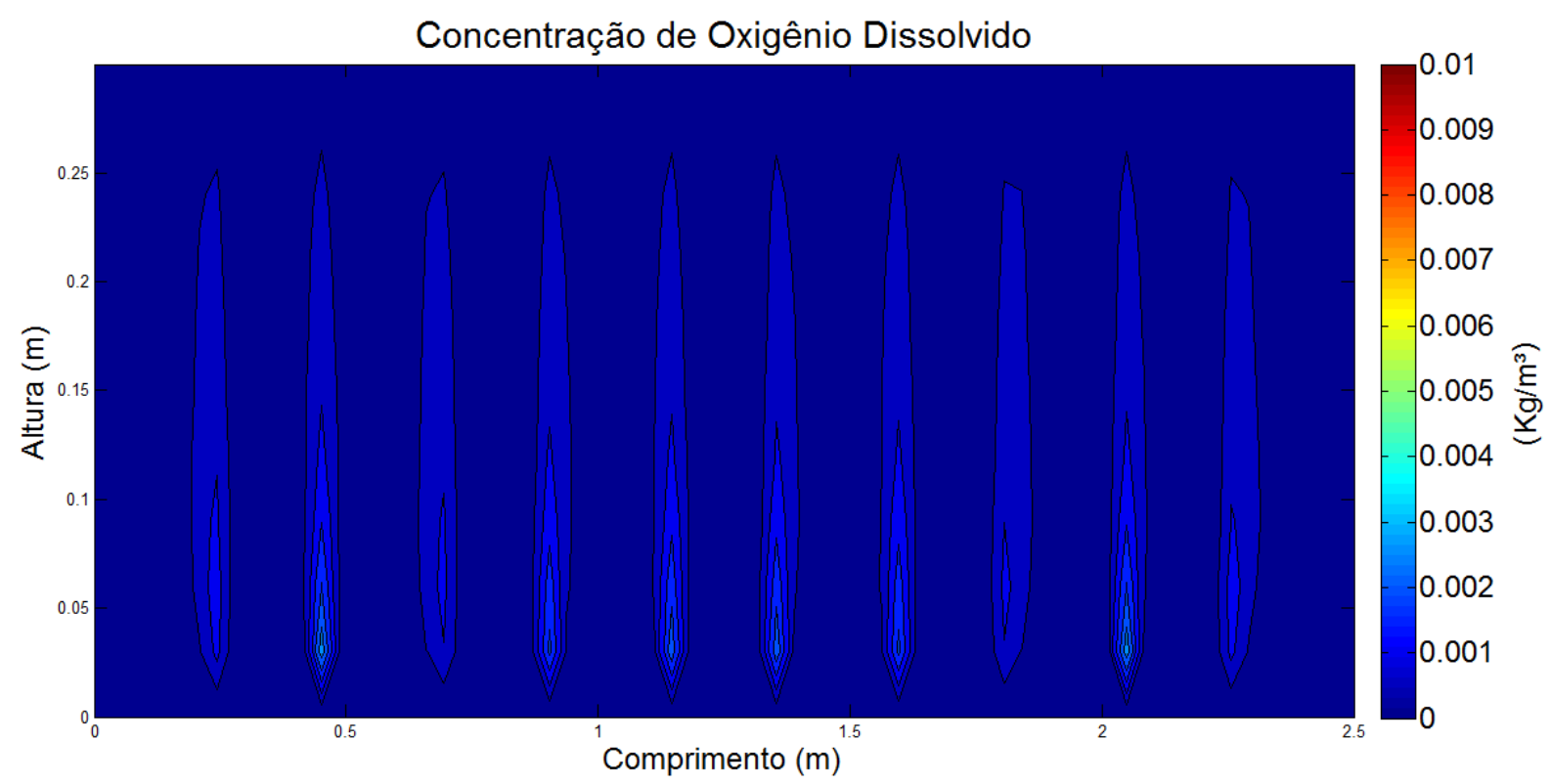

Figura 30 - Perfil da $\mathrm{C}_{\mathrm{OD}}\left(\mathrm{Kg} / \mathrm{m}^{3}\right)$ no tanque para 10 injetores dispostos igualmente entre si por aproximadamente 0,23m. Malha de 10x72. Tempo simulado: $1 \mathrm{~s}$. 
Conforme a Figura 31, observa-se um perfil para $C_{O D}$ entre 0,004 e $0,005 \mathrm{Kg} / \mathrm{m}^{3}$. Assim como na Figura 27, o primeiro bico injetor da figura analisada quase desaparece em termos de concentração de OD, porém o valor mais alto para o coeficiente global de transferência de massa - maior comparado as simulações para 5 bicos injetores - faz com que ainda seja possível a visualização do mesmo. Os valores mais elevados de concentração sempre aparecem ao logo do eixo $y$ dos bicos injetores.

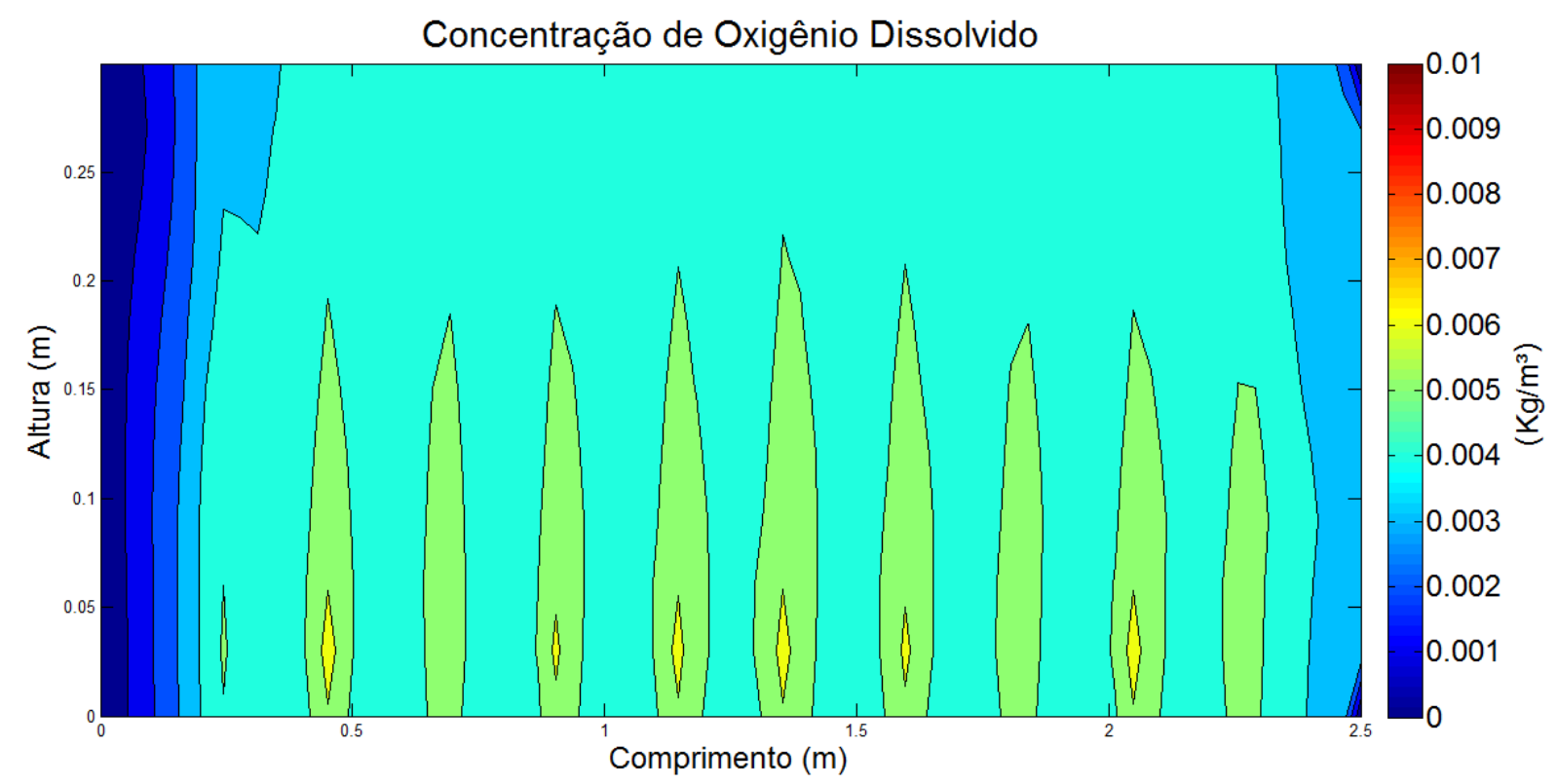

Figura 31 - Perfil da $\mathrm{C}_{\mathrm{OD}}\left(\mathrm{Kg} / \mathrm{m}^{3}\right)$ no tanque para 10 injetores dispostos igualmente entre si por aproximadamente 0,23m. Malha de 10x72. Tempo simulado: $25 \mathrm{~s}$.

Com 50 segundos de simulação, a Figura 32 mostra um tanque mais homogêneo com a $C_{O D}$ entre 0,006 e $0,007 \mathrm{Kg} / \mathrm{m}^{3}$. As concentrações são mais elevadas para os bicos injetores centrais, não somente nesta figura, provavelmente devido a menor influência causada pelas regiões fronteira. 


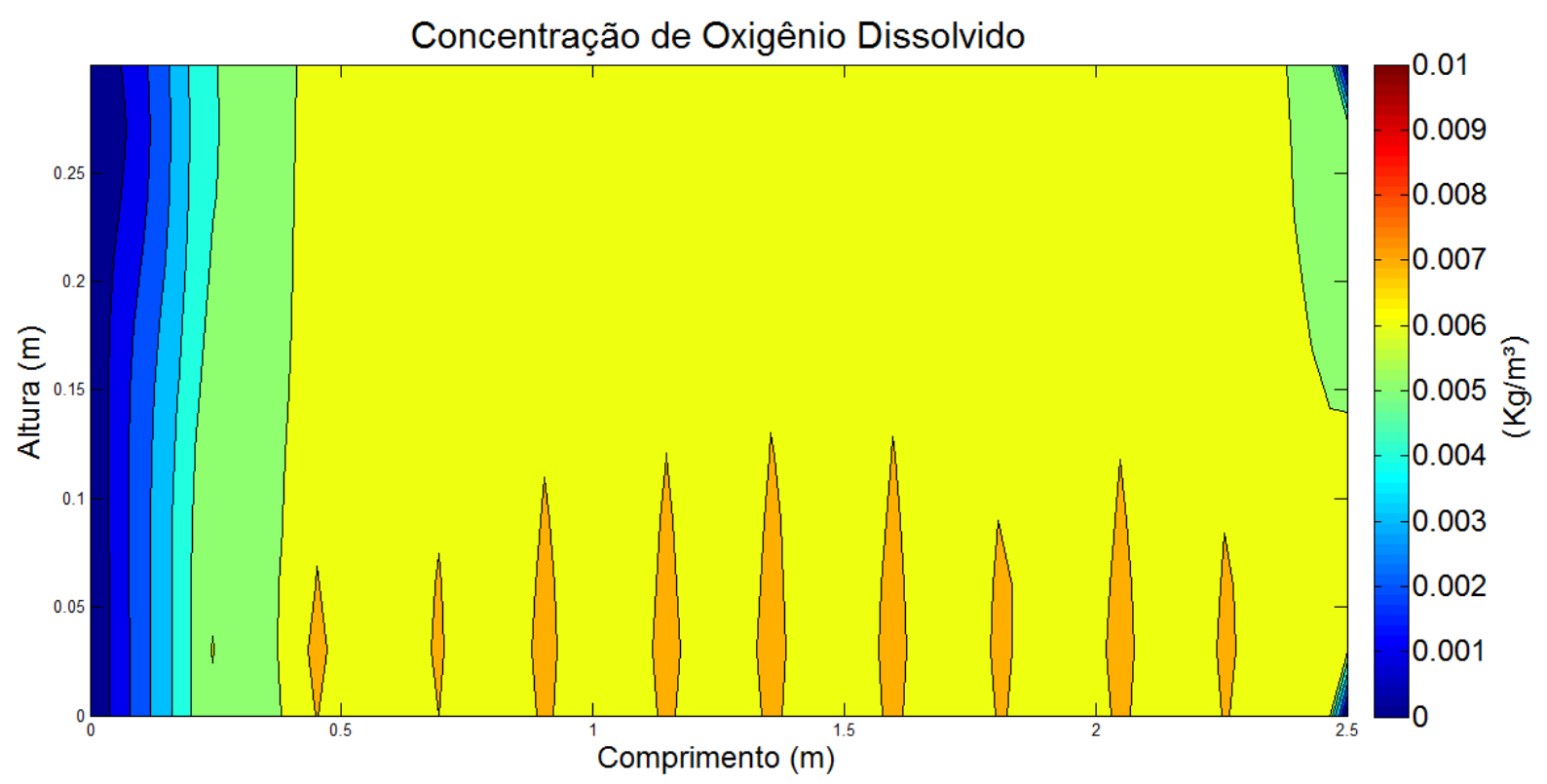

Figura 32 - Perfil da $\mathrm{C}_{\mathrm{OD}}\left(\mathrm{Kg} / \mathrm{m}^{3}\right)$ no tanque para 10 injetores dispostos igualmente entre si por aproximadamente $0,23 \mathrm{~m}$. Malha de 10x72. Tempo simulado: $50 \mathrm{~s}$.

O perfil final para 10 bicos injetores pode ser visualizado na Figura 33. A concentração de saturação foi praticamente alcançada com 200 segundos simulados em quase todo o tanque. As regiões de cor "laranja escuro" indicam uma elevada concentração devido à grande quantidade de bolhas. Apesar do coeficiente de transferência de massa ser mais elevado para 10 bicos injetores, os três primeiros bicos, em termos de concentração de OD, praticamente ficaram homogêneos.

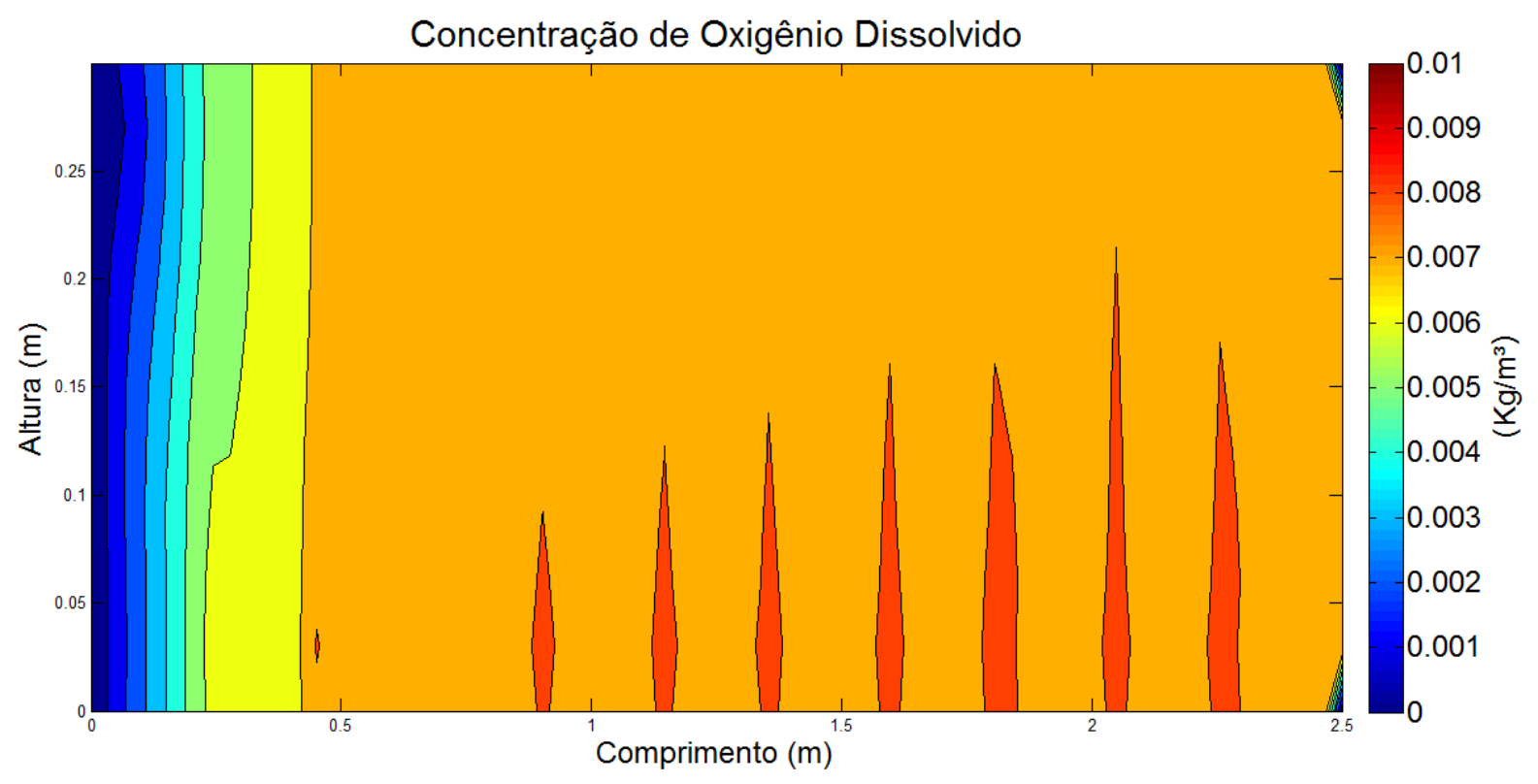

Figura 33 - Perfil da $\mathrm{C}_{\mathrm{OD}}\left(\mathrm{Kg} / \mathrm{m}^{3}\right)$ no tanque para 10 injetores dispostos igualmente entre si por aproximadamente 0,23m. Malha de 10x72. Tempo simulado:200 s. 
As Figuras 34 a 37 representam os perfis de $C_{O D}$ para 24 bicos injetores, com o valor $K_{L}$ igual a 0,012748804 (Tabela 1). Para a Figura 34, no instante inicial da simulação, percebe-se a presença dos 24 bicos injetores. Devido ao valor do coeficiente de transferência de massa, logo no primeiro segundo é possível perceber logo nas saídas dos injetores um valor levemente elevado para $C_{O D}$. Novamente as concentrações parecem estar espelhadas.

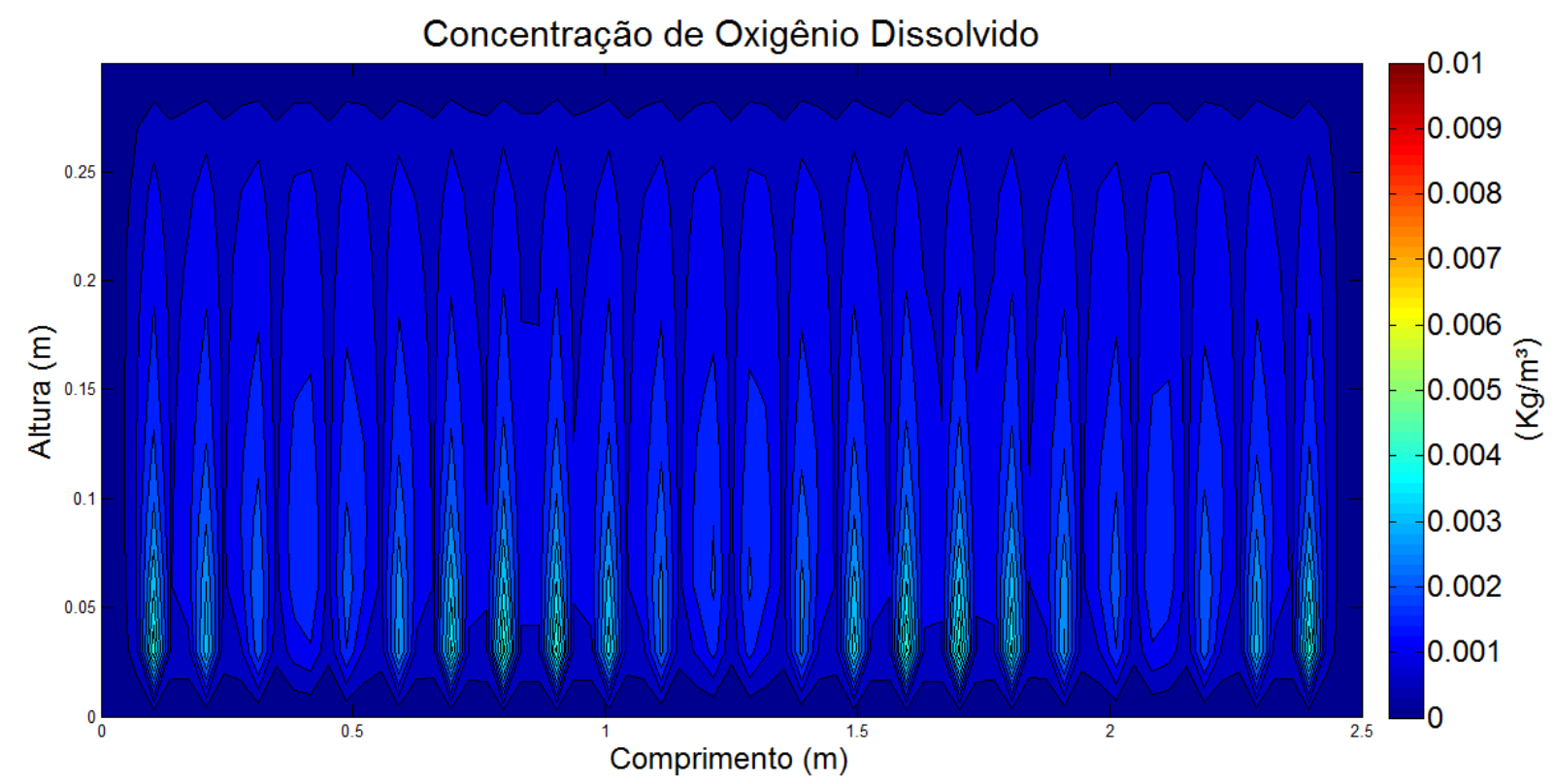

Figura 34 - Perfil da $\mathrm{C}_{\mathrm{OD}}\left(\mathrm{Kg} / \mathrm{m}^{3}\right)$ no tanque para 24 injetores dispostos igualmente entre si por aproximadamente 0,10m. Malha de 10x72. Tempo simulado: $1 \mathrm{~s}$.

As Figuras 35 e 36 apresentam a sequência do rápido aumento da $C_{O D}$ no tanque. Em apenas 10 segundos a concentração de OD passou de aproximadamente $0,002 \mathrm{Kg} / \mathrm{m}^{3}$ para $0,006 \mathrm{Kg} / \mathrm{m}^{3}$. 


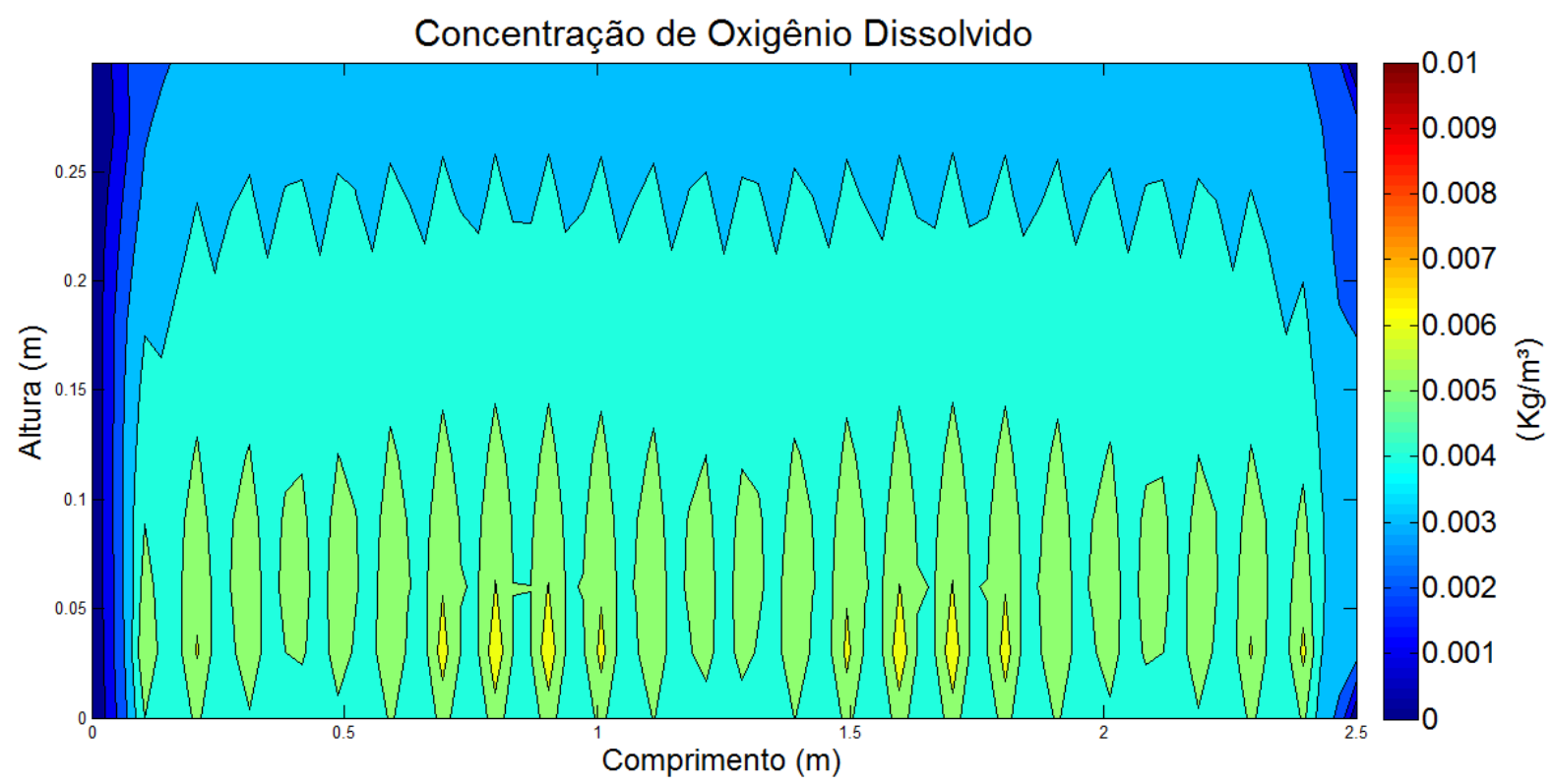

Figura 35 - Perfil da $\mathrm{C}_{\mathrm{OD}}\left(\mathrm{Kg} / \mathrm{m}^{3}\right)$ no tanque para 24 injetores dispostos igualmente entre si por aproximadamente $0,10 \mathrm{~m}$. Malha de 10x72. Tempo simulado: $5 \mathrm{~s}$.

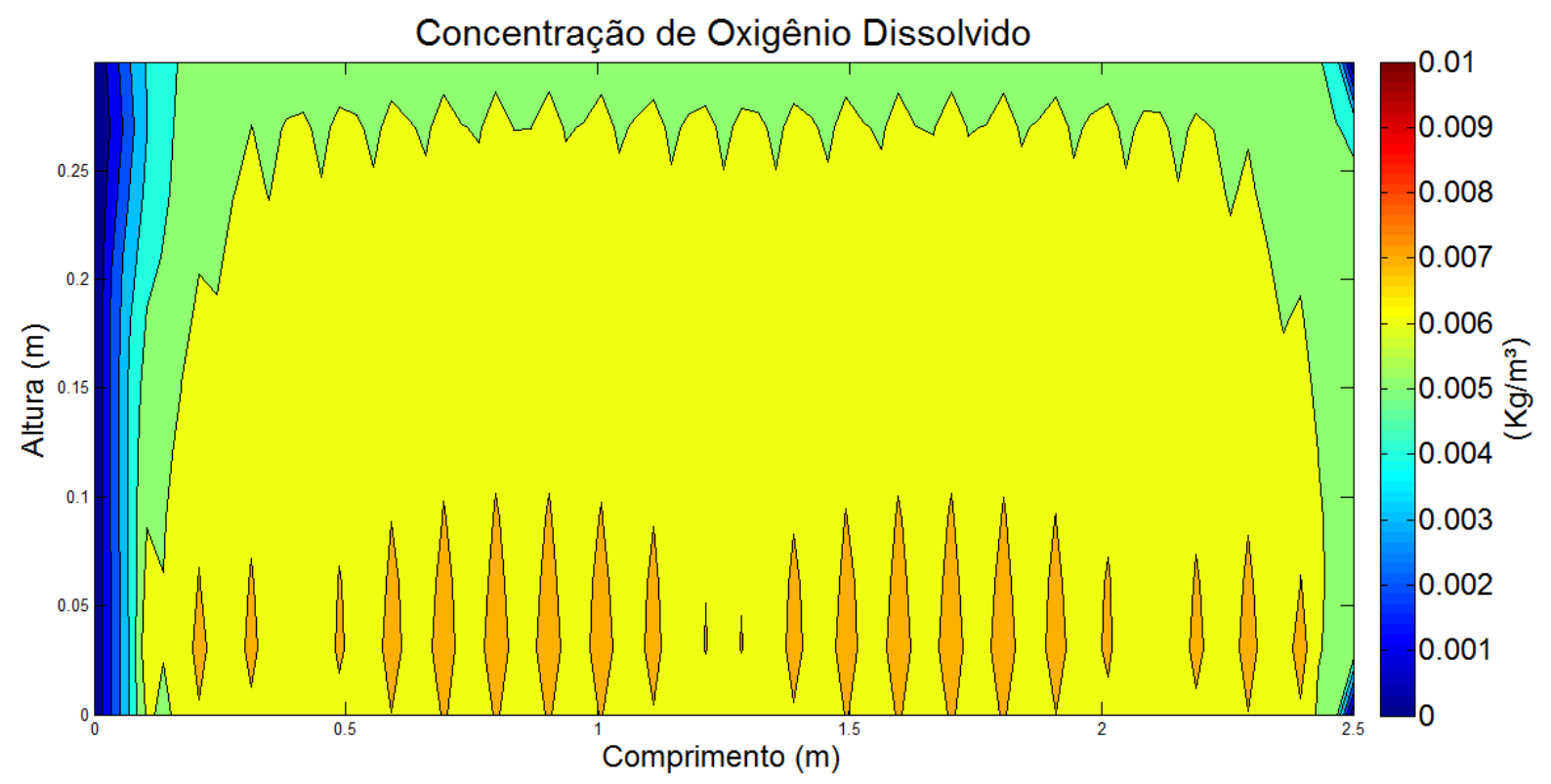

Figura 36 - Perfil da $\mathrm{C}_{\mathrm{OD}}\left(\mathrm{Kg} / \mathrm{m}^{3}\right)$ no tanque para 24 injetores dispostos igualmente entre si por aproximadamente $0,10 \mathrm{~m}$. Malha de 10x72. Tempo simulado: $10 \mathrm{~s}$. 
Por fim tem-se o perfil de concentração de OD para 24 injetores, com apenas 50 segundos simulados na Figura 37. Observa-se a concentração de saturação em praticamente todo o tanque e a clara percepção dos locais onde ocorrem as plumas de bolhas.

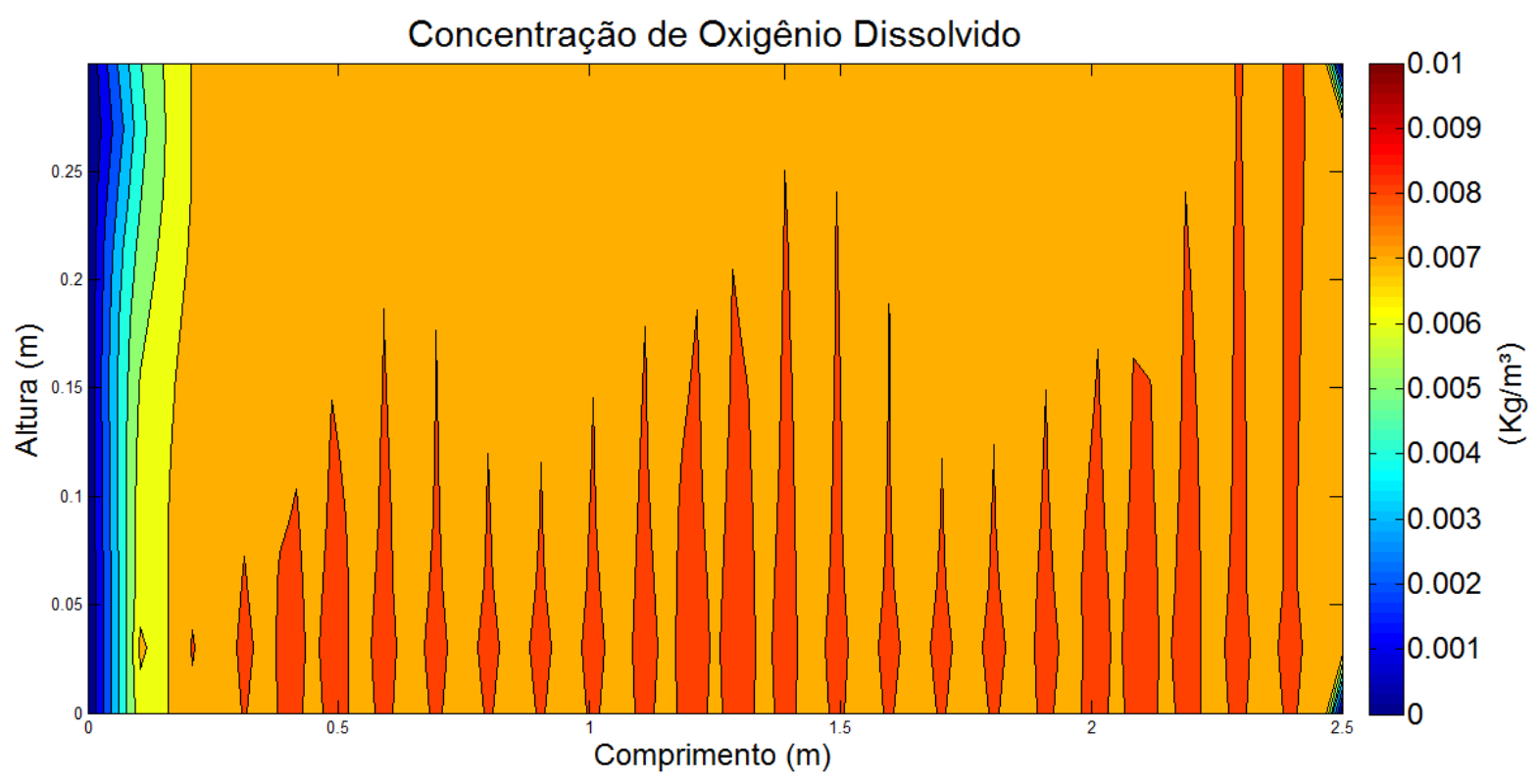

Figura 37 - Perfil da $\mathrm{C}_{\mathrm{OD}}\left(\mathrm{Kg} / \mathrm{m}^{3}\right)$ no tanque para 24 injetores dispostos igualmente entre si por aproximadamente $0,10 \mathrm{~m}$. Malha de 10x72. Tempo simulado: $50 \mathrm{~s}$. 


\section{CONCLUSÕES E RECOMENDAÇÕES}

O presente trabalho representou um estudo com o objetivo de obter um modelo simplificado que simulasse a transferência de oxigênio em sistema bifásico ar-água por meio de aeração forçada por bolhas. Assim, para o estudo necessitou-se entender o fenômeno ocorrido no processo e escolher as equações que pudessem ter uma correspondência aproximada à realidade do sistema. As conclusões obtidas são para as condições utilizadas neste trabalho, tais como equações, condições de contorno, simplificações e parâmetros adotados.

A equação de um perfil estacionário para concentração de bolhas, utilizando a equação da dispersão sugerida por Vuitik (2013) representou de forma satisfatória o perfil da pluma para os bicos injetores. As concentrações de bolhas foram maiores no eixo central da pluma, como já era esperado e foi se dispersando conforme a altura do tanque. Sabe-se também que a componente de velocidade $V_{x}$ do escoamento é a que mais interfere na dispersão das plumas em tanques.

A concentração de oxigênio dissolvido no tanque foi fortemente influenciada pelo coeficiente de transferência de massa $K_{L}$. Para um injetor somente este coeficiente foi bem baixo, resultando em uma baixa transferência de massa, pois mesmo com dois mil segundos simulados a concentração de oxigênio dissolvido no tanque foi bem baixa. Simulações para diferentes correlaçoes do $K_{L}$ seriam interessantes para verificar a se a concentração de OD se daria da mesma forma.

O método explícito MAC representou de maneira aceitável o sistema proposto, com as as regiões de entrada e saída de fluido bem explícitas nos resultados. As condições de contorno adotadas para parede não-escorregadia e superfície livre deram uma noção geral de como o fluido se comporta ao longo do escoamento.

O método de Crank-Nicolson para resolução da concentração de OD é aceita, pois os resultados apresentados concordam com o esperado, como: a transferência de massa é maior quando se tem um valor maior para o $K_{L}$; as maiores concentrações de OD foram verificadas nas posições dos bicos injetores, onde a fração de vazios foi mais elevada, havendo maior concentração de bolhas e, consequentemente, de OD e a componente de velocidade na direção $x$ interferiu no processo de transferência de massa, pois constantemente estava-se considerando entrada de fluido no tanque. 


\subsection{Trabalhos futuros}

Para trabalhos futuros a contribuição deste estudo sugere que:

1.Estudar mais a fundo o efeito da superposição de bolhas de modo que não ocorra o espelhamento das plumas;

2. Incorporar nos cálculos de dispersão de bolhas, em tanques, a componente da velocidade no sentido do escoamento, pois ela influenciará no perfil de dispersão da pluma gaussiana;

3. Realizar simulações para diferentes correlações do $K_{L}$;

4. Comparar o método com dados experimentais para validar a simulação e fazer os ajustes necessários;

5. Realizar simulações com uma malha mais refinada para obter resultados que melhor representem o domínio. 


\section{REFERÊNCIAS BIBLIOGRÁFICAS}

BOUAIFI, M. et al. A comparative study of gas hold-up, bubble size, interfacial area and mass transfer coefficients in stirred gas-liquid reactors and bubble columns. Chemical Engineering and Processing, v.40, p.97-111, 2001.

CONGRESSO BRASILEIRO DE ENG ${ }^{\text {a }}$ SANITÁRIA E AMBIENTAL, 21, 2001, João Pessoa, PA. Afinal, qual é melhor, aeração mecânica ou aeração por ar difuso em estações de tratamento de esgotos. O caso de Jundiaí - SP (Anais). 2001. 6p.

DIONÍSIO, R. P. Simulação tridimensional de uma coluna de bolhas - Diferentes abordagens geométricas e modelagem. Campinas: Universidade Estadual, 2008. 79 p.

EKAMBARA, K; DHOTRE, M. T.; JOSHI, J. B. CFD simulations of bubble column reactors: 1D, 2D ad 3D approach. Chemical Engineering Science, v. 60, p. 6733-6746, 2005.

EKAMBARA, K.; JOSHI, J. B. CFD simulation of mixing and dispersion in bubble column. Chemical Engineering Research and Design, v. 81, p. 987-1002, set. 2003a.

EKAMBARA, K.; JOSHI, J. B. CFD simulations of residence time distribution and mixing in bubble column reactors. Canadian Journal of Chemical Engineering, v. 81, p. 669-676, jun. 2003b.

FORTUNA, A. O. Técnicas computacionais para dinâmica dos fluidos: Conceitos básicos e aplicações. São Paulo: Edusp, 2000. 426 p. ISBN 85-314-0526-2.

BIRD, R. B; STEWART, W. E.; LIGHTFOOT, E, N. Transport Phenomena. $2^{\text {nd }}$ edition. John Wiley \& Sons, 2006. 905 p. ISBN 0470115394.

GRIEBEL, M.; DORNSEIFER, T.; NEUNHOEFFER, T. Numerical simulation fluid dynamics. Filadélfia, Society for Industrial and Applied Mathematics (SIAM), 1998.

HARLOW, F. H., WELCH, J. E. Numerical Calculation of Time-Dependent Viscous Incompressible Flow of Fluid with Free Surface. Physics of Fluids, v.8, p. 2182-2189, dez. 1965.

HIKITA, H., et al. Heat transfer coefficient in bubble column. Industrial and Engineering Chemistry Process Design and Development, v.20, n.3, p.540-545, 1981. 
HIRT, C. W. Simplified Solution Algorithms for Fluid Flow Problems. Numerical methods for partial differential equations, San Diego, Academic Press, p. 193-211, 1979.

HIRT, C. W.; NICHOLS, B. D.; ROMERO, N. C. SOLA - A numerical solution algorithm for transient fluid flows. Loas Alamos Scientific Report LA-5852, 1975

HORVATH, A., et al. CFD simulation of bubble columns using the VOF model - comparison of commercial and open source with an experiment. Chemical Engineering Transactions, v. 18, p. 605-610, 2009.

JAKOBSEN, H. A., et al. Modelling of vertical bubble-driven flows. Industrial and Engineering Chemistry Research, v. 36, p. 4052-4074, out. 1997.

JOSHI, J. B. Computational flow modelling and design of bubble column reactors. Chemical Engineering Science, v. 56, p. 5893-5933, nov. 2001.

LEWIS, W.K.; WHITMAN, W.G. Principles of gas absorption. Industrial and Engineering Chemistry, v.16, n.12, p.825-833, 1924.

MOCROSKY, J. F. Potencialidades da dinâmica dos fluidos computacional em projetos mecânicos. Curitiba: Universidade Tecnológica Federal do Paraná, 97 p., 2007.

MALISKA, C. R. Transferência de calor e mecânica dos fluidos computacional. 2 ed. Rio de Janeiro: LTC, 2004. 453 p. ISBN 85-216-1396-2.

OISHI, C. M. Análise e implementação de métodos implícitos e de projeção para escoamentos com superfície livre. Tese (Doutorado). Instituto de Ciências Matemáticas e de Computação. Universidade de São Paulo, São Carlos, 2008.152p.

OLIVEIRA, A. B. F. Análise da dispersão turbulenta em aeração de corpos hídricos usando a técnica PIV (velocimetria por imagem de partículas). Dissertação (Mestrado). São Carlos: Escola de Engenharia de São Carlos, Universidade de São Paulo, 2008. 59p.

PAINMANAKUL P., et al. Theoretical prediction of volumetric mass transfer coefficient (kLa) for designing an aeration tank. Engineering Journal, 13(3), 13-28, doi: 10.4186/ej.2009.13.3.13, 2009.

PATANKAR, S. V.; SPALDING, D. B. A calculation procedure for heat, mass and momentum transfer in three-dimensional parabolic flows. International Journal of Heat and Mass Transfer, v. 15, 1787-1806, out. 1972. 
ROMA, W.N.L. Fenômenos de transporte para engenharia. $2^{a}$ ed. São Carlos: RIMA, 2006.

SALLA, M. R. Sistema de ozonização em esgoto de reator anaeróbio: Estudo da hidrodinâmica e das respostas oscilantes de DQO. Tese (Doutorado). São Carlos: Escola de Engenharia de São Carlos, Universidade de São Paulo, 2006. 446p.

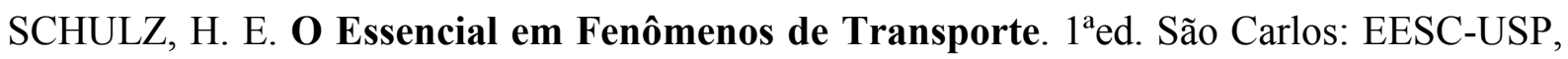
2003.

SIMIANO, M. Experimental investigation of large-scale three dimensional bubble plume dynamics. Tese de Doutorado, Instituto Federal de Tecnologia de Zurique: Suíça, 2005. $104 p$.

SOKOLICHIN, A.; EIGENBERGER, G.; LAPIN, A. Simulation of buoyancy driven bubbly flow: established simplifications and open questions. American Institute of Chemical Engineering Journal, v. 50, p. 24-45, jan. 2004.

STEWART, H. B.; WENDROFF, B. Two-phase flow models and methods. Journal of Computer Physics, v. 56, p. 363-409, 1984.

UNIVERSIDADE DE WATERLOO. Disponível em $<$ http://www.mhtl.uwaterloo.ca/properties.html>. Acesso em: 18 mar. 2013.

VITANKAR, V. S.; DHOTRE, M. T.; JOSHI, J.B. A low Reynolds number k- $\varepsilon$ model for the prediction of flow pattern and pressure drop in bubble column reactors. Chemical Engineering Science, v. 57, p. 3235-3250, ago. 2002.

VUITIK, G. A. Estudo de parâmetros envolvidos na transferência de oxigênio em meio hídrico aerado por bolhas. Dissertação de Mestrado, Escola de Engenharia de São Carlos: São Carlos, 2013, 149 p.

WESSELING, P. An introduction to multigrid methods. Chichester: John Wiley \& Sons, 1992, $284 \mathrm{p}$. 
APÊNDICE - Programação MATLAB 
clear;
clc;
clf;

$\mathrm{NX}=72$;

- Número de células em x, inclusive células dos contornos.

$\mathrm{NY}=10$;

$\mathrm{L}=2.5$;

Número de células em y, inclusive células dos contornos.

$\mathrm{H}=0.30$;

- Largura do tanque.

visc $=0.001$;

\% Altura do tanque.

dens $=1000$;

\% Viscosidade cinemática turbulenta do fluido.

deltax $=\mathrm{L} / \mathrm{NX}$;

- Densidade do fluido.

deltay $=\mathrm{H} / \mathrm{NY}$;

- Largura da célula discreta.

o Altura da célula discreta.

beta $=\left(\operatorname{deltax}{ }^{*} \operatorname{deltax}\right) /(\operatorname{deltay} \operatorname{deltay})$;

omeg=1.5; \% (Sobre-relaxação $1<=$ omeg (tentativa) $<2, \quad$ sub-relaxação $0<0$ meg<1) deltat $=0.0006$;

$\operatorname{tmax}=575$;

$\mathrm{u}=\operatorname{zeros}(\mathrm{NY}, \mathrm{NX})$;

$\mathrm{V}=\mathrm{zeros}(\mathrm{NY}, \mathrm{NX})$;

$\mathrm{p}=\operatorname{zeros}(\mathrm{NY}, \mathrm{NX})$;

$\mathrm{F}=\operatorname{zeros}(\mathrm{NY}, \mathrm{NX})$;

$\mathrm{G}=\operatorname{zeros}(\mathrm{NY}, \mathrm{NX})$;

umx $=$ zeros $(\mathrm{NY}, \mathrm{NX})$;

$\mathrm{Pe}=\mathrm{zerOs}(\mathrm{NY}, \mathrm{NX})$;

fat $=$ zeros $(N Y, N X)$;

$\mathrm{S}=$ zeros (NY, NX) ;

upx $=\operatorname{zeros}(\mathrm{NY}, \mathrm{NX})$;

$\mathrm{udcX}=\operatorname{zeros}(\mathrm{NY}, \mathrm{NX})$;

uix=zeros (NY,NX);

$\mathrm{CONV1}=\operatorname{zeros}(\mathrm{NY}, \mathrm{NX})$;

$\mathrm{vm}=\operatorname{zeros}(\mathrm{NY}, \mathrm{NX})$;

umy $=$ zeros $(N Y, N X)$;

upy=zeros $(N Y, N X)$;

udcy $=\operatorname{zeros}(\mathrm{NY}, \mathrm{NX})$;

ui $\mathrm{y}=\operatorname{zeros}(\mathrm{NY}, \mathrm{NX})$;

CONV2=zeros (NY, NX) ;

$\mathrm{CONVX}=$ zeros $(\mathrm{NY}, \mathrm{NX})$;

$\operatorname{VISC} 1=\operatorname{zeros}(\mathrm{NY}, \mathrm{NX})$;

$\operatorname{VISC} 2=\operatorname{zeros}(\mathrm{NY}, \mathrm{NX})$;

$\mathrm{VISCX}=\operatorname{zeros}(\mathrm{NY}, \mathrm{NX})$;

$\mathrm{vmy}=\mathrm{zeros}(\mathrm{NY}, \mathrm{NX})$;

$\mathrm{vpY}=\mathrm{zeros}(\mathrm{NY}, \mathrm{NX})$;

$\mathrm{vdcy}=\operatorname{zeros}(\mathrm{NY}, \mathrm{NX})$;

viY=zeros (NY, NX) ;

$\mathrm{um}=\operatorname{zeros}(\mathrm{NY}, \mathrm{NX})$;

$\operatorname{vmx}=\operatorname{zeros}(\mathrm{NY}, \mathrm{NX})$;

$\operatorname{vpx}=\operatorname{zeros}(\mathrm{NY}, \mathrm{NX})$;

$\operatorname{vdcx}=\operatorname{zeros}(\mathrm{NY}, \mathrm{NX})$;

vix=zeros (NY, NX) ;

CONVY=zeros $(\mathrm{NY}, \mathrm{NX})$;

VISCY=zeros (NY, NX);

$\mathrm{bf}=\operatorname{zeros}(\mathrm{NY}, \mathrm{NX})$;

$\mathrm{b}=\operatorname{zeros}(\mathrm{NY}, \mathrm{NX})$;

$\mathrm{pn}=\mathrm{zeros}(\mathrm{NY}, \mathrm{NX})$;

$\mathrm{R}=$ zeros $(\mathrm{NY}, \mathrm{NX})$;

umed=zeros (NY, NX) ;

vmed=zeros (NY, NX) ;

upos=zeros (NY,NX);

vpos $=\operatorname{zeros}(\mathrm{NY}, \mathrm{NX})$; 


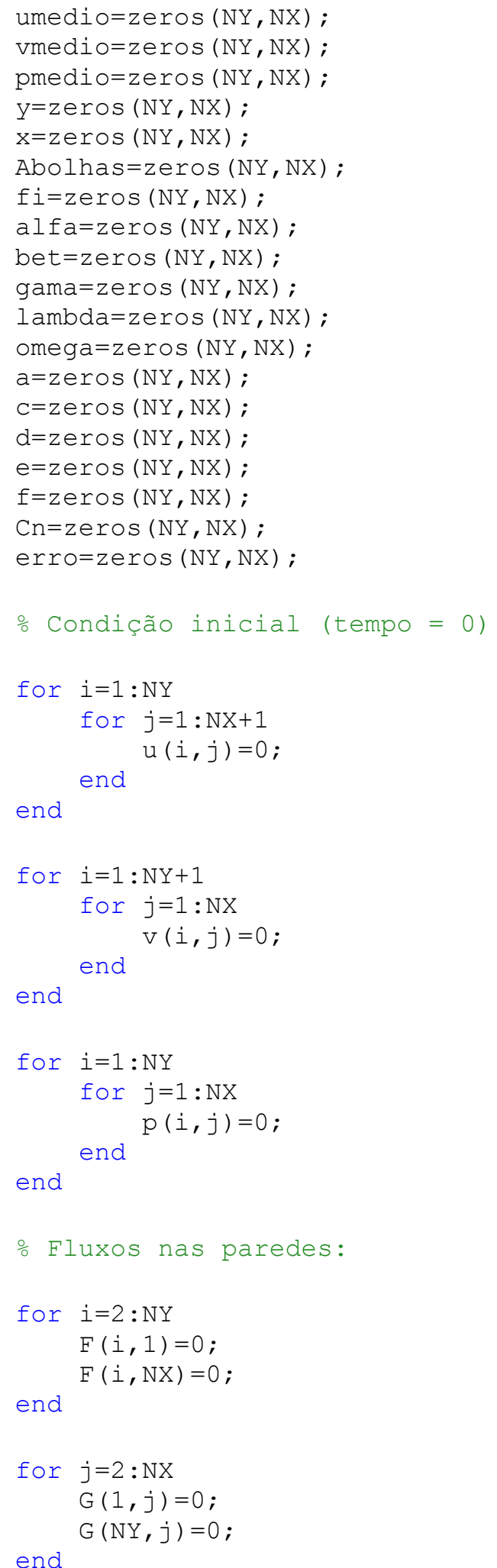

LOOPING TEMPORAL:

for $k t=1: t m a x$

$k t$ 


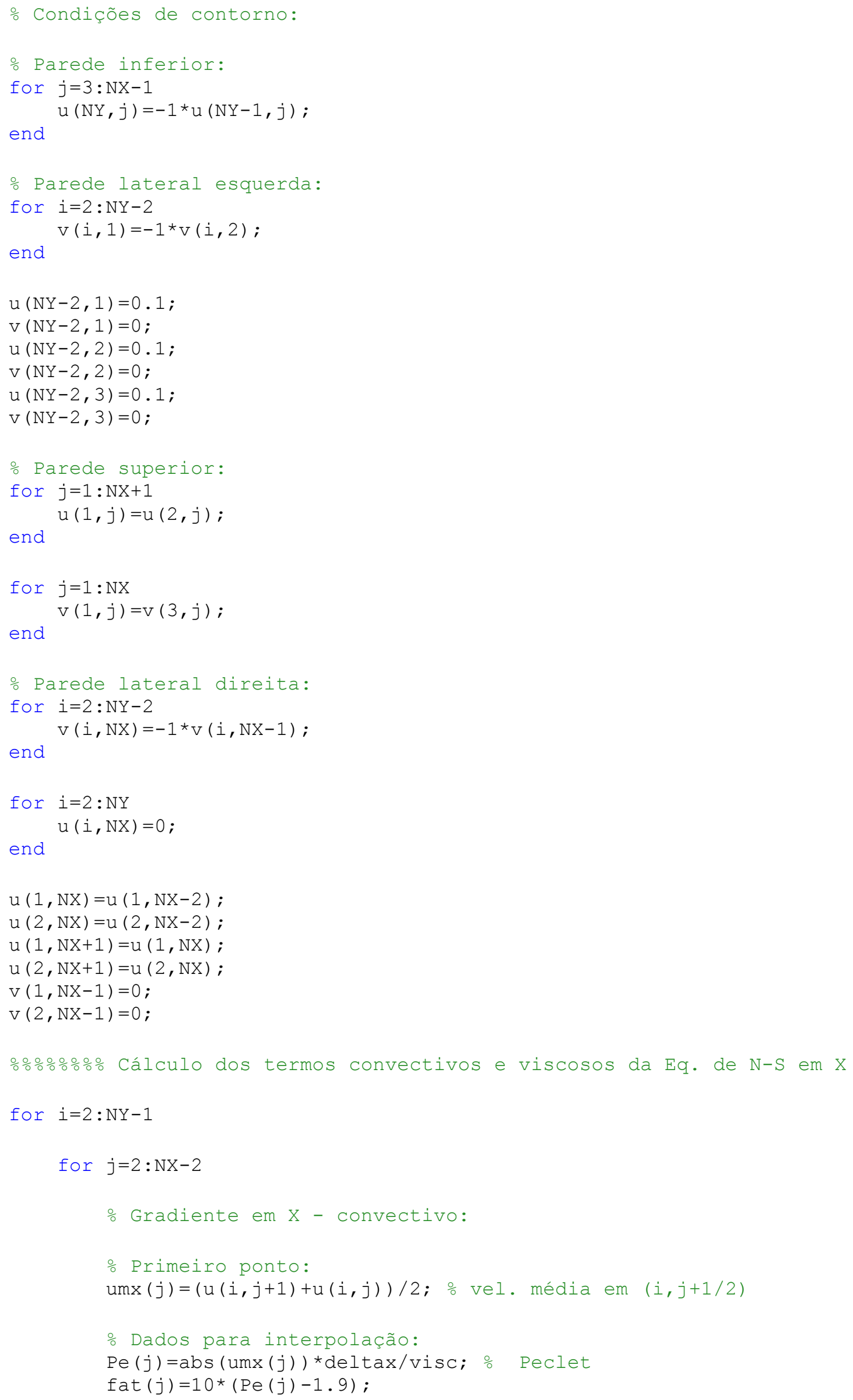




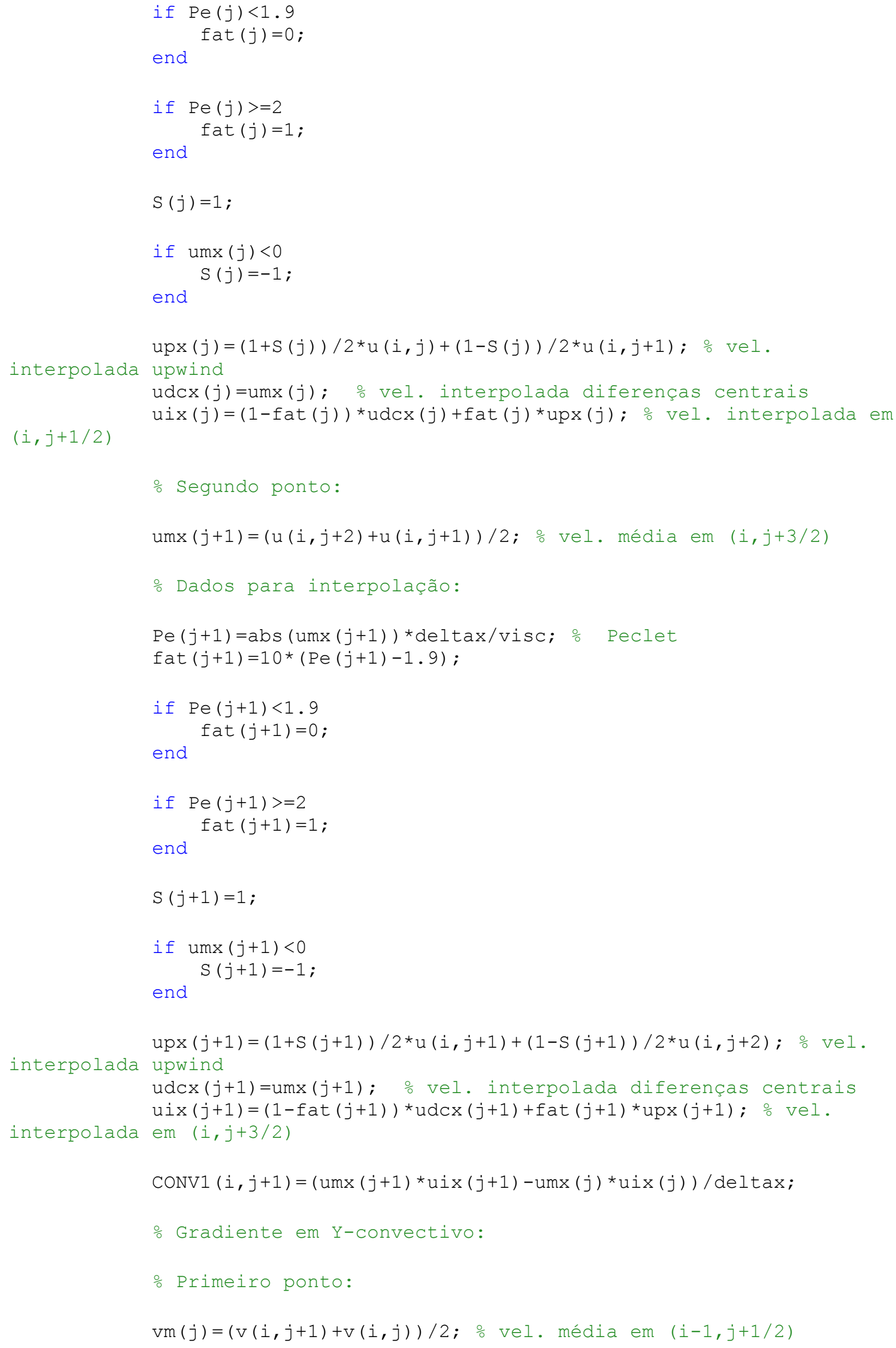


o Dados para interpolação:

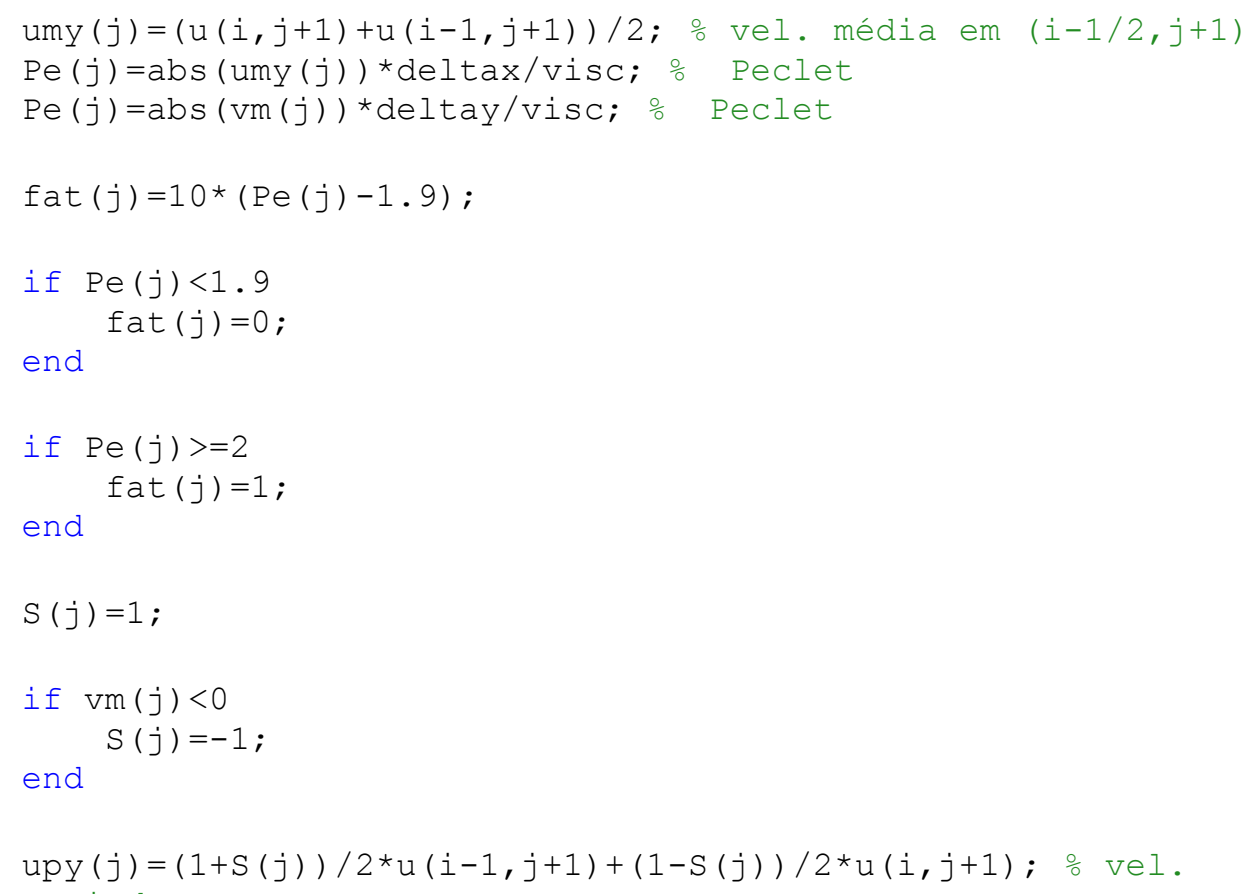
interpolada upwind

udcy $(j)=u m y(j) ; \quad$ vel. interpolada diferenças centrais $(i-1 / 2, j+1 / 2)$ $\operatorname{uiy}(j)=(1-f a t(j)) * u d c y(j)+f a t(j) * u p y(j) ; \%$ vel. interpolada em

응 Segundo ponto:

$\operatorname{vm}(j+1)=(v(i+1, j+1)+v(i+1, j)) / 2 ;$ vel. média em $(i, j+1 / 2)$

- Dados para interpolação:

$\operatorname{umy}(j+1)=(u(i+1, j+1)+u(i, j+1)) / 2$; $\frac{o}{\circ}$ vel. média em $(i+1 / 2, j+1)$ $\operatorname{Pe}(j+1)=\operatorname{abs}($ umy $(j+1)) *$ deltax/visc; $\%$ Peclet

Pe $(j+1)=\operatorname{abs}(\operatorname{vm}(j+1)) *$ deltay/visc; $\%$ Peclet

fat $(j+1)=10 *(\operatorname{Pe}(j+1)-1.9)$;

if $\operatorname{Pe}(j+1)<1.9$

end

end

$S(j+1)=1$

if $\operatorname{vm}(j+1)<0$

end

$S(j+1)=-1$

$\operatorname{upy}(j+1)=(1+S(j+1)) / 2 * u(i, j+1)+(1-S(j+1)) / 2 * u(i+1, j+1) ; \quad$ vel. interpolada upwind $\operatorname{udcy}(j+1)=\operatorname{umy}(j+1) ; \quad$ vel. interpolada diferenças centrais 
$\operatorname{uiy}(j+1)=(1-f a t(j+1)) * u d c y(j+1)+f a t(j+1) * u p y(j+1) ; \% \operatorname{vel}$.

interpolada em $(i+1 / 2, j+1 / 2)$

$\operatorname{CoNv2}(i, j+1)=(\operatorname{vm}(j+1) * u i y(j+1)-\operatorname{vm}(j) * u i y(j)) / \operatorname{deltay}$

ㅇ Conveç̧ão de Q.M. total:

$\operatorname{ConVX}(i, j+1)=\operatorname{CoNV} 1(i, j+1)+\operatorname{CoNV} 2(i, j+1)$;

을 Divergente em X - Viscoso:

$\operatorname{vISC} 1(i, j+1)=\operatorname{visc} *(u(i, j)-2 * u(i, j+1)+u(i, j+2)) / \operatorname{deltax} / \operatorname{del} t a x$;

응 Divergente em Y - Viscoso:

$\operatorname{vISC} 2(i, j+1)=v i s c *(u(i+1, j+1)-2 * u(i, j+1)+u(i-$

$1, j+1)$ ) /deltay/deltay;

\% Difusão de Q.M. total:

$\operatorname{VISCX}(i, j+1)=\operatorname{VISC} 1(i, j+1)+\operatorname{VISC} 2(i, j+1)$;

$\circ$ Fluxo $\mathrm{F}$

$F(i, j+1)=u(i, j+1)+\operatorname{deltat} *(\operatorname{VISCX}(i, j+1)-\operatorname{CoNVX}(i, j+1)) ;$ end

end

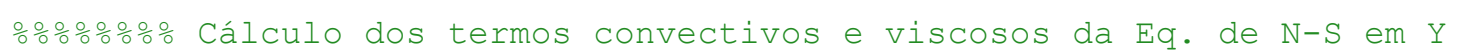

for $j=2: N X-1$

for $i=2: N Y-2$

응 Gradiente em Y - convectivo:

\% Primeiro ponto:

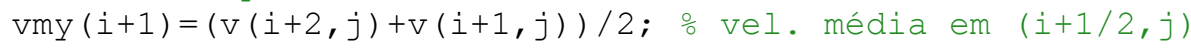

\% Dados para interpolação:

$\operatorname{Pe}(i+1)=\operatorname{abs}(\operatorname{vmy}(i+1)) *$ deltay/visc; $\%$ Peclet

fat $(i+1)=10 *(\operatorname{Pe}(i+1)-1.9)$;

if $\operatorname{Pe}(i+1)<1.9$

fat $(i+1)=0$;

end

if $\mathrm{Pe}(i+1)>=2$

fat $(i+1)=1$;

end

$S(i+1)=1 ;$

if $\operatorname{vmy}(i+1)<0$

$S(i+1)=-1$;

end

interpolada upwind

$\operatorname{vpy}(i+1)=(1+S(i+1)) / 2 \star^{*}(i+1, j)+(1-S(i+1)) / 2 \star v(i+2, j) ; \quad$ vel. $\operatorname{vdcy}(i+1)=\operatorname{vmy}(i+1) ; \quad$ vel. interpolada diferenças centrais $\operatorname{viy}(i+1)=(1-f a t(i+1)){ }^{*} \operatorname{vdcy}(i+1)+f a t(i+1) * \operatorname{vpy}(i+1) ; \% \operatorname{vel}$

interpolada em $(i+1 / 2, j)$

ㅇ Segundo ponto: 


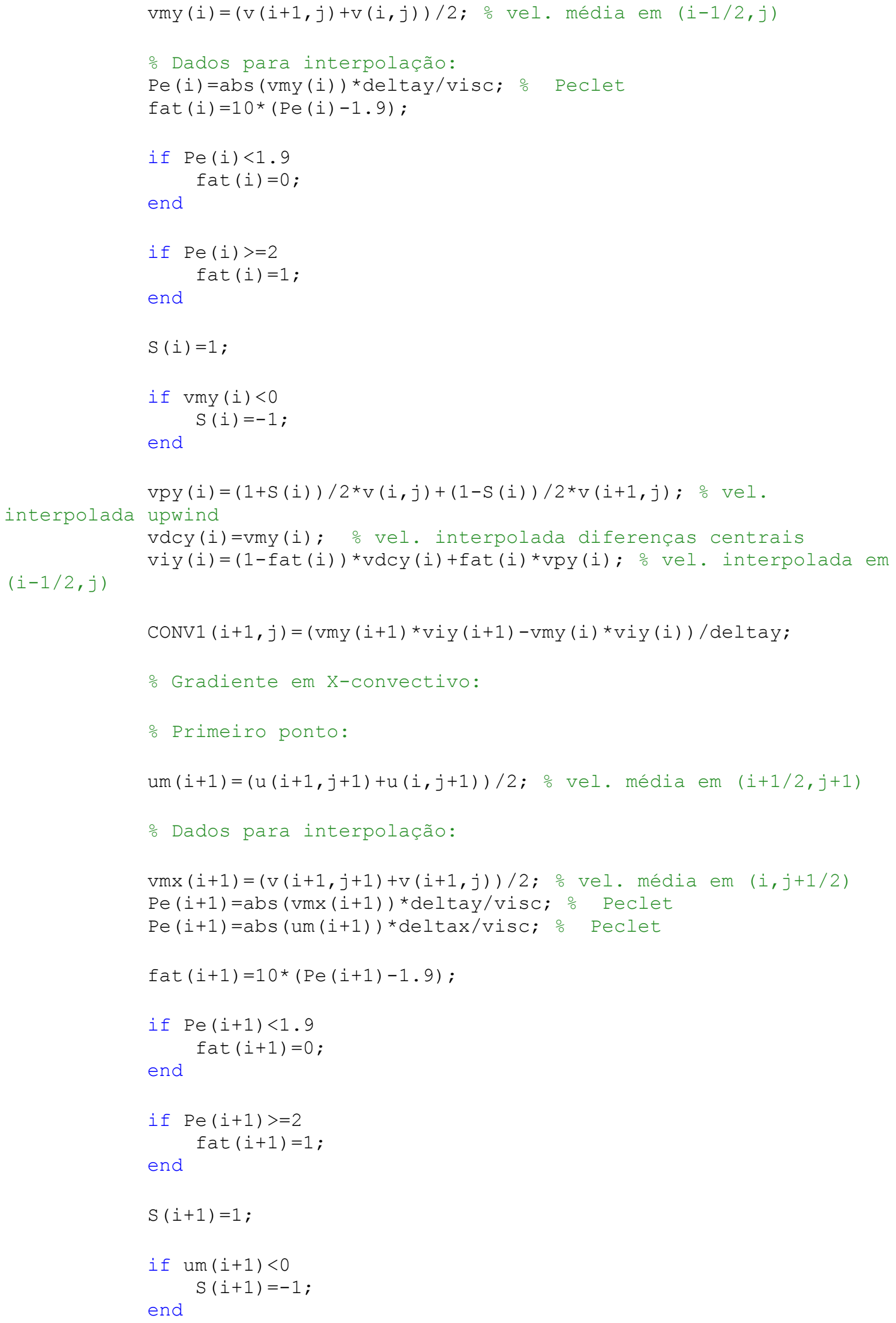




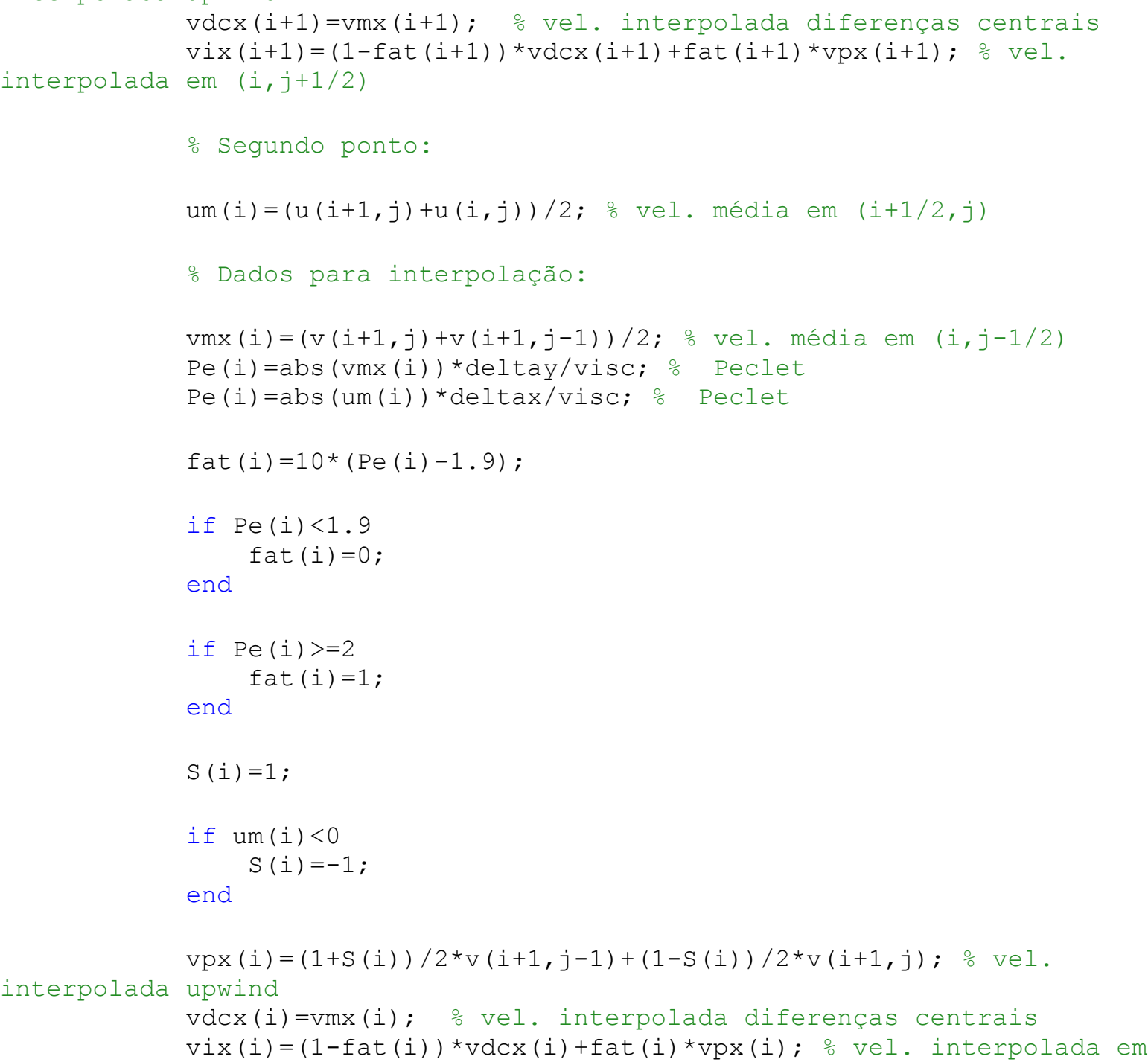

$\operatorname{vdcx}(i+1)=\operatorname{vmx}(i+1) ; \quad$ vel. interpolada diferenças centrais $\operatorname{vix}(i+1)=(1-f a t(i+1)){ }^{*} \operatorname{vdcx}(i+1)+f a t(i+1){ }^{*} \operatorname{vpx}(i+1)$; $\frac{\circ}{0} \operatorname{vel}$

- Segundo ponto:

$u m(i)=(u(i+1, j)+u(i, j)) / 2$; $\frac{0}{v}$. média em $(i+1 / 2, j)$

$\operatorname{vmx}(i)=(v(i+1, j)+v(i+1, j-1)) / 2$; $\frac{\circ}{v} \operatorname{vel}$. média em $(i, j-1 / 2)$

$\operatorname{Pe}(i)=a b s(\operatorname{vmx}(i)) *$ deltay/visc; $\%$ Peclet

fat $(i)=10 *(\operatorname{Pe}(i)-1.9)$;

if $\mathrm{Pe}(\mathrm{i})<1.9$

end

if $\operatorname{Pe}(i)>=2$

end

$S(i)=1$;

end

$\operatorname{vix}(i)=(1-f a t(i)){ }^{*} \operatorname{vdcx}(i)+f a t(i) * \operatorname{vpx}(i) ; \% \operatorname{vel}$. interpolada em $(i, j-1 / 2)$

$\operatorname{vpx}(i+1)=(1+S(i+1)) / 2{ }^{*} \operatorname{v}(i+1, j)+(1-S(i+1)) / 2{ }^{\star} v(i+1, j+1) ; \quad$ vel upwind

$\operatorname{CONV} 2(i+1, j)=\left(u m(i+1){ }^{*} \operatorname{vix}(i+1)-u m(i){ }^{\prime} \operatorname{vix}(i)\right) / \operatorname{deltax}$;

oConveç̧ão de Q.M. total:

$\operatorname{CONVY}(i+1, j)=\operatorname{CONV} 1(i+1, j)+\operatorname{CONV} 2(i+1, j)$;

ㅁ Divergente em X - Viscoso:

$\operatorname{VISC} 1(i+1, j)=\operatorname{visc} *\left(v(i, j)-2{ }^{*}(i+1, j)+v(i+2, j)\right) /$ deltay/deltay;

\% Divergente em Y - Viscoso:

$\operatorname{VISC} 2(i+1, j)=\operatorname{visc} *(v(i+1, j-1)-$

$\left.2{ }^{*} v(i+1, j)+v(i+1, j+1)\right) /$ deltax/deltax;

․ Difusão de Q.M. total:

$\operatorname{VISCY}(i+1, j)=\operatorname{VISC} 1(i+1, j)+\operatorname{VISC} 2(i+1, j)$;

디의 G

$G(i+1, j)=V(i+1, j)+\operatorname{deltat} *(\operatorname{VISCY}(i+1, j)-\operatorname{CONVY}(i+1, j))$; end

end 


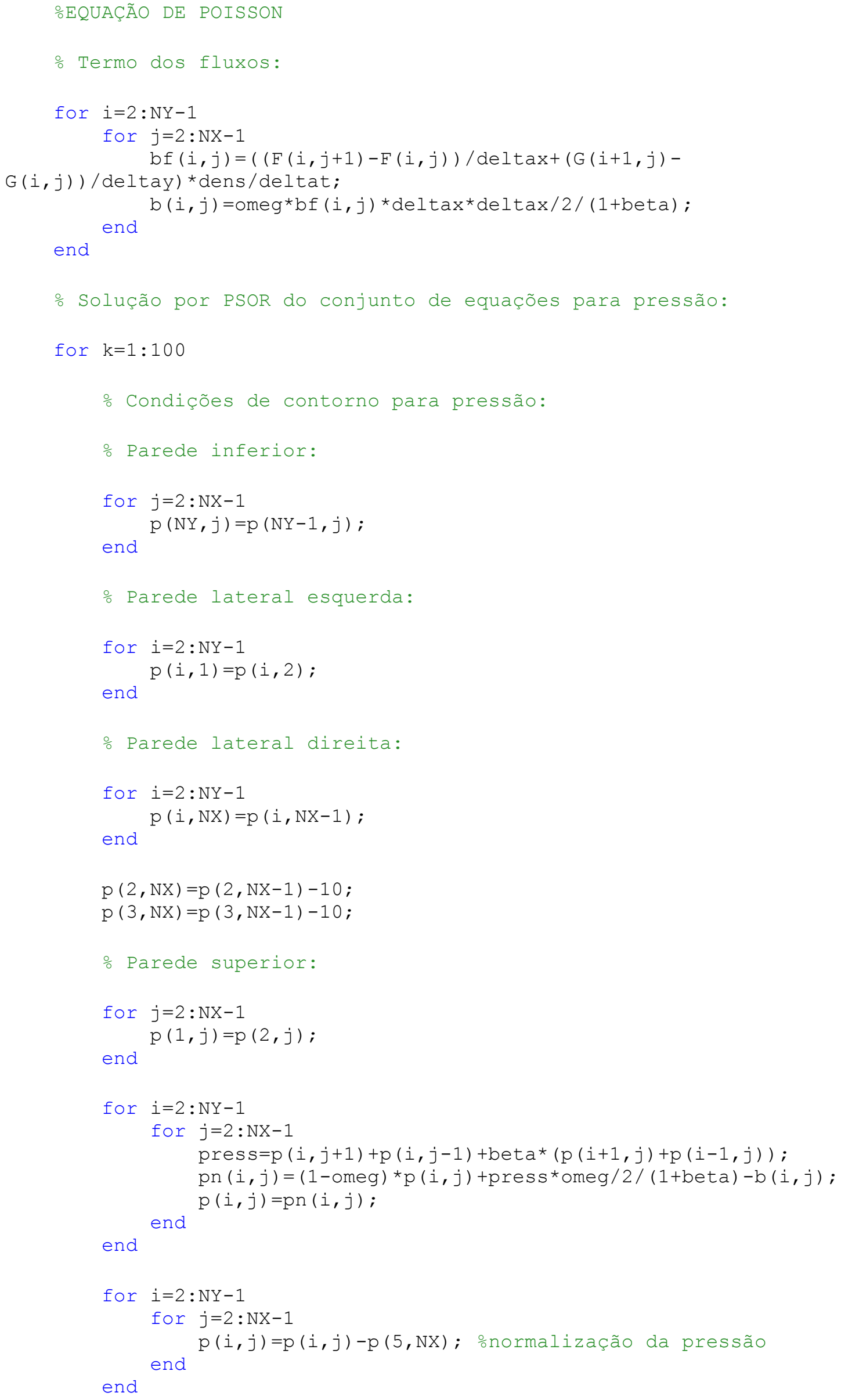


o Critério de parada: norma euclidiana do resíduo ||$R||$ :

$\mathrm{add}=0$;

for $i=2: N Y-1$

for $j=2: N X-1$

termo $1=\mathrm{p}(i+1, j)-2 * \mathrm{p}(i, j)+\mathrm{p}(i-1, j)$;

termo2 $=\mathrm{p}(i, j+1)-2 * \mathrm{p}(i, j)+\mathrm{p}(i, j-1)$;

$R(i, j)=b f(i, j)$-termo1/deltay/deltay-termo2/deltax/deltax; end $\operatorname{add}=\operatorname{add}+R(i, j) * R(i, j)$;

end

$\mathrm{NRE}=\mathrm{add}^{\wedge} 0.5$

if $\mathrm{NRE}<=1 \mathrm{e}-08$

break;

end

end

\% Cálculo do novo perfil de velocidades:

for $i=2: N Y-1$

for $j=2: N X-2$

$u(i, j+1)=F(i, j+1)-(p(i, j+1)-p(i, j)) *$ deltat/dens/deltax;

end

end

for $i=2: N Y-2$

for $j=2: N X-1$

$v(i+1, j)=G(i+1, j)-(p(i+1, j)-p(i, j))$ *deltat/dens/deltay; end

end

- Critério para o intervalo de tempo:

$\mathrm{xdumax}=\operatorname{deltax} / \max (\max (\operatorname{abs}(u)))$;

ydvmax $=$ del tay $/ \max (\max (\operatorname{abs}(v)))$;

deltat $1=0.99 * \min ([\mathrm{xdumax}, \mathrm{ydvmax}])$;

deltat $2=(0.99 / 2 /$ visc $) /(1 /$ deltax $/$ deltax $+1 /$ deltay/deltay $)$;

deltat=min $([$ deltat1, deltat2] $)$

for $i=2: N Y-1$

for $j=2: N X-1$

umed $(i-1, j-1)=(u(i, j)+u(i, j+1)) / 2$;

$\operatorname{vmed}(i-1, j-1)=-(v(i, j)+v(i+1, j)) / 2$;

upos $(i-1, j-1)=i-1$;

end

$\operatorname{vpos}(i-1, j-1)=j-1$;

end

for $i=1: N Y-2$

for $j=1: N X-2$

umedio $(N Y-1-i, j)=\operatorname{umed}(i, j)$;

vmedio $(\mathrm{NY}-1-i, j)=\operatorname{vmed}(i, j)$;

pmedio $(N Y-1-i, j)=p(i, j)$;

end 
end

oquiver (umedio, vmedio); hold on;

ocontourf (pmedio, 50); hold on;

oquiver(umedio, vmedio); hold on;

ocolorbar;

ohold on;

opause $(0.1)$;

ohold off;

end

\% Cálculo do perfil de concentrações de oxigênio dissolvido em um tanque aerado com bolhas

$\mathrm{EDP}$ :

$d(f \cdot C) / d t+V x \cdot d(f \cdot C) / d x+V y \cdot d(f \cdot C) / d y=D t x(d 2(f \cdot C) / d y 2)+D t y(d 2(f \cdot C) / d y)+k \cdot a \cdot(C$ $\mathrm{s}-\mathrm{C})$

o f é a fração de líquido

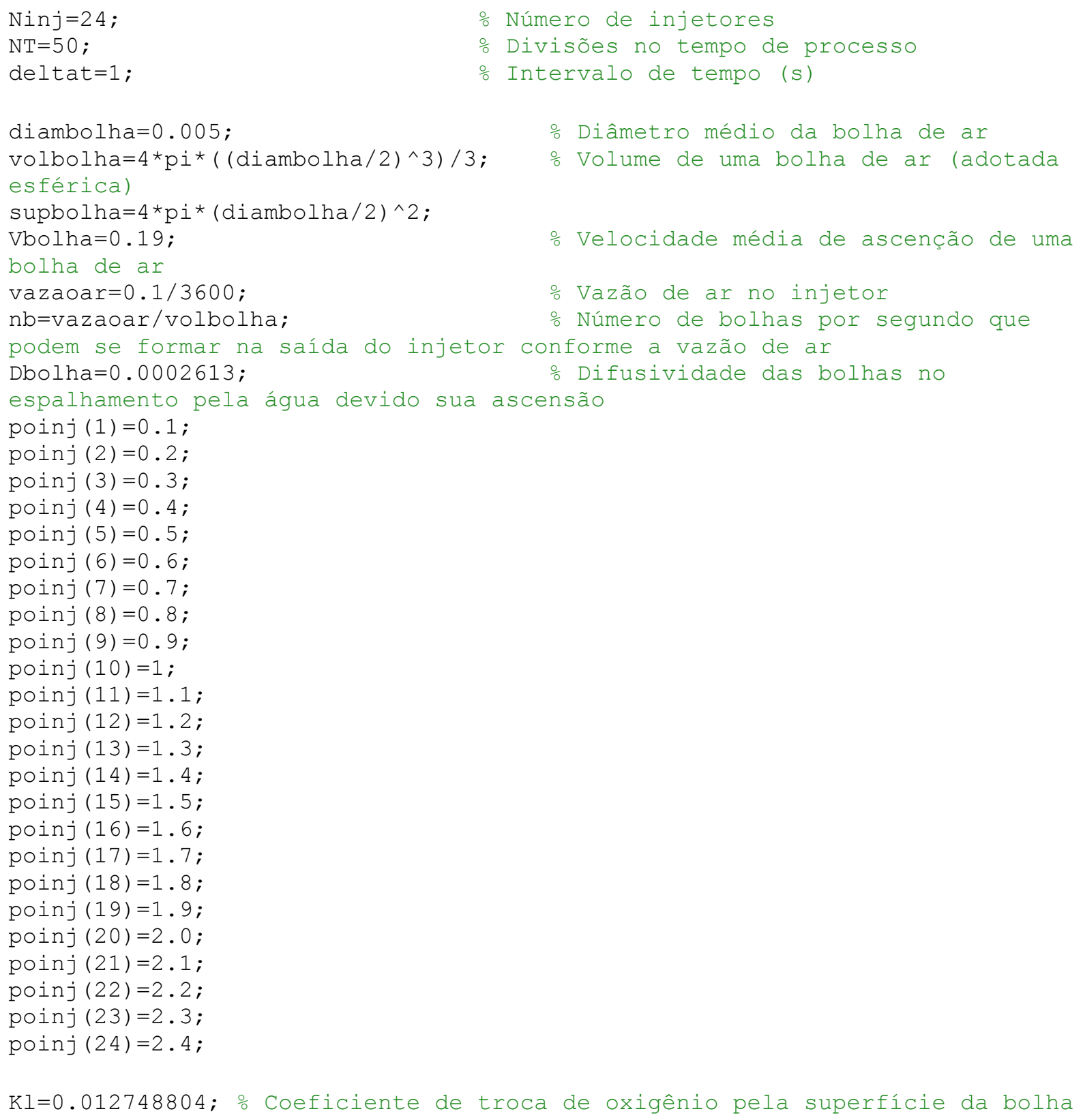


Cs=0.008; $\quad$ o Concentração de oxigênio dissolvido saturado a $\mathrm{T}$ ambiente de $250 \mathrm{C}$ ( $\mathrm{Kg}$ de Ox./m3 de água)

Dtx $=$ visc;

\% Difusividade turbulenta em X;

Dty $=\mathrm{visc}$;

- Difusividade turbulenta em Y;

$\mathrm{Re}=($ Vbolha*diambolha $) /(1 e-6) ;$

$\mathrm{SC}=1000$;

ㅇchimdt molecular

- Para inverter e percorrer y de baixo para cima conforme o sistema cartesiano adotado:

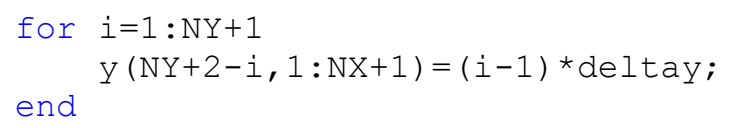



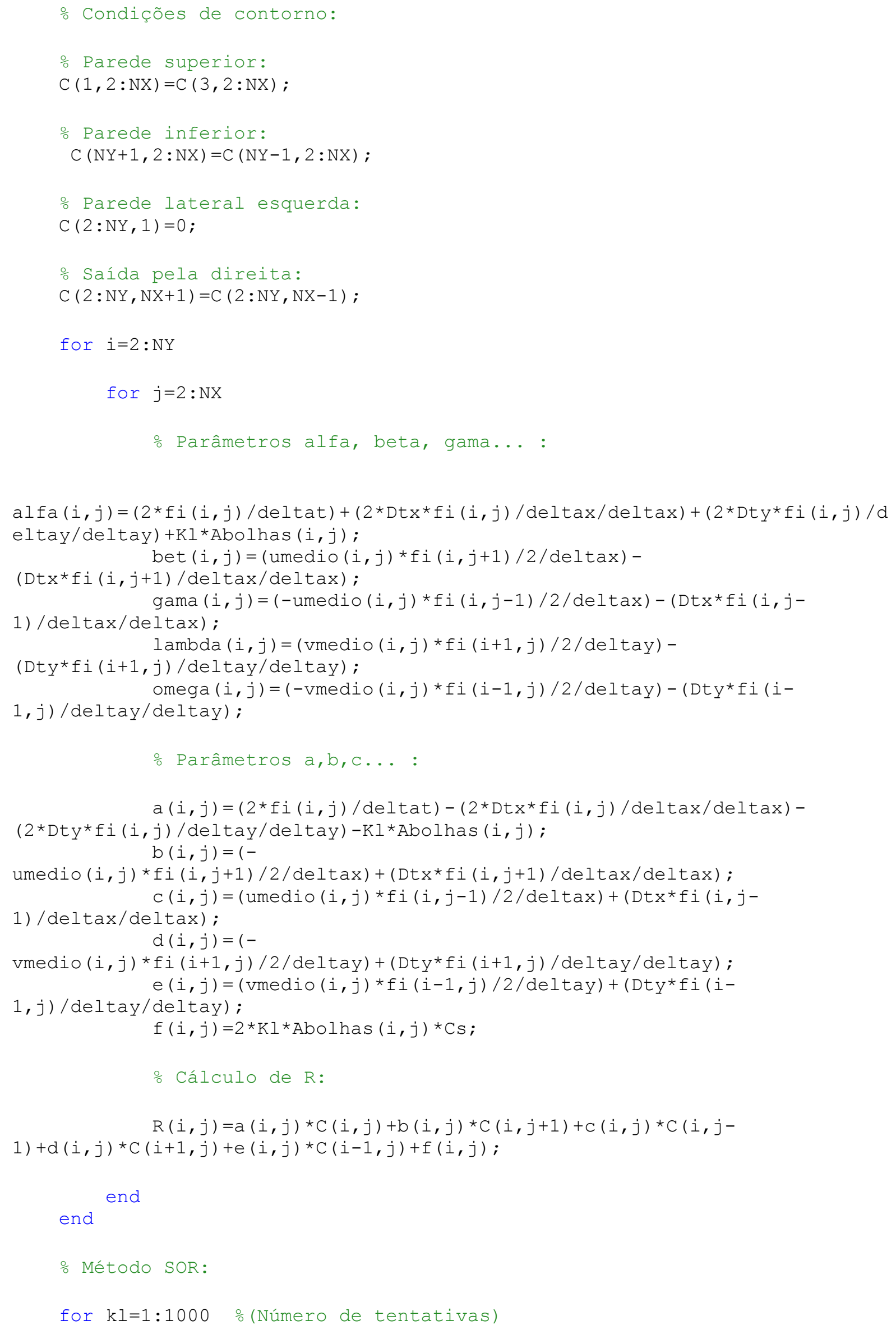


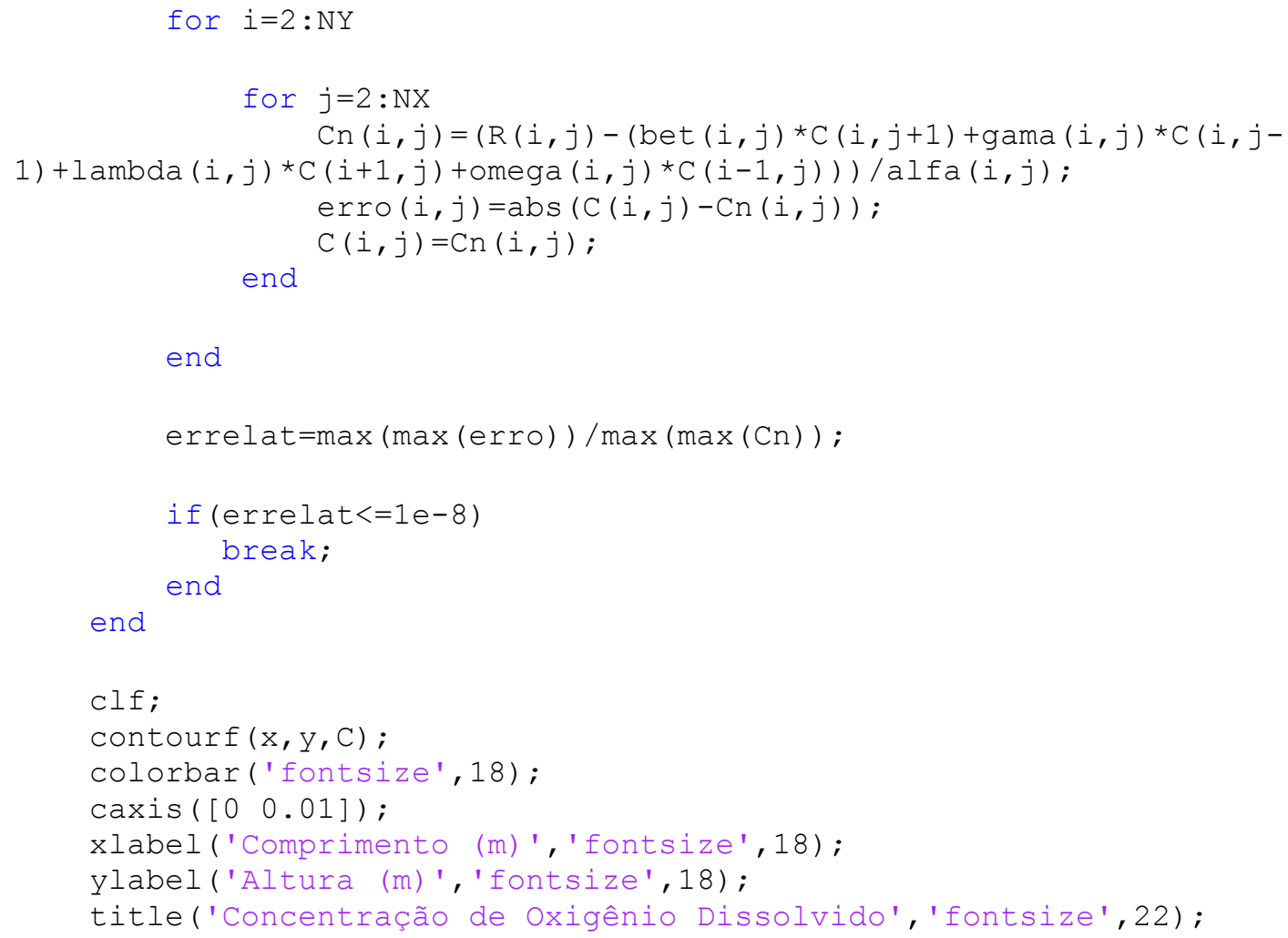

end 